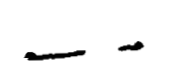

(NASA-CR-114666)

DEVLLOPIU TOBOICAL TANKS FOQ STODY OF

S2ACECRAFT Final Repr.rt (partin harietta

Corp.) 78 p HC 56.00

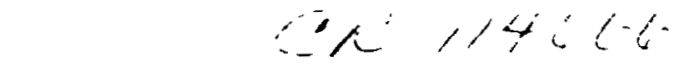

$N 73-31766$

G3/31 Unclas $14034 \quad$ MCR-73-223

\title{
A FEASIBILITY STUDY OF DEVELOPING TOROIDAL TANKS FOR A SPINNING SPACECRAFT
}

FINAL REPORT

By

John E. Anderson and Daie A. Fester

September 1973

Distribution of this report is provided in the interest of information exchange. Responsibility for the contents resides in the author or organization that prepared it.

Prepared under Contract No. NAS2-7489 by

MARTIN MAEIETTA CORPORATION DENVER DIVISION

Denver, Colorado 80201

for

AMES RESEARCH CENTER

AMES RESEARCH CENTER
NATIONAL AERONAUTICS AND SPACE ADNINISTRATIUN?
Moffett Field, California 94035 
MCR-13-223

A FEASTBILITY STLDY OF DEVELOPING

TOROIDAL TANKS FOR A SPINNING SPACECRAFT

FINAL REPORT

September 1973

PREPARCD FOR

ANES RESEARCH CENTER

NATIONAL AERONAUTICS AND SPACE ADMINISTRATION

MOEFETT FIELD: CALIFORNIA 94C35

CONTRACT NO. NAS2-7489

PREPARED BY

JOHN E. ANDERSON AND DALE A. FESTER

APPROVED

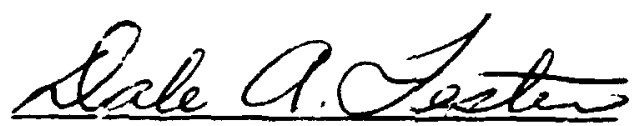

DALE A. FESTER

PROGRAM MANAGER

MART IN MARIETTA CORPORATION

DENVER DIVISION

DENVER, COLORADO 80201 
This report is submitted to the National Aeronautics and Space Administration, Ames Research Center, by Martin Marietta Corporation, Denver Division, in accordance with Article iV, Paragraph B. 3 of Contract NAS2-7489, dated 20 March 1973.

The work was administered under the techni $i$ direction of Mr. Duane W. Dugan, NASA-ARC Technical Monitor. Mr. Dale A. Fester, Analytical Unit Head, Tnermodynamics and Fluid Mechanics Section, Propulsion Department, was the Martin Marietta Prugram Manager. 
CONTENTS

Dage

SUMMARY .................. v v

I. INTRODUCTION ................ 1 thru 3

II. MISSION CRITERIA AND STUDY GUIDELINES . . . 4

A. Mission Operaticnal Sequence . . . . . . . 4 thru 7

B.

C.

D.

E.

III. PROPELLANT ACQUISITION SYSTEM EVALUATION . - 15

A. Operational Principles........... 15 thru 19

B. Candidate Concepts........... 19 thru 23

C. Fluid Behavior Analysis .......... 23 thru 44

D. System Selection and Design . . . . . . 44 thru 49

IV. EVILUATION OF TOROIDAL TANKAGE ...... 50

A. Previous Experience . . . . . . . . . 50

B. Candidate Material Selection ....... 50 and 51

C. Tank Weight Comparison......... 51 thru 55

D. Tank Fabrication . . . . . . . . 55 thru 61

E. Tank System Design ............. 60 thru 65

V. CONCLUSIONS AND RECOMMENDATIONS ...... 66

A. Conclusions .............. 66

B. Recommendations .......................... 66 and 67

VI. REFERENCES ................ 68 thru 72

Figure $--\cdots----\cdots---\cdots$

1 Program Schedule ............. 2

2 Pioneer Jupiter Orbiter Configuration

$(\operatorname{Ref} 16)$................. 9

3 Liquid/Solid Contact Angle ........ 13

4 Interface Orientation at the Beginning and End of $3 \mathrm{rd}$, 4th, 5 th and 6 th Burn

Periods ............... . 21

Candidate Propellant Acquisition Concept for use in a Toroidal Tank ...........

6 Liquid Orientation in the Oxidizer Tank at

Various Times during the Mission . . . . 


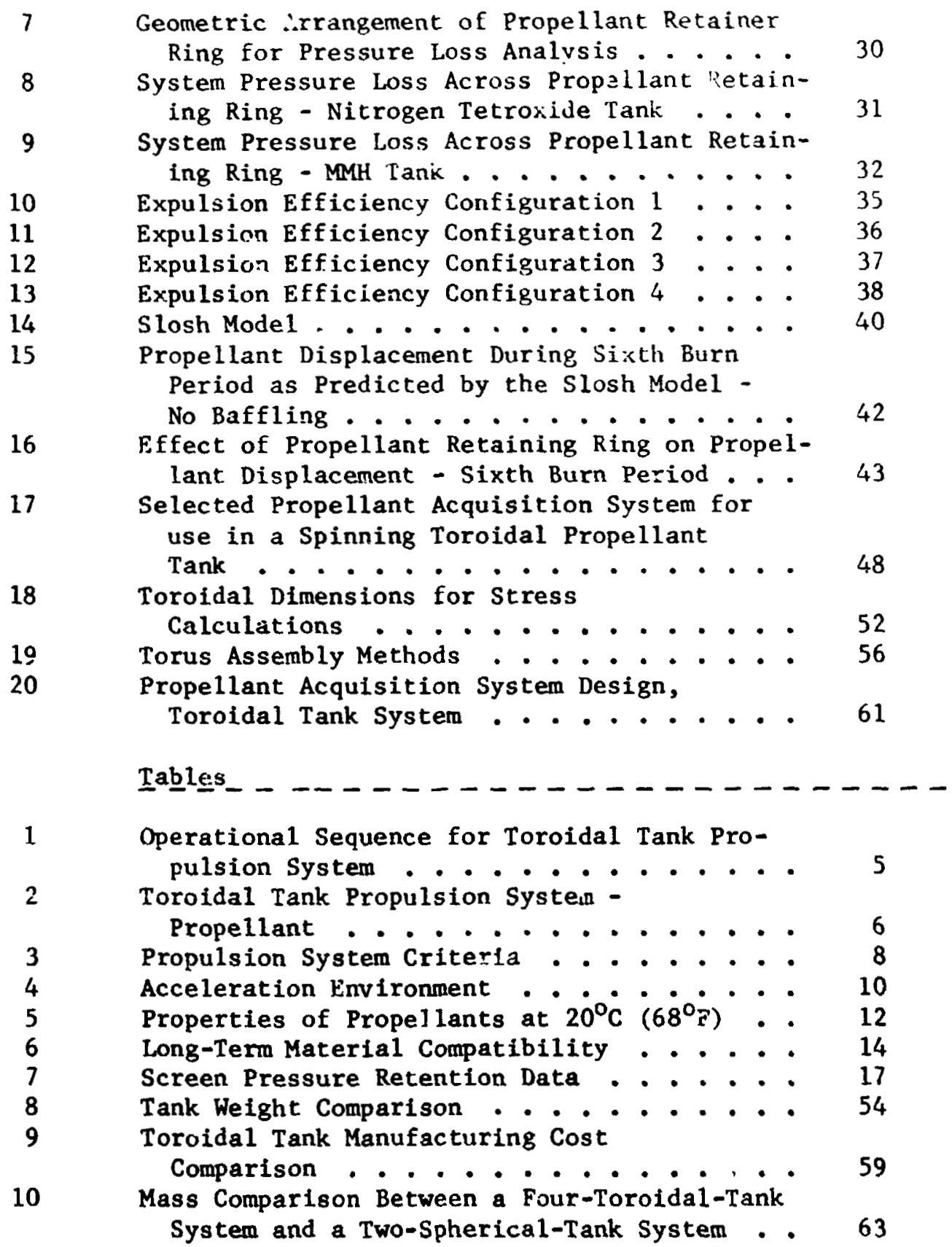




\section{SUMMARY}

A study was made to determine the feasibility of developing toroidal propellant tanks for a bipropellant $\left(\mathrm{N}_{2} \mathrm{O}_{4} /\right.$ MMH) propulsion system to be used in a proposed advanced Pioneer spin-stabilized vehicle intended for a Jupiterorbiter and possibly a Saturn-orbiter mission. The rationale for considering the use of two toroidal tanks rather than the proposed use of four spherical tanks includes the belief that a more symmetrical distribution of propellant mass and a smaller variation in the position of the vehicle center-of-mass during propellant consumption would result, reducing requirements for attitudecontrol propellants, for balance weight, and for other weights associated with the dynamics of the spinning spacecraft. These advantages, it was hoped, would more than offset an anticipated larger weight of the toroidal tankage.

Results of the study lead to the conclusion that a toroidal tank containing an effective. passive surface tension propellant acquisition device could be íbricated with available manufacturing methods and could be used interchangeably for either fuel or oxidizer. A two-toroidal-tank system is attractive bec use of packaging, spacecraft center-of-mass and sp .t control, mass and propellant outflow considerations. A single tank outlet satisfies the requirements for both normal propellant feed and emergency draining. The tanks can be stacked at the aft end of the spacecraft, centered about the spin axis. Propellant motion in the toroidal tanks tends to be balanced, e.g., propellant settling due to thrust acceleration is symetrical. Because of this symmetry, a more balanced spacecraft requiring lesser control should result. In addition, a two-tank system is inherently more reliable and with the single tank outlets, eliminates the need for outflow balancing from parallel fuel tanks and parallel oxidizer tanks.

No major problems are foreseen that would prevent the selected propellant acquisition device from performing as predicted theoretically, although drop tests with non-spinning toroidal tanks have indicated an ullage bubble offset when the tanks are nearly full. The centrifugal force present in a spinning vehicle is believed sufficient to waintain symetry of the ullage bubble and prevent separation into two or more bubbles. A realistic test with an actual tank could resolve this problem. 
The materials considered for the toroidal tanks include 2219- and 6061-aluminum alloys and 6A1-4V titanium. Comparison of the mass of two constant-wal1-thickness toroidal tanks with that of four spherical tanks (equal total volumes) shows that, without fropellant acquisition devices, the toroiáal tanks are heavier by about $8 \mathrm{Kg}\left(18 \mathrm{lb}_{\mathrm{m}}\right)$ and $12.5 \mathrm{Kg}(28 \mathrm{lb})$ with the two aluminum alloys, respectively, and abcut $2.5 \mathrm{Kg}(5.7 \mathrm{lb})$ if titanium is used. These mass differences between toroidal and spherical tank systems can be reduced significantly if a varying wall thickness is used in the toroidal tank design. For the two aluminum alloys considered, the mass differences are reduced to $4.1 \mathrm{Kg}$ $\left(8.81 b_{m}\right)$ and $7.1 \mathrm{~kg}\left(161 b_{m}\right)$, respectively. With titanium, the toroidal tank system mass is actually less than the spherical tank system mass by $0.6 \mathrm{Kg}$ $1.3 \mathrm{lb}_{\mathrm{m}}$ ) if a variable wall hickness if employed. The passive surface tension propellant-acquisition devices for the two toroidal tanks weigh only $2.45 \mathrm{Kg}$ $\left(5.41 b_{m}\right)$. Similar devices for the four spherical tanks are estimated to be about $1.36 \mathrm{Kg}(3.0 \mathrm{lb})$. For titanium there is a relatively small weight penalty in using two toroidal tanks instead of four spherical tanks. If the proposed relatively heavy bladder-type expulsion devices for the four spherical tanks should not be discarded in favor of lighter surface tension devices, the total weight of two toroidal tanks would be approximately 73 percent of that of the four spherical tanks of the same volume $(18.2 \mathrm{Kg}$ compared with $24.9 \mathrm{Kg}$ ). Support of toroidal tanks in the spacecraft appears to be relatively simple and structurally efficient, although some modifications to the advanced Pioneer orbiter vehicle are required in order to accommodate the tanks at the desired location. Analysis of the overall effects of substituting toroidal tanks for spherical tanks in the proposed spin-stabilized spacecraft is not within the scope of the present study. 
I. - _ - INTRODUCTIION

Toroidal tanks are being considered for incorporation in a retropropulsion system to be coupled with the Pioneer spacecraft for performing Jupiter and/or Saturn orbiter missions. Vehicle spin stabilization would be accomplished with the current Pioneer monopropellant propulsion system, while the toroidal-tank bipropellant system would be used for midcourse correction and the Jupiter/Saturn orbit insertion and trim burns. Since the spacecraft is spin stabilized, toroidal tanks offer potential advantages in regard to packaging, center-ofmass control, and propellant expulsion interactions.

The objective of the study was to determine the feasibility of developing a combined toroidal tank/surface tension propellant acquisition system for a spinning spacecraft. In particular, the feasibilities of fabricating the toroidal tanks and of supplying gas-free liquid from the tanks during specified mission operations were to be evaluated. A comparison of the mass of toroidal tanks with that of spherical tanks was also to be made.

Prior studies have shown passive surface tension $s$; stems to be superior in a number of applications over other propellant acquisition methods for providing gas-free liquid on demand (Ref 1 through 5). This acquisition method is being employed for the Viking Orbiter 1975 interplanetary spacecraft (Ref 6). Most of the experlence has been with 3-axis stabilized spacecraft using earth-storable propellants; capillary systems have been developed and flight-qualified for Transtage, Agena, Apollo SPS and LEM, Mariner 9, and Viking Orbiter 1975. Surface tension systems have also been used on several target drones, have been applied to an air-launched packaged liquid missile ( $\operatorname{Ref} 7$ ), have been studied, and subsequently selected, for the Space Shuttle aMS and RCS (Ref 8 through 10), and have been selected fir the Space Tug (Ref 11). These syetems have also been designed, fabricated, and tested for cryogenic propellant applications (Ref 12 through 14). However, the use of a surface tension system with toroidal tanks in spinning spacecraft requires further evaluation.

The six-month study, including distribution of the final report, was accomplished in three tasks, as shown by the program schedule in Figure 1. Task 1, begun in March 


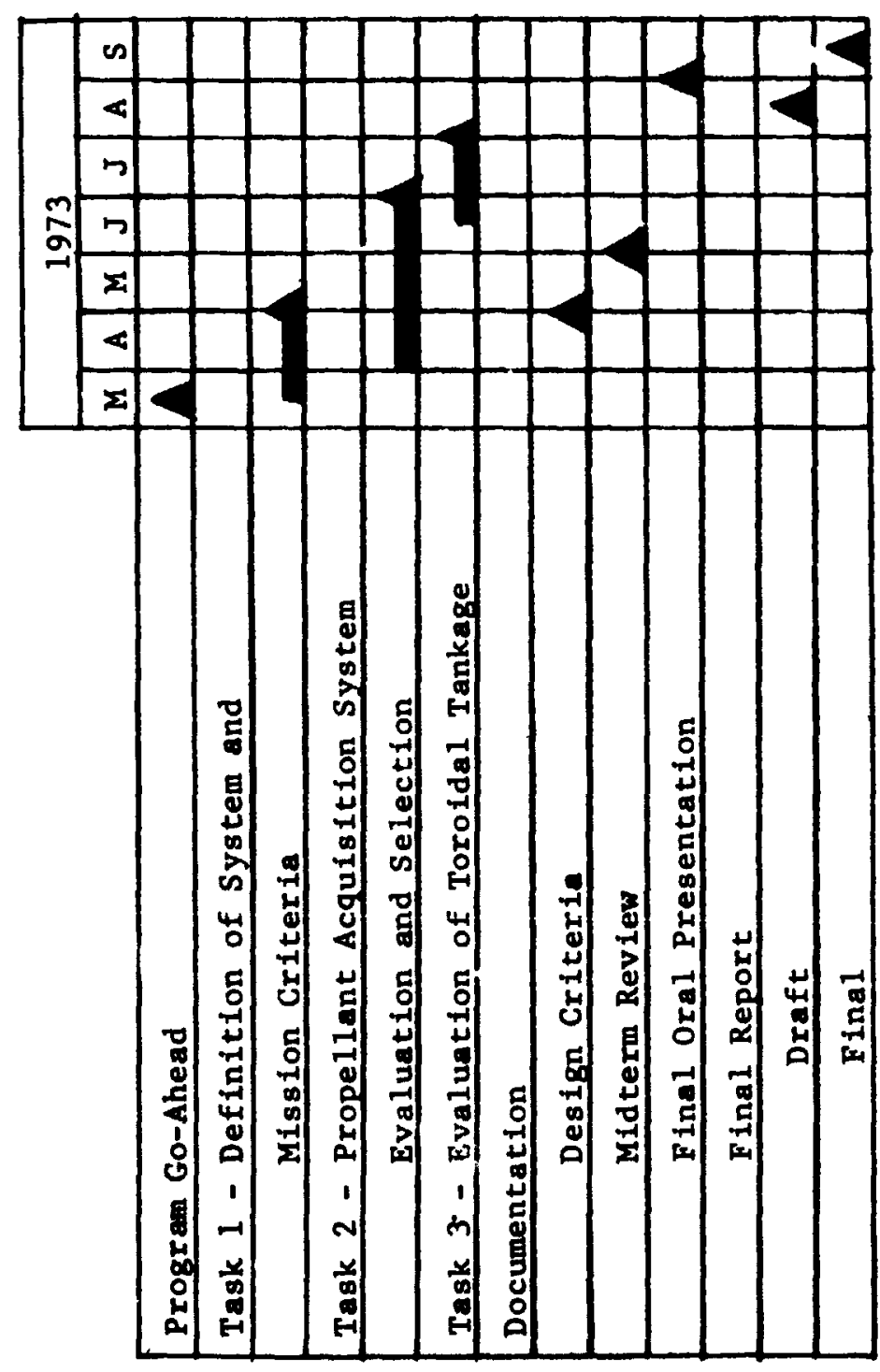


1973, was devoted to gathering system and mission criteria. The results of this activicy were assembled into a design criteria and study guideiine document (Ref 15) to complete Task 1 . These criteria were updated throughout the program to ensure relevancy and are presented in Chapter II. Pertinent information on propellant properties and material compatibility is included.

Task 2 was begun in April 1973 to define and evaluate surface tension propellant acquisition concepts. Various concepts were considered and candidate systems were defined. Concept evaluation considered various aspects of fluid behavior in a spinning toroidal tank, including propellant orientation, slosh, pressure drop during outflow, number of tank out lets, and expulsion efficiency. Base? on the evaluation, the preferred toroidal-tank surface tension system was selected. This effort is discussed in Chapter III.

Under Task 3, both the feasibility and capability of fabricating toroidal tanks were assessed. Weight and cost comparisons were made with an equivalent spherical tank system. A preliminary design of a combined toroidal tank/acquisition system was prepared. The Task 3 work, including the tank system design, is presented in Chapter IV.

Conclusions and reconnendations resulting from the study are presented in Chapter $v$. References are contained in Chapter VI. 
II. - _ MISSION_CRITERIA AND STUDY GUIDELINES

The baseline mission criteria used in the troidal tank study were derived from a typical Jupiter orbiter mission as might be performed by a Pioneer-type spacecraft. Mission timeline, operational sequence, anc. acceleration envirc nments were obtained from NASA-ARC and Erom data presented in Ref 16. The bipropeliant propulsion system supplies impulse for major spacecraft velocity changes only. Attitude and precession maneuvering requirements are provided by the Pionecr monopropellant (hydrazine) propulsion system. The mission criteria and propulsion system requirements, originally published in Ref 15, are presented in this chapter. Propellant properties important to the design 0 - surface tension devices and compatibility of the propellants with materials of construction are also included.

A. MISSION OPERATIONAL SEQUENCE

For the baseline mission, the main $(\Delta v)$ propulsion system will perform one midcourse correction and five major velocity changes for insertion and maneuvers in Jupiter orbit. Because of the vehicle spin stabilization, the propellant is subjected to a continuous but variable acceieration field. During cruise phases of the mission, the vehicle will spin at a rate of 4.8 $\mathrm{rpm}$. This spin rate will be increased to $10 \mathrm{rpm}$ just prior to firing the propulsion "'ztem to minimize attitude changes resulting from center-of-ruass offsets and thrust misalignments. Following firing, the vehicle spin rate is lowered to $4.8 \mathrm{rpm}$ for cruise. Prior to and after certain main engine firings, the vehicle spin axis orientation must be changed by means of the attitude control system. These attitude changes, together with the spin-rate change, impose accelerations that will affect propellant orientation. After entry into Jupiter orbit, the vehicle spin rate will be reduced to a minimum value of 2 rpm for science imaging requirements. A summary of these required operations, the system performing the operation, and the time of occurrence during the mission is presented in Table 1.

Propellant requirements for the $3 i x$ burn mission are presented In Table 2. These requirements are based on: 


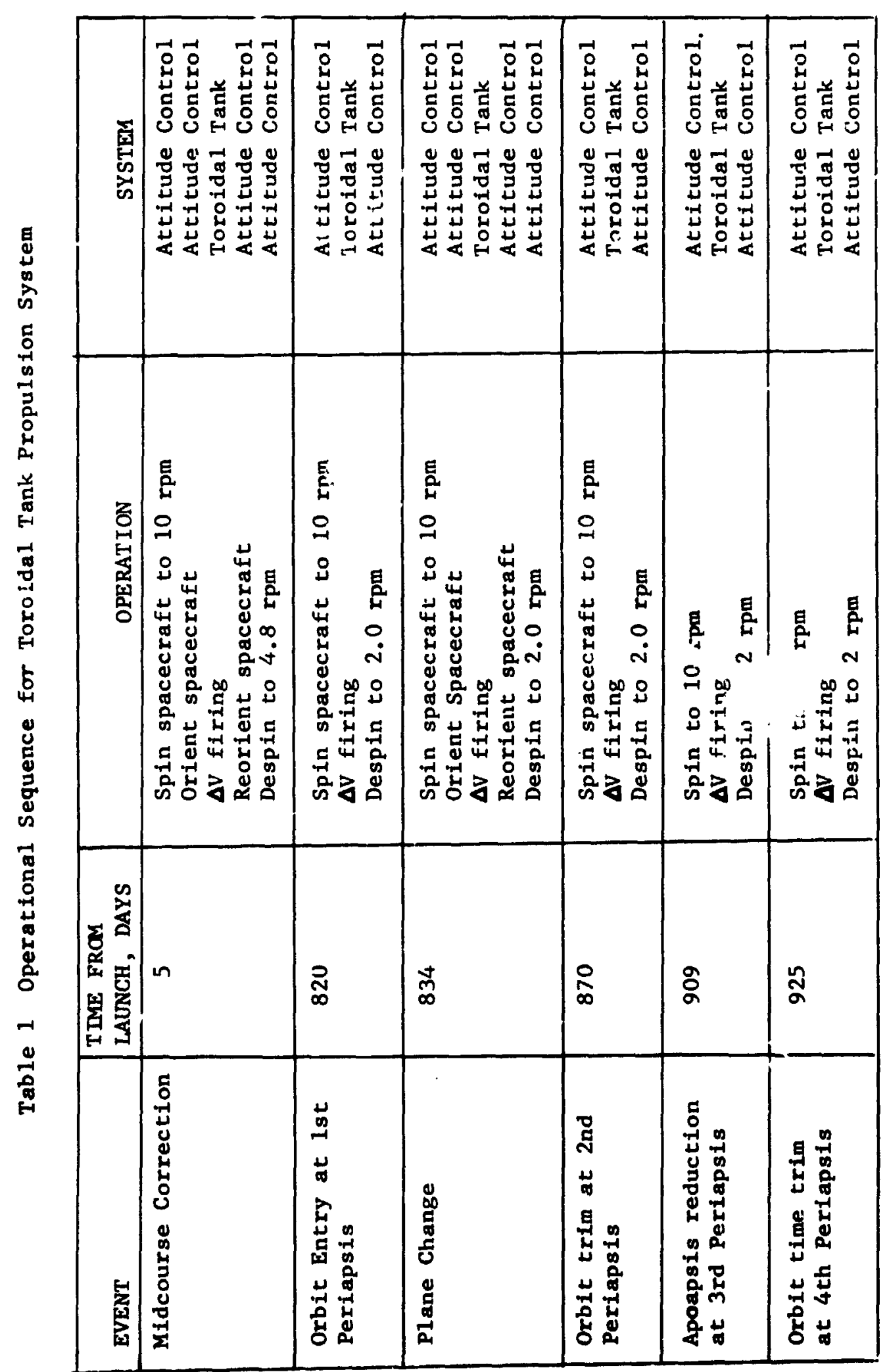




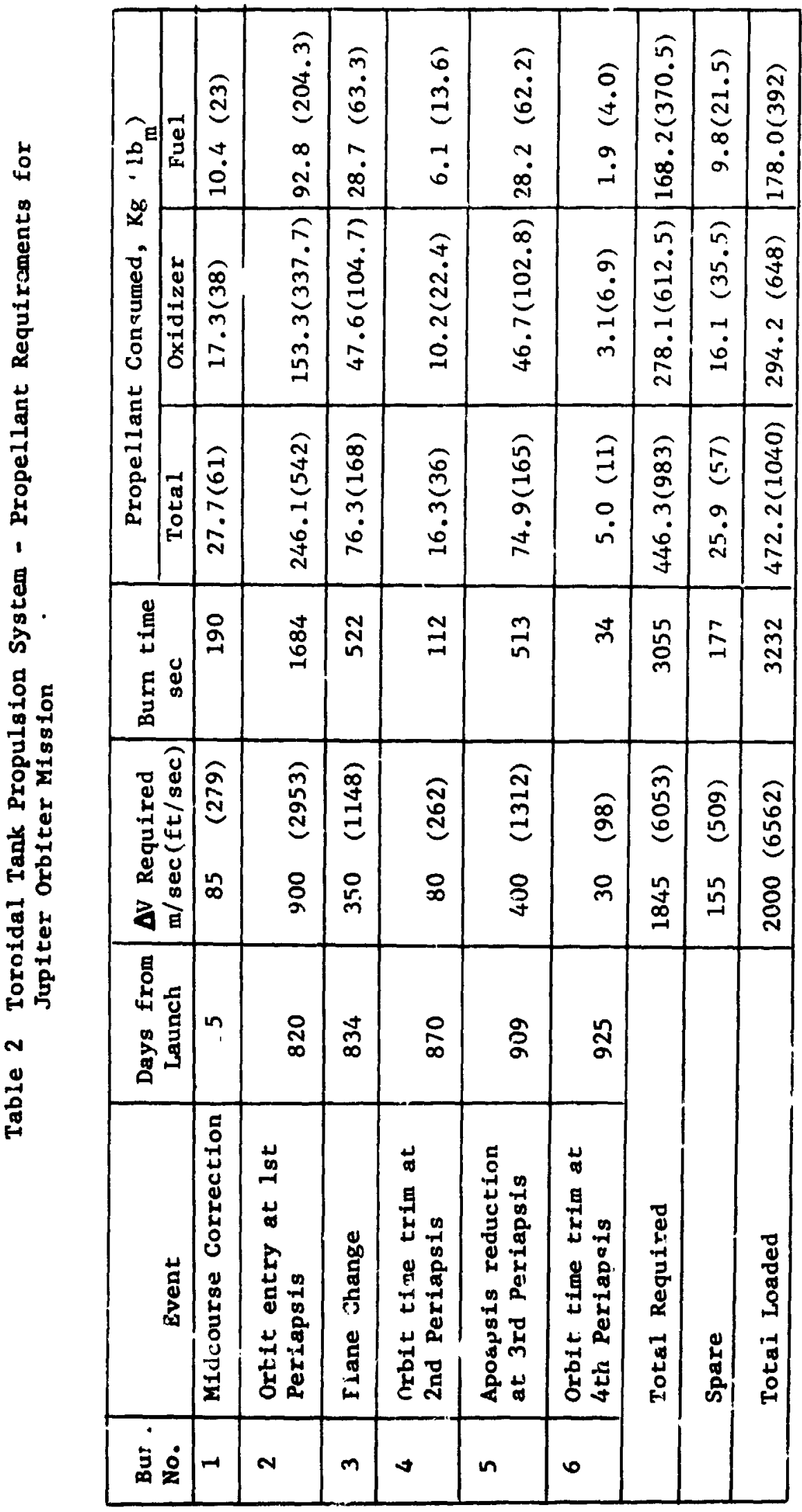

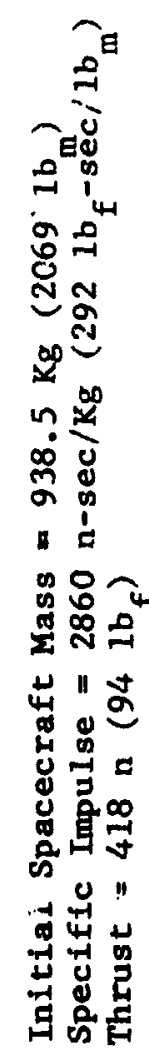


1) Total velocity changes $=2000 \mathrm{~m} / \mathrm{sec}(6562 \mathrm{ft} / \mathrm{sec})$;

2) Initial spacecraft mass $=938.5 \mathrm{Kg}\left(2069 \mathrm{lb}_{\mathrm{m}}\right)$;

3) Engine thrust $=418 \mathrm{n}\left(94 \mathrm{1b} \mathrm{f}_{\mathrm{f}}\right)$; and,

4) Engiue specific impulse $=2860 \ldots-\mathrm{sec} / \mathrm{K}_{\mathrm{B}}\left(2921 \mathrm{~b}_{\mathrm{f}}^{-}\right.$ $\left.\sec / 1 b_{\mathbf{m}}\right)$.

B. PROPULSION REQUIRAMENTS

The main $(\Delta V)$ propulsion system is a bipropellant system employing monomethylhydrazine (MH) fuel and nitrogen tetroxide $\left(\mathrm{N}_{2} \mathrm{O}_{4}\right)$ oxidizer. The engine produces 418 newtons $\left(941 \mathrm{~b}_{f}\right)$ thrust at an oxidizer to fuel mixture ratio of 1.65 . This mixture ratio results in equal volume propellant tanks. Table 3 presents the pertinent engine system data together with the propellant tank requirements. Tank operating pressure is regulated to $155 \mathrm{n} / \mathrm{cm}^{2}$ (225 psia); the normal operating temperature is $21^{\circ} \mathrm{C}\left(70^{\circ} \mathrm{F}\right)$ with an allowable range of 7 to $32^{\circ} \mathrm{C}\left(45\right.$ to $\left.90^{\circ} \mathrm{C}\right)$. A minimum ullage volume of 47 at the maximum propellant temperature of $32^{\circ} \mathrm{C}\left(90^{\circ} \mathrm{F}\right)$ was used to determine tank volume.

Two identical $0.214-\mathrm{m}^{3}\left(7.58-\mathrm{ft}^{3}\right)$ toroidal tanks are employed, one for fuel and one for oxidizer. Installation of the two toroidal tanks into an envelope allocated for four spherical tanks of approximately equal volume (Ref 16) is shown in Figure 2.

C. ACCELERATION ENV IRONAET

The acceleration environments to be expected during each phase of the mission are presented in rable 4. The system is launched by a Iitan IIID(5)/Centaur/TE364-4 system. The boost accelerations shown are the maximum values that could be obtained.

During operation of the TE364-4 stage and subsequent mission operations, the toroidal tanks will be subjected to a continuous centrifugal acceleration resulting from the spin stabllization process. Such acceleration levels are those experienced at the center of the toroidal tank circular cross-section. Steady-state spin rates of $60 \mathrm{rpm}$ are experienced dur- 
Table 3 Propulsion System Criteria

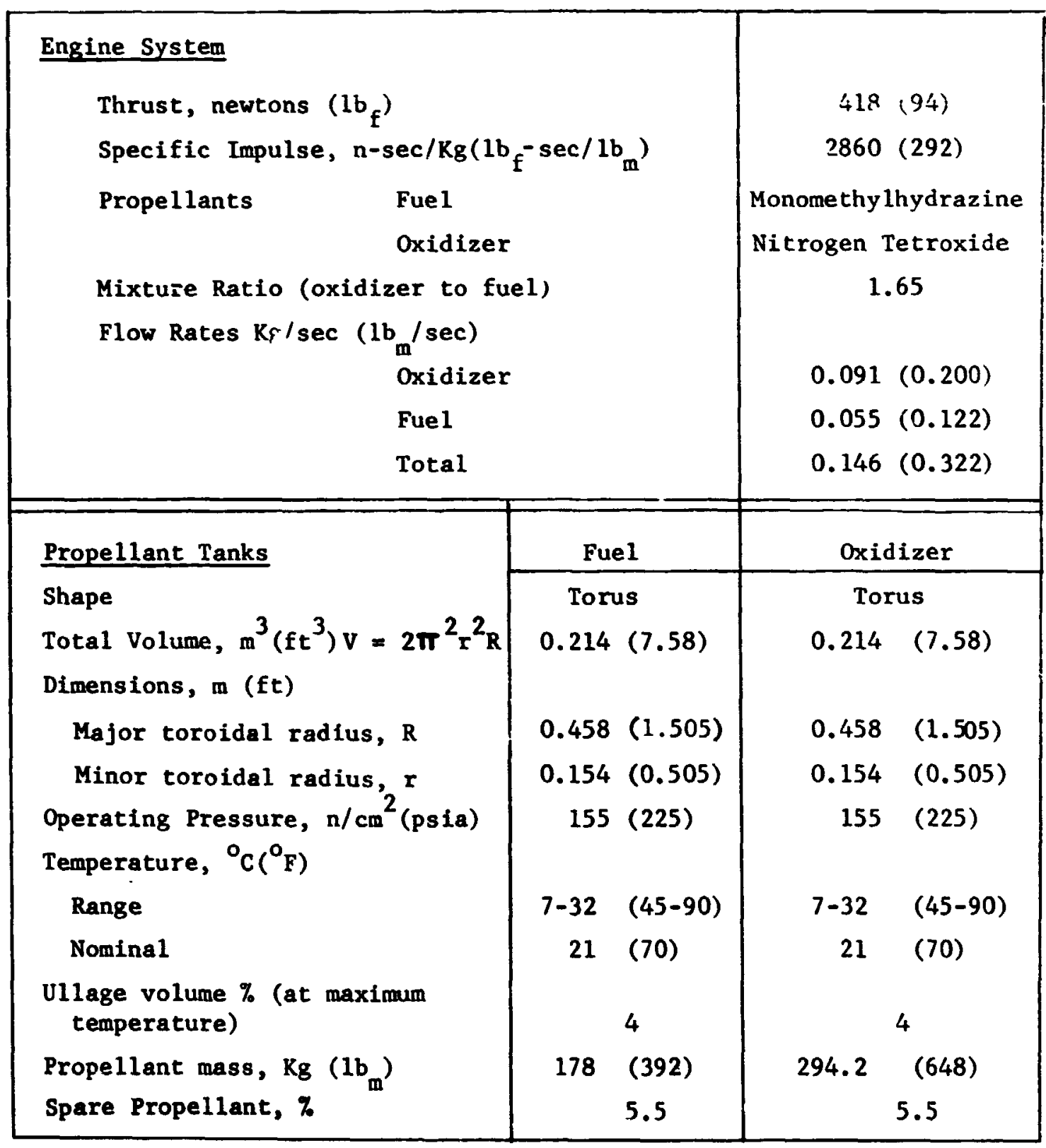




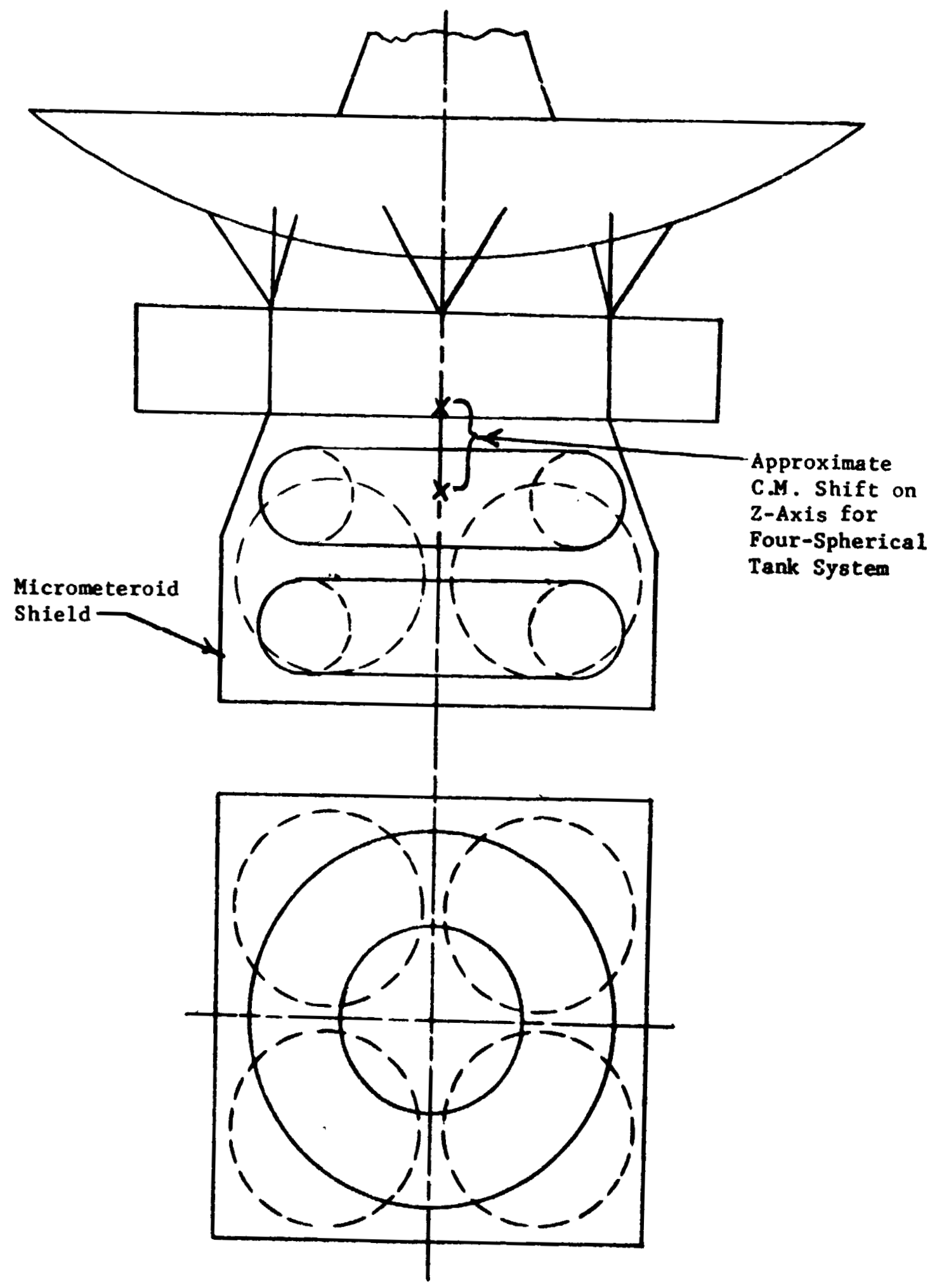

Figure 2 Pioneer Jupiter Orbiter Configuration (Ref 16) 
Table 4 Acceleration Environment

\begin{tabular}{|c|c|}
\hline Function & Acceleration (g) \\
\hline \multicolumn{2}{|l|}{ Boost } \\
\hline Axial & $+9.3,-3.5$ \\
\hline Lateral & $+3.9,-3.9$ \\
\hline Spin $(\omega=60 \mathrm{rpm}) *$ & 1.85 \\
\hline \multicolumn{2}{|l|}{ Steady State Spin (Centrifugal)* } \\
\hline Cruige $(\omega=4.8 \mathrm{rpm})$ & 0.012 \\
\hline $\begin{array}{l}\text { During attitude and } \Delta v \text { changes } \\
(\omega=10 \mathrm{rpm})\end{array}$ & 0.0515 \\
\hline $\begin{array}{l}\text { During imaging operations } \\
\quad(\omega=2 \mathrm{rpm})\end{array}$ & 0.0021 \\
\hline Spin/Despin Operations (tangential)* & $4.9 \times 10^{-4}$ \\
\hline $\begin{array}{l}\text { Precession Maneuvers*t } \\
\text { (Maximum rotation of tank about } \\
\text { vehicle center of gravity) }\end{array}$ & $\begin{array}{l}0.03 \text { per } \\
\text { thruster pulse }\end{array}$ \\
\hline$\Delta v$ Corrections (axial) & $0.045-0.091$ \\
\hline
\end{tabular}

* Based upon a radius from the vehicle spin axis to the center of the torus cross-section.

** Based upon a radius from the vehicle center-of-gravity to the center of the torus cross-section.

**thruster pulse duration is 0.125 seconds. 
ing the terminal phase of the boost uperation by the TE364-4. Following boost, spin rates of $2,4.8$, and 10 rpm are employed by the spacecraft, depending on the operation being performed. During changes of spin rate, the spin control thrusters of the attitude control system produce tangential accelerations of $4.9 \times$ $10^{-4} \mathrm{~g}$ at the tank cross-section centers.

The precession-maneuver acceleration, assuming negligible nutation and wobble effects, is based on the following:

1) Spin axis is precessed $2.62 \times 10^{-3}$ radians $(0.15$ degrees) in 0.125 seconds of thruster pulsing; and

2) Rotation of spin axis is about the vehicle centerof-mass in one plane only.

The accelerations produced by the propulsion system vary from a minimum value of $0.045 \mathrm{~g}$ at the start of the mission to a maximum value of $0.091 \mathrm{~g}$ at the end of the mission (assuming all propellant including the spare is consumed). These $\Delta V$ accelerations are assumed to act along the spacecraft spin axis.

D. PROPELLANT PHYSICAL PROPERTIES

The propellant properties important to the design of a surface tension propellant acquisition system are density, surface tension, and viscosity. Values of these properties are 1isted in Table 5, (Ref 9). Variation of these properties with temperature must be considered; the effect of pressure is small and can be neglected. MMH has a surface tension $25 \%$ higher than that of $\mathrm{N}_{2} \mathrm{O}_{4}$. The kinematic surface tension $(\sigma / p)$ is usually of greater interest since, in any application, body forces will be involved in addition to capillary forces. MH has a kinematic surface tension $106 \%$ higher than that of $\mathrm{N}_{2} \mathrm{O}_{4}$. MMH also has a higher viscosity; the kinematic viscosity $(\mu / \rho)$ of MH is about 3.4 times that of $\mathrm{N}_{2} \mathrm{O}_{4}$. Specific implications of these differences in physical properties are:

1) $\mathrm{N}_{2} \mathrm{O}_{4}$ has a kinematic surface tension about onehalf that of MoH. This makes it the more diffi- 
Table 5 Properties of Propeli: nts at $20^{\circ} \mathrm{C}\left(68^{\circ} \mathrm{F}\right)$

\begin{tabular}{|c|c|c|c|c|c|c|c|c|c|c|}
\hline \multirow[b]{2}{*}{ Propellant } & \multicolumn{2}{|c|}{ Density, $\rho$} & \multicolumn{2}{|c|}{$\begin{array}{l}\text { Surface } \\
\text { Tension, } 0\end{array}$} & \multicolumn{2}{|c|}{$\begin{array}{l}\text { Kinematic Surface } \\
\text { Tension, } ;\end{array}$} & \multicolumn{2}{|c|}{ VIscosity, $\mu$} & \multicolumn{2}{|c|}{$\begin{array}{l}\text { Kinematic } \\
\text { Yiscosity, v }\end{array}$} \\
\hline & $\frac{\mathrm{gm}^{\mathrm{m}}}{\mathrm{cm} \mathrm{m}^{3}}$ & $\frac{1 \mathrm{bm}}{\mathrm{ft}^{3}}$ & $\frac{\text { dynes }}{\mathrm{cm}}$ & $\begin{array}{l}\frac{1 b f}{f t} \\
x 10^{3}\end{array}$ & $\frac{\text { dyne } \mathrm{cm}^{2}}{\mathrm{gm}}$ & $\begin{array}{l}\frac{1 \mathrm{bf}}{1 \mathrm{bm}} \\
\times 1 \mathrm{ft}^{2}\end{array}$ & $\begin{array}{l}\text { Centipoise } \\
\text { (cp) }\end{array}$ & $\begin{array}{l}\frac{1 \mathrm{bm}}{\mathrm{ft}-\mathrm{s}} \\
\times 10^{3}\end{array}$ & $\begin{array}{l}\text { Cent1stoke } \\
\text { (cs) }\end{array}$ & $\begin{array}{l}\frac{\mathrm{tt}^{2}}{\mathrm{~s}} \\
\times 10^{5}\end{array}$ \\
\hline Oxidizer & & & & & & & & & & \\
\hline $\mathrm{N}_{2} \mathrm{O}_{4}$ & 1.447 & 90.2 & 27.4 & 1.88 & 18.94 & 2.08 & 0.421 & 0.283 & 0.291 & 0.314 \\
\hline Fuel & & & & & & & & & & \\
\hline MMH & 0.880 & 54.9 & 34.3 & 2.35 & 38.98 & 4.28 & 0.860 & 0.578 & 0.977 & 1.052 \\
\hline
\end{tabular}

cult of the propellants for a surface tension system to retain;

2) $\mathrm{N}_{2} \mathrm{O}_{4}$ has the higher density. For a given volumetric flow rate, it will produce higher pressure losses due to change in flow area and friction;

3) MMH has the higher kinematic viscosity. Entrance losses due to flow through screen will be larger with this propellant.

The liquid/solid contact angle is another property that is important to the operation of capillary systems. This angle, $\theta$, is defined in Figure 3 . A liquid that readily wets a surface, $1 . e .$, has a near-zero contact angle, is the most desirable for a capillary system. Contact angle is independent of pressure and temperature, but is sensitive to the purity of the propellant and the cleanliness of the solid surface. On a previously-wetted, clean metal surface, the propellants will have contact angles of 2 degrees or less (Ref 17 through 19).

E. MATERIAL COMPATIBILITY

An important consideration in the design of propellant management devices is the compatibility of the construction materials with the propellants.

To ald in selecting system materials and designing and evaluating the propellant management devices, available information was complled on the long-tein (10year) compatibility of spacecraft materials with the 


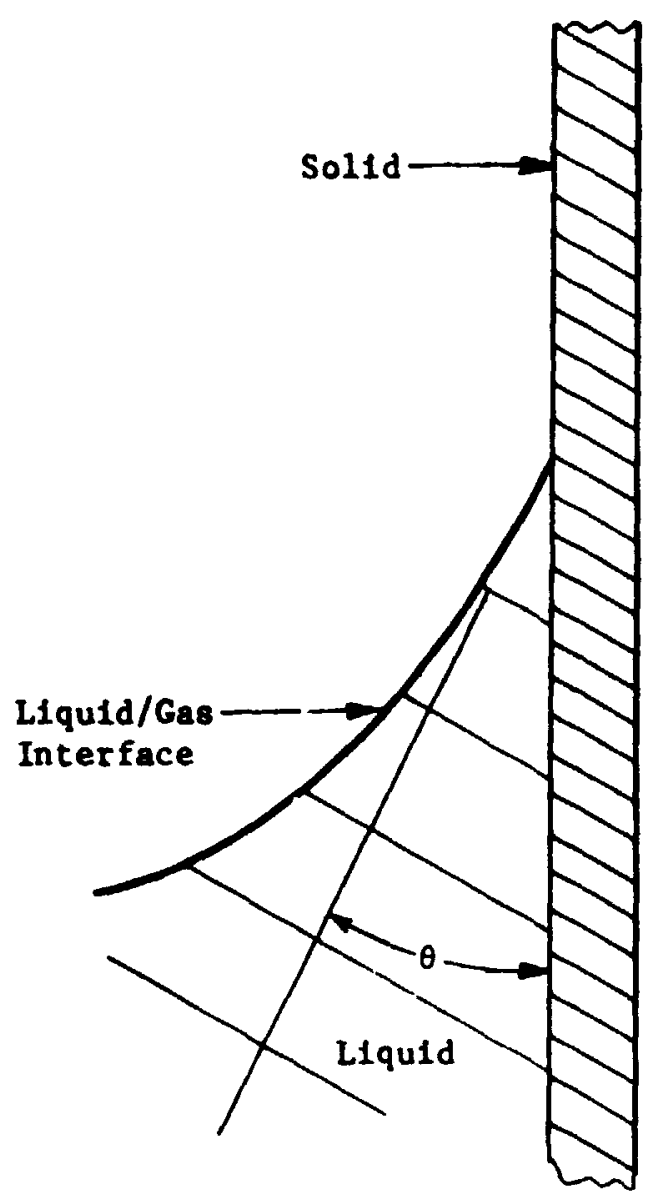

Figure $3 \quad$ Liquid/Solid Contact Angle 
propellants. Table 6 summarizes this information for the more commonly used aerospace materials. The information was obtained primarily from Reference 20 . Compatibility of a material with a propellant is based on the criteria that the material be essentially unaffected by propellant exposure (negligible corrosion for metals and negligible loss of physical properties for nonmetals) and that it should not significantly affect either the physical properties or the stability of the propellant. Reference 20 should be consulted for a more detailed discussion of propellant/material compatibility.

Table 6 Long-Term Material Compatibility

\begin{tabular}{|c|c|c|}
\hline \multirow{2}{*}{ Material } & \multicolumn{2}{|c|}{ Propellant } \\
\hline & $\mathrm{N}_{2} \mathrm{O}_{4}$ & MMH \\
\hline \multicolumn{3}{|l|}{ Aluminum } \\
\hline $1100,2219,6061$ & B & $\mathbf{A}$ \\
\hline \multicolumn{3}{|l|}{ Stainless Steel } \\
\hline $304,321,347,316$ & B & $\mathbf{A}$ \\
\hline $6 A-4 V T i$ & A & $\mathbf{A}$ \\
\hline \multicolumn{3}{|l|}{ Nonmetals } \\
\hline Tefion & B & A \\
\hline Kel-F & C & C \\
\hline EPR & C & B \\
\hline \multicolumn{3}{|c|}{$\begin{array}{ll}\text { Legend: } & \text { A - Good } \\
\text { B - Acceptable } \\
\text { C - Undesirable }\end{array}$} \\
\hline
\end{tabular}


IIII._ _ _PROPELLANT ACQUISITTION SYSTEM_EVALUATION

The purpose of any propellant acquisition system is to provide gas-free liquid propellant to the engine, on demand, regardless of the orientation of the propellant bulk. Several different propellant acquisition system concepts have been studied, evaluated, and compared under NASA-funded programs (Ref 1 and 3 ). The conclusions reached during both of these programs was that surface tension propellant acquisition systems offered the best approach to propellant control for earth orbital missions as well as deep space interplanetary probes. The features making the surface tension systems most attractive are the completely passive operation (no moving parts), simplicity in design, higl reliability and light wefoht. Subsequent to the two previously mentioned comp ative evaluations, additional contractual and Martin Marletta-sponsored programs have been conducted to analyze, design, fabricate, test, and qualify surface tension propellant acquisition systems (Ref $4,5,6,9,12,13,14,20,21)$. In general, these programs have been concerned with three-axis stabilized spacecraft; none have considered a spin-stabilized spacecraft. Also, the surface tension propellant acquisition system designs have been primarily concerned with either spherical or cylindrical tanks . . not toroidal tanks. In this study, the impacts of both spin stabilization and toroidal propellant tanks are considered in the evaluation and selection of the preferred surface tension propellant acquisition system.

A. OPERAT IONAL PRINCIPLES

The operation of a sucface tension propellant acquisition device depends on the interaction of the liquidgas interface with the device. The small pressure difference across the liquid-gas interface can be used to retain, orient, and distribute propellant within the tank. In order to utilize this pressure difference, certain operating principles must be considered.

1. Pressure Retention

A pressure differential exists at any curved liquid-gas interface due to intermolecular forces. Termed the 
capillary pressure differential, this is the maximum pressure difference that may exist across a stable interface. The capillary pressure differential, $\Delta P_{C}$, at any point on the interface can be expressed as follows:

$\Delta \mathrm{P}_{\mathrm{c}}=\sigma\left(\frac{1}{\mathrm{R}_{1}}+\frac{1}{\mathrm{R}_{2}}\right)$

where $\sigma$ is the liquid surface tension and $R_{1}$ and $R_{2}$ are principle radii of curvature of the interface. For a spherical interface, $R_{1}$ and $R_{2}$ are equal, so that

$\Delta P_{c}=\frac{2 \sigma}{R_{S}}$

where $R_{S}$ is the spherical surface radius of curvature. The capillary pressure difference can be related to a dimension (other than the radius of curvature) such as a pore radius, $R$, and a second parameter, the liquidto-solid contact angle, $\theta$. Equation (2) can be expressed in terms of these parameters as follows:

$\Delta P_{c}=\frac{2 \sigma \cos \theta}{R}$

The capillary pressure difference for a circular pore, as in a perforated plate, and a given fluid can be calculated from Equation (3). For pore geometries other than circular, the capillary pressure difference is more accurately determined empirically. The accepted technique is the "bubble point" method. Foraminous material, such as fine mesh screen whose complex pore dimensions are not easily defined, is covered by a thin layer of liquid, usually alcohol, and its underside pressurized with alr or nitrogen. The pressure difference at which the first bubble passes through the material is termed the bubble point (BP). This bubble point is the capillary pressure difference or the pressure-retention capability of the material. The pressure-retention capability for various screen mesh sizes, as determined by Martin Marietta using the BP technique, is presented in Table 7. Pressure retention for the material in other 11quids may be obtained by the following relation: 
Table 7 Screen Pressure Retention Data

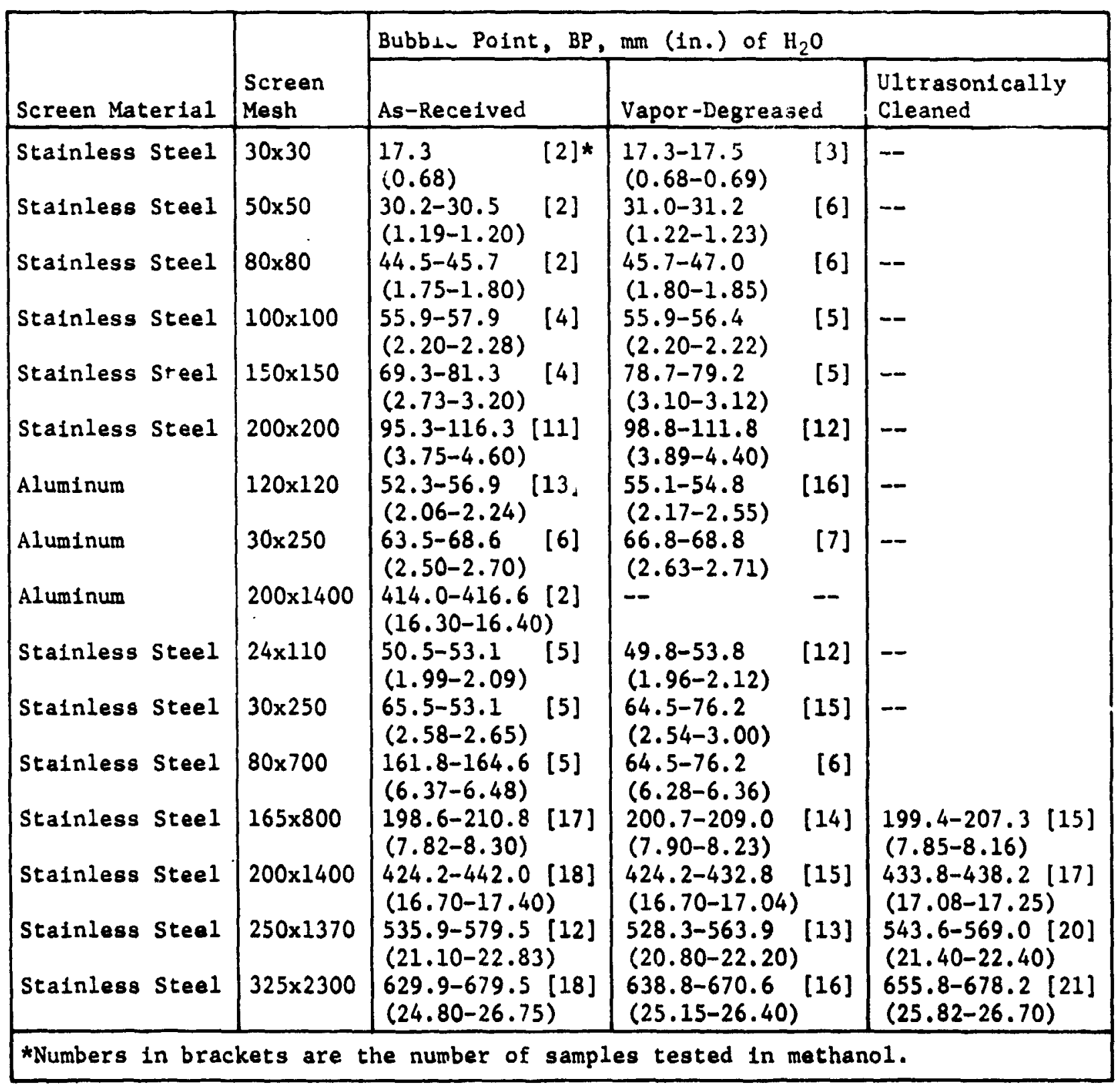


$(\mathrm{BP})_{1}=\frac{\sigma_{1}}{\sigma_{t l}}(\mathrm{BP})_{t i}$

where the subscript 1 refers to the liquid in question and $t 1$ refers to the test 1 iquid.

2. Hydrostatic Interface Stability and Shape

Two other considerations influencing the design of a surface tension system are the stability and shape of the propellant liquid-gas interface under the influenc. of the acceleration environment. The stability of the 1iquid-gas interface primarily determines the ability of a capillary barrier, such as perforated plate or screen, to maintain a separation of liquid and ullage gas in the propellant tank. The stability of the interface in capillary barriers has been shown to correlate with a dimensionless parameter called the Bond number (Bo), a dimensionless ratio of body forces to capillary forces :

Bo $=\frac{\rho a L^{2}}{\sigma}=\frac{a L^{2}}{\beta}$

where $\rho$ is propellant density, $\sigma$ is propellant surface tension, $a$ is system acceleration, and $L$ is the system characteristic dimension.

For a perforated plate with circular pores, the characteristic dimension is the pore radius. It has been shown experimentally ( $\operatorname{Ref} 22$ ) that the pore liquid-gas interface is stable for Bo equal to or less than 0.84 .

Drop tower tests have also shown that the liquid-gas interface in square weave screen is stable if the Bond number is equal to or less than $0.45(\operatorname{Ref} 22)$.

The second consideration is oncerned with the shape and orientation of the liqui",-gas interface of the propellant mass in the tank. The 1iquid-gas interface shape in spherical and cylindrical tanks has also been shown to correlate with the Bond number. The characteristic dimension in this case is the tank radius. Work performed at Marshall Space Flight Center indicated that a Bond number of 50 or greater results in an essentially flat interface at all propellant volumes 
for spheres, cylinders, and similar axisymmetric containers ( $\operatorname{Ref} 23$ ).

3. Capillary Pumping

One attractive feature of surface teision systems is the possibility of pumping prodellant from one location in the tank to another by capillary sition. This can be accomplished in low-g environmen. ere capillary forces exceed all other forces $=$ on the liquid. A surface tension devise can $r_{t} r_{i}^{+}$is pressure, $i$ the liquid adjacent to and withii: ievice to a value lower than the pressure of the ilquid locater away from the device. This low-pressure region will be created when the device causes the curvatire of the interface about the device to be large (smail radius of curvature) in comparison to the curvature of the liquid elsewhere in the tank. As a result, liquid will flow toward the device until the pressure throughout the tank reaches equilibrium.

\section{CANDIDATE CONCEPTS}

In selecting andidate concepts for the spinning toroidal tank syst'sm, the entire spectrum of surface tension devices was considered.

In general, surface tension devices can be divided into two categories--devices that use fine-mesh screens and those that to not. The devices that do not use sriren=: use open sheet-metal structures to orient and retain the liquid. The characteristic dimension of the capillary system, pore size, is the significant parameter that differentlates the two concepts. Screen systems can have pore sizes as small as 10 microns $\left(4 \times 10^{-4}\right.$ in), while a practical pore size limit for a sheet metal baffled tank device is on the order of $2 \mathrm{~cm}(0.79 \mathrm{in})$. Since the pressure-rciention capability is related to pore size, the acceleration environment in which the system can operate also depends on pore size. Therefore, the screen systems can operate over a wide range of accelerations, but sheet metal, baffled-tank systems will operate only in a low-g environment.

The nonscreen systems use capillary pumping and other low-g fluid mechanics phenomena to orient the liquid. Typical systems require $g$-levels less than $10^{-4} \mathrm{~g}$ to be operable. 
The minimum acceleration to be experienced in the spinning toroidal tank was obtained from the misslon criteria as $2.1 \times 1^{-3} \mathrm{~g}$, which would orcur during imaging operations at a spin rate of $2.0 \mathrm{rpm}$. Since this glevel is approximately 20 times greater than the value that can be tolerated by the concepts employing sheet metal structures, these concepts are not attractive for propellant control in a spinning torus. Only systems employing fine-mesh screen will provide the retention capability to keep propellant properly oriented, i.e., maintain a stable liquid-gas interface within the system in the mission acceleration environment.

Screen systems can take many forms, each with its own unique capabilities and performance. However, all screen devices function essentiall; the same--they position a volume of liquid at a specified location in the tank.

In defining screen system concepts for a spinning toroidal tank, prelimiuary escimates were made of the shape and orientation of the propellant liquic-gas interface as a function of both acceleration an propellant remaining. The liquid-gas interface shape and orientation Influence the design and geometric arrangement of the propellant acquisition device and tank outlet location. Bond numbers were calculated during spin operations, using torus minor radius as the characteristic dimension. At $10 \mathrm{rpm}$, the calculated Bond number was greater than 50 for both tanks, while at the lowest spin rate $(2 \mathrm{rpm})$, the corresponding Bond numbers were less than 40 . Since the spacecraft is always spun up to $10 \mathrm{rpm}$ before firing the $\Delta V$ engine, it was coniluded that the liquid-gas interface in each tank would be nearly flat prior to and during each burn period. This conclusion was based on the assumption :hat Bond number criterla for spheres and cylinders were also applicable to toroidal tanks. This assumption was subsequently verified by a more rigorous analysis discussed in a later section.

Prior to starting a burn perlod, the liquid-gas intarface would be normal to the centrifugal acceleration resulting from spin. When the $\Delta \mathrm{V}$ engine is started, the interface would move, neglecti. $=$ slosh effects, until it reached a position essentially normal to the acceleration vector resulting from combinad axial thrusting and spinning. Figure 4 illustrates the 


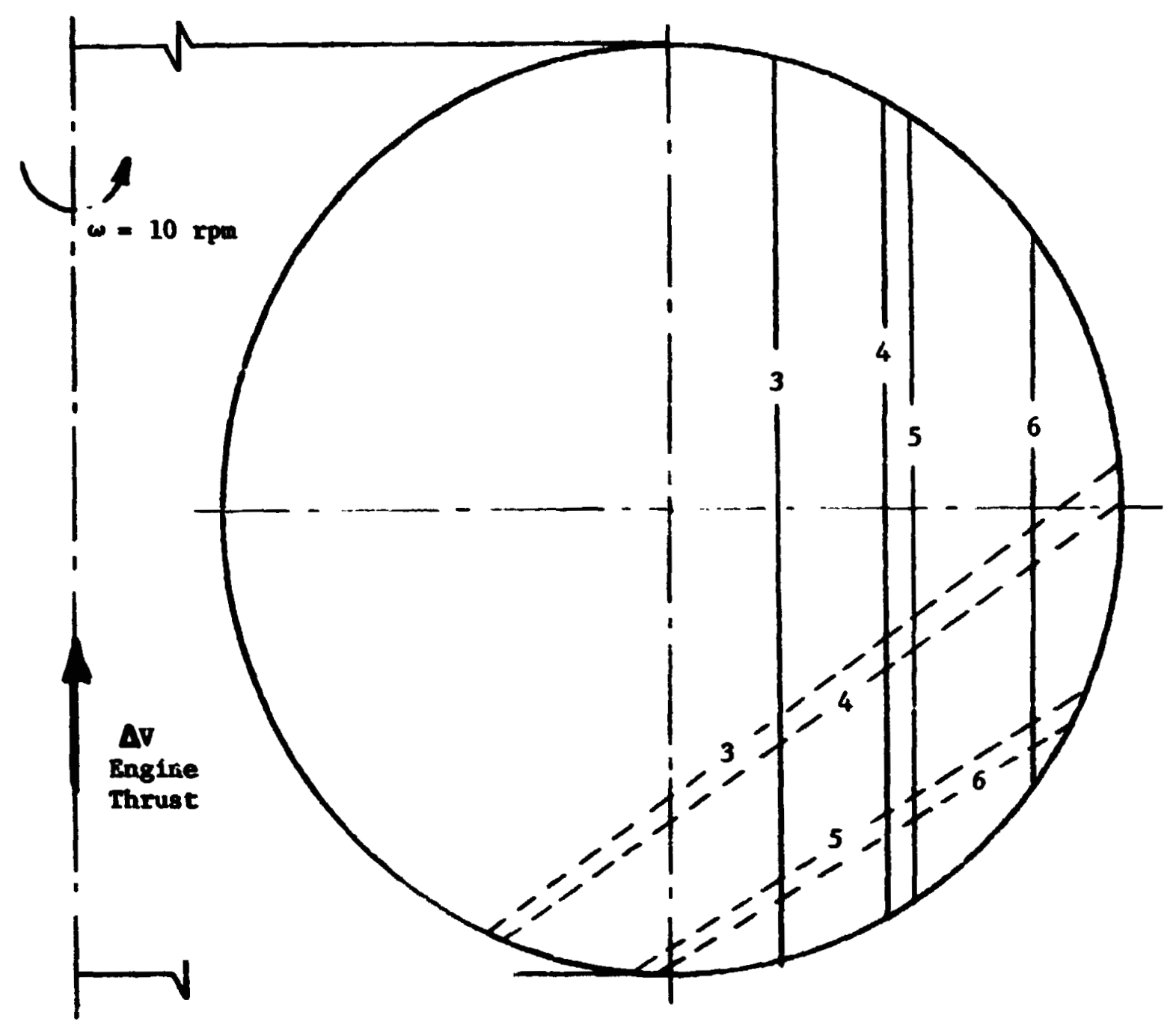

Interface at Start of Burn (Spin Only)
$\ldots-\ldots$ Interface at End of Burn (Spin and Axial Thrusting)

81gure 4 Interface Orientation at the Beginning and Bnd of 3rd, 4th, 5th, and 6th Burn Perlode 
relative positions of the interface at the beginning and end of the $3 \mathrm{rd}, 4 \mathrm{th}, 5 \mathrm{th}$ and 6 th burn periods. From this figure, it appeared that the tank outlet could not be located so that it would always remain in contact with propellant and, at the same time, insure complete emptying of the tank. Thus, some means of supplying propellant to the outlet was required.

As discussed previously, only screen devices possess the requisite pressure-retention capability to ensure delivery of gas-free liquid from the tank under the mission accelerations. Screen devices can be arbitrarily divided into two general categories--traps and liners. The trap positions a volume of liquid directly at the tank outlet in the form of a reservoir. This volume is sufficient to supply engine requirements until the propellant bulk is settled at the outlet to maintain the required flow rate. The Iiner, in the form of a complete liner or separate flow channels, positions the liquid to form a flow annulus or communication channel to the tank outlet.

Traps are most practically applied in tanks of cylinirical or spherical shape where the main propellant bulk tends to settle in the vicinity of the outlet. In a spinning torus, however, the propellant is initially distributed along the " $e l$ wail and setties in a distributed fashion around : $1 e$ bottom of the torus after the engine starts. As a result, some means of communicating between the distributed propellant and the outlet is required. For this reason, a total communication, flow-channel-type system was considered for this application.

In considering the tank outlet location, the orientation of the propeliant interface at the end of the sixth burn indicated that the outlet, or outlets, should be positioned in the lower outside quadrant of the tank, approximately 0.524 radians $\left(30^{\circ}\right)$ from vertical. Location of the outlet, or outlets, in this position axound the tank would allow expulsion of the $6 \%$ spare propellant included in the propellant volume at the end of the sixth burn, using a ring-shaped flow channel system with minimum feeder arms.

Fnllowing the preliminary evaluation of interface shape and orientation, four different fine-mesh screen flow- 
Channel and liner propellant acquisition concepts were established as candidates, as shown schematically in Figure 5. Configuration 1 consists if a fine-mesh screen liner located in the lower half of the toroidal tank along the outer wall. The liner provides a continuous communication path between the propellant bulk and one or more tank outlets during all modes of operation. Configuration 2 consists of a ring of semicircular cross-section in the tank, supplying propellant to one or more outlets. Four feeder-arms are connected to the ring at four equally-spaced locations. The ring-and-feeder-arm combination forms a continuous flow path between the propellant bulk and one or more outlets. For bot: configuratiuns 1 and 2 , the tank outlet, or outlets, was assumed to be located 0.524 radians $\left(30^{\circ}\right)$ from vertical.

Configuration 3 employs a conical propellant sump at a single tank outlet displaced 0.524 radians $\left(30^{\circ}\right)$ from vertical. Propellant is retained in the sump by centrifugal forces during spinning. A fine-mesh-screen cover prevents gas ingestion. A ring-channel and four feeder-arms of square cross-section provide communication between the propellant bulk in the tank and the sump. Configuration 4 employs a toroidal tank with a non-circular cross-section and single or multiple outlets. Titis ctuss-section $i=0$ sombingtinn of a circle and a triangle forming a tear-drop shape. Orientation of the tear drop with the triangle apex farthest away from the spin axis allows centrifugal forces to move the propellant to the region of the apex. A fine-mesh screen is located in the triangular section as shown in Figure 5 . This screen prevents gas ingestion and also forms a flow channel in the tank.

c.

FLUID BEHAVIOR ANALYSIS

Following definition of the candidate concepts, a more detailei analysis of fluid behavior in a spinning toroidal tank was performed in evaluating the candidate concepts. In conducting the evaluation, it was desired to select a system which would minimize both propellant residuals and spacecraft control requirements. An analysis was performed to establish the location and configuration of the propellant as a function of miseion events. These data were then employed in the subsequent analyses together with 

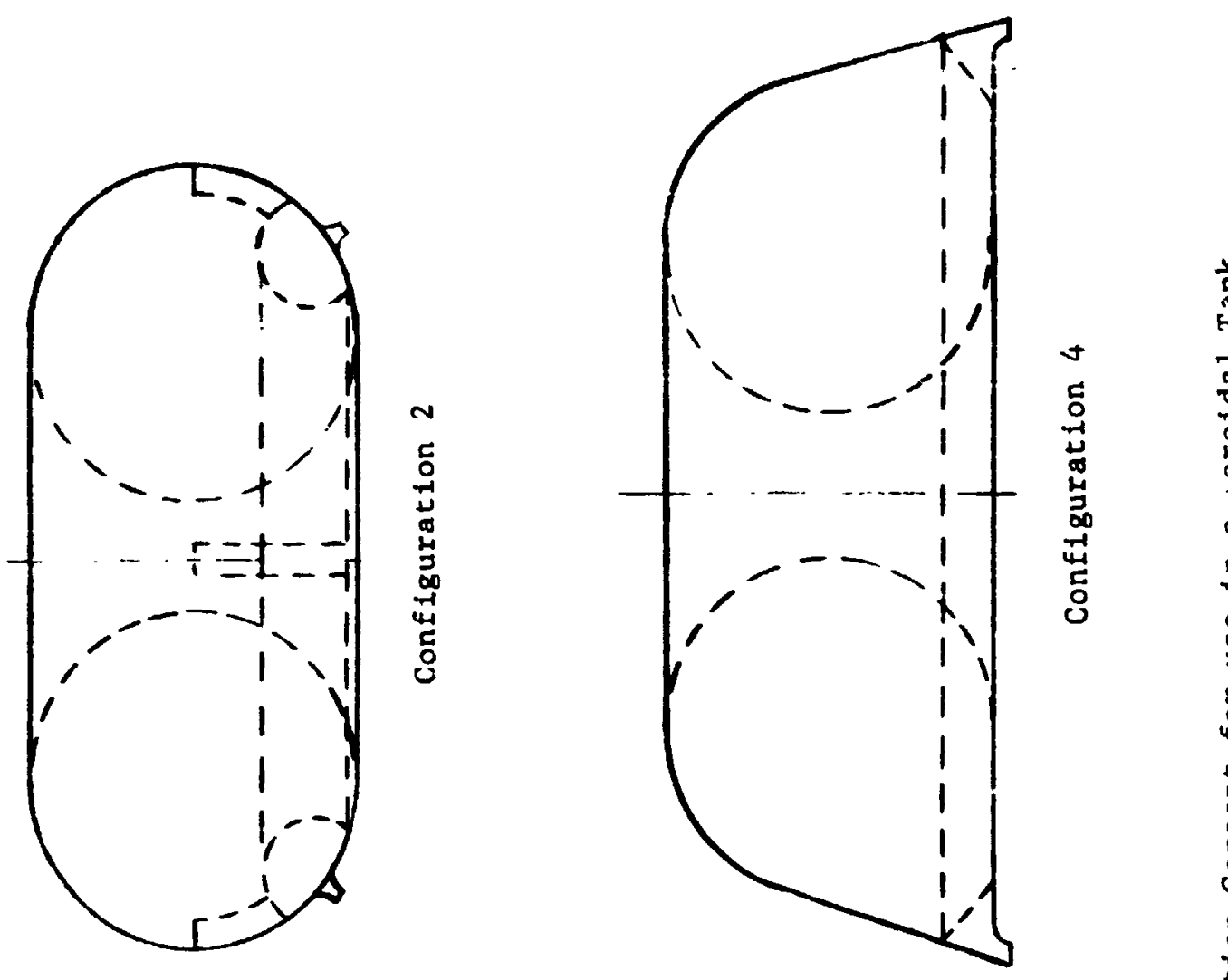

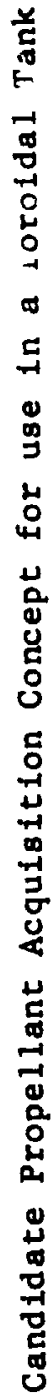
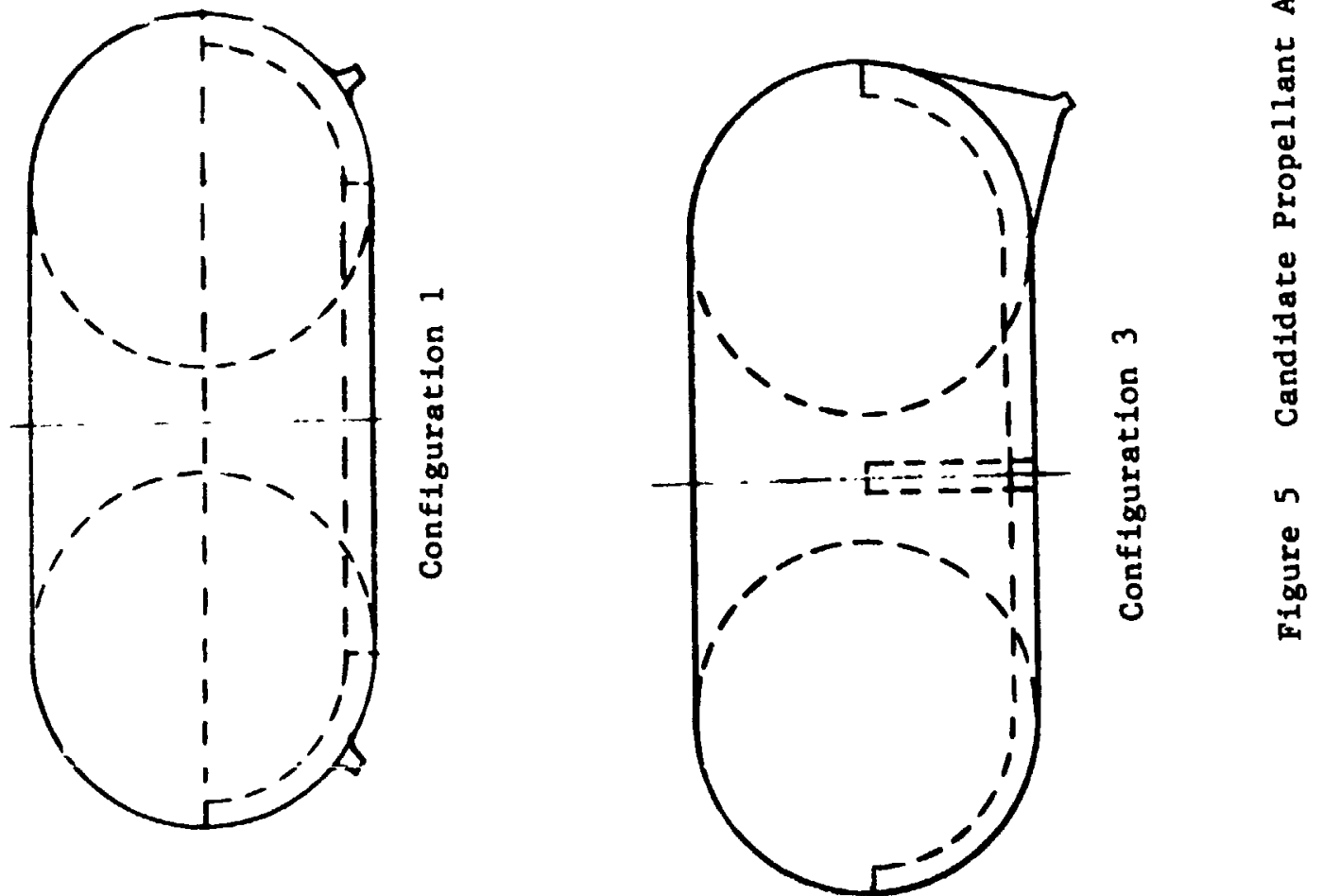
flow-loss data of the surface tension device to establish the number and location of tank outlets and system expulsion efficiency. The history of the liquid-gas interface orientation was also used in evaluating propellant slosh, center-of-mass shift, and effects

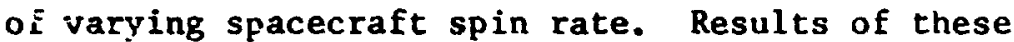
analyses a 2 presented in this section.

\section{Liquid-Gas Interface Orientation}

A Martin Marietta computer program was used to calculate the actual liquid-gas interface shape in a toroidal tank. The computer program, capable of determining the interface in any spinning container, was developed under a company-funded research task, "Low-g Fluid Behavior and Control." For this case, the boundary conditions for a toroidal tank were input into the program.

The program takes into account tive liquid-solid contact angle, angular spin rate, axial aceleration, liquid volume, liquid density and surface tension, and the tank dimensions in determining the interface shape. The angle of inclination of the interface with respect to the tank under the combined effects of axial and centrifugai acceleration was the most significant information provided by the program. This analysis also verified previous assumptions regarding the interface shape, such as the Bond number at which the interface is flat.

Computer generated plots of the resulting oxidizer tank interface shapes are shown in Figure 6 for each burn period. Similar results were obtained for the fuel tank. The top row of plots indicates the orientation of the propellant just prior to each burn. At this time, the propellant is subjected to the accelerations resulting from the spacecraft spinning at 10 rpm. The bottom row of plots indicates the orientation of the propellant just prior to terminating each burn. At this time, the acceleration field imposed upon the propellant is a combination of the 10-rpm spin acceleration and the axial acceleration produced by the $\Delta v$ engine. All interface shapes are essentially flat; the greatest interface survature appears to exist during the first burn where the ullage volumes are the smallest. 


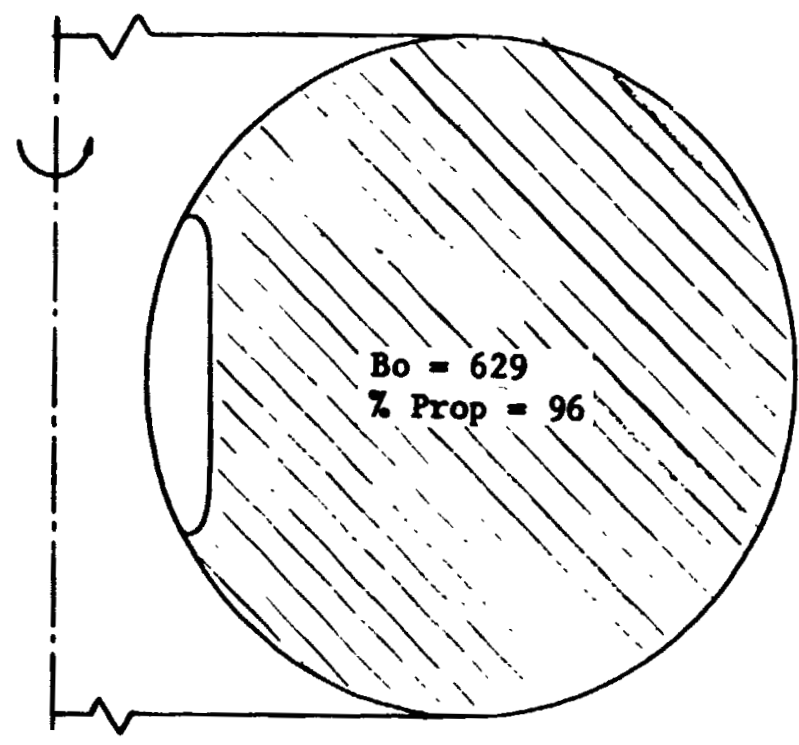

Event: 1st - Mldcourse

Correction

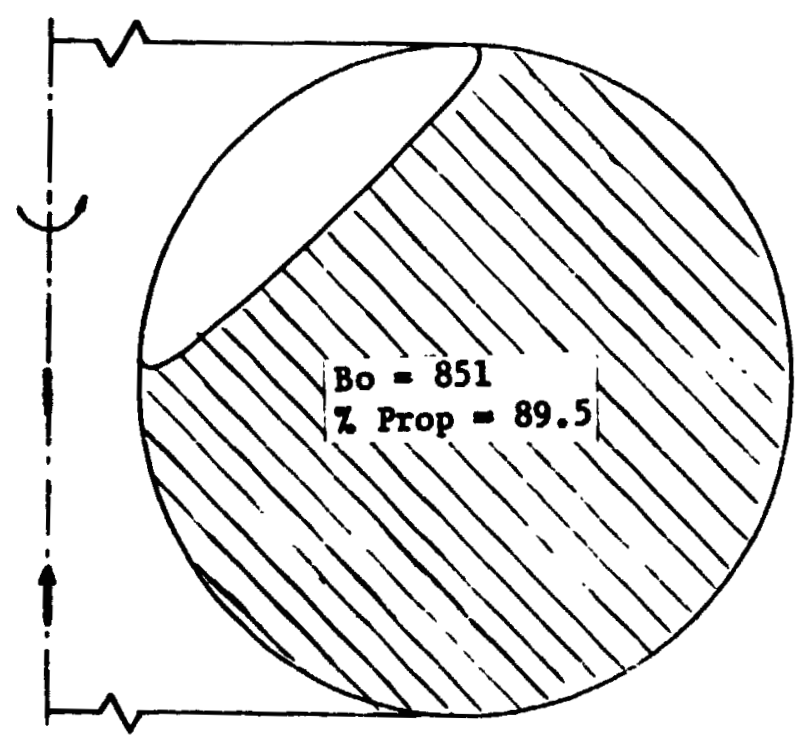

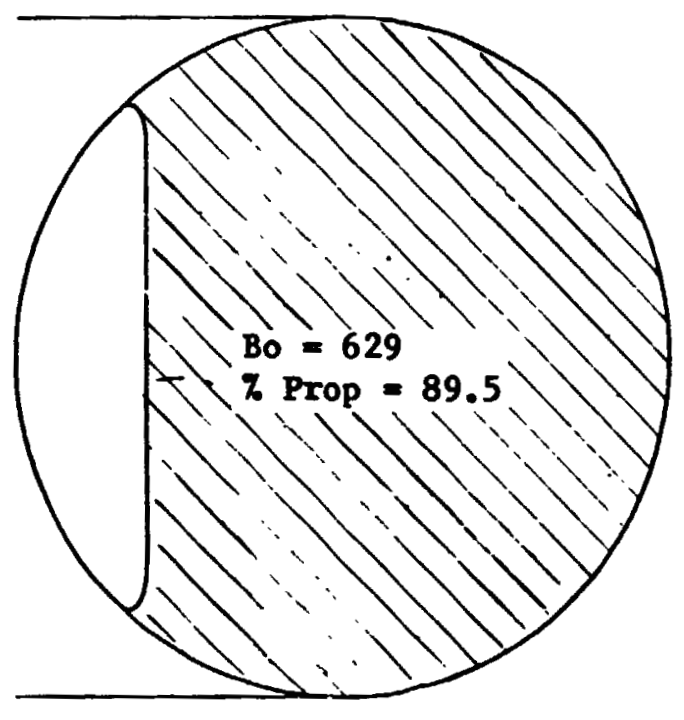

2nd - Orbit
Injection

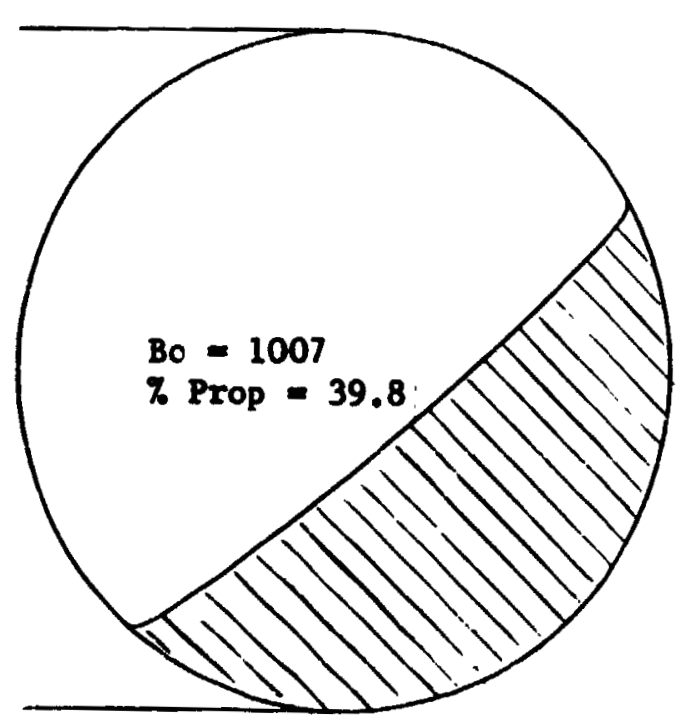

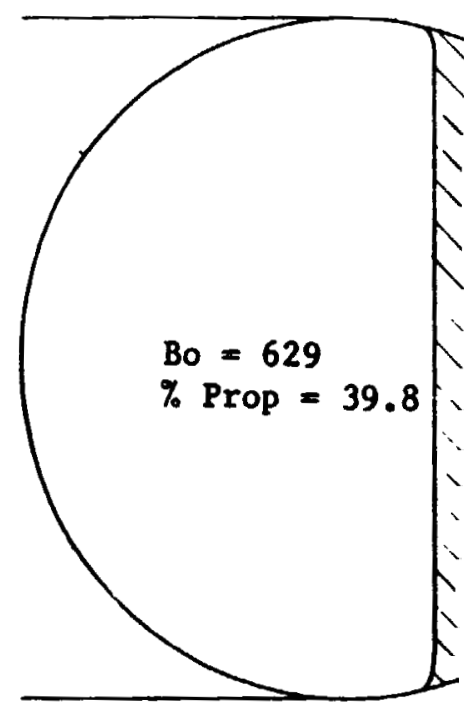

3rd - Plane Change

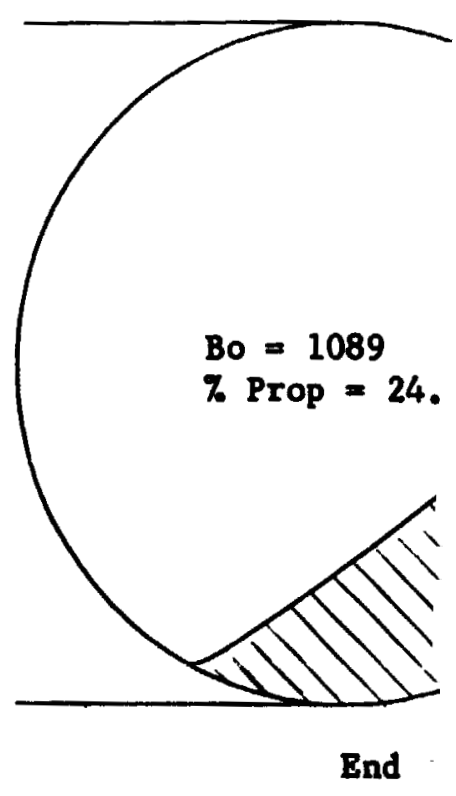


TOLDOUT FRAME

2
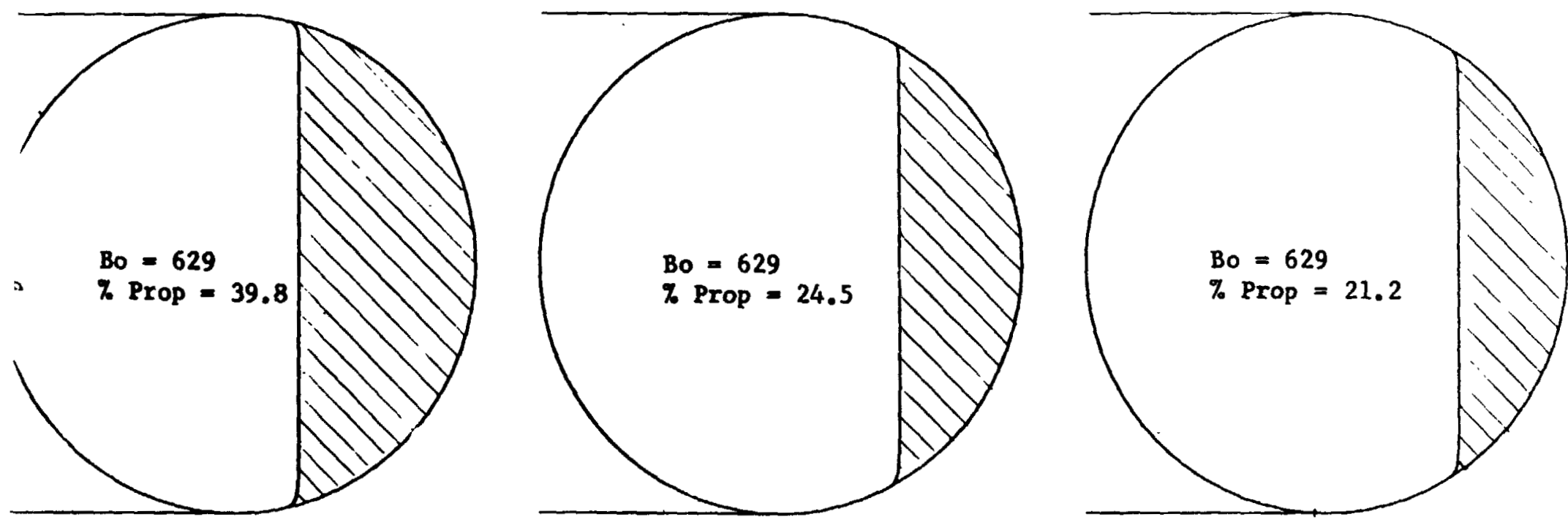

Start of Burn (Spin Only)

3rd - Plane

Change

/
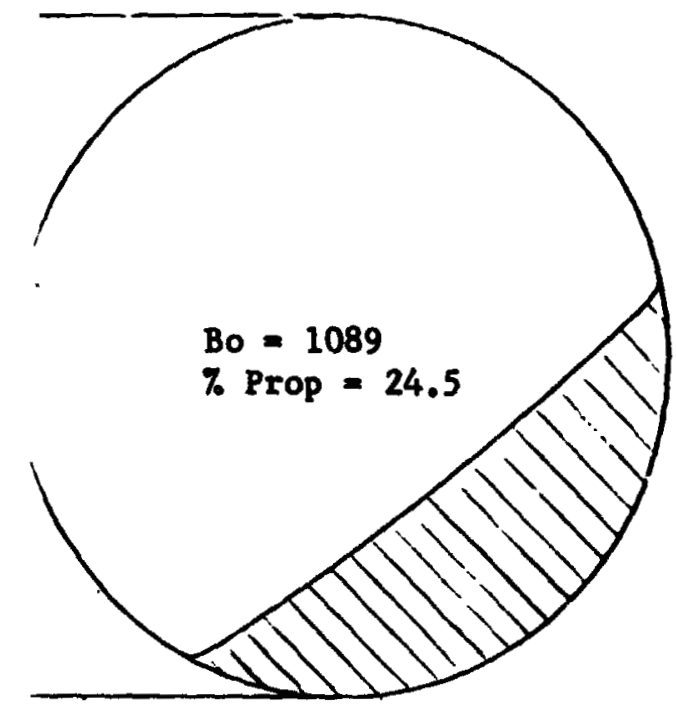

End of Burn (Spin and Axial Thrusting) 4th - Orbit

Trim

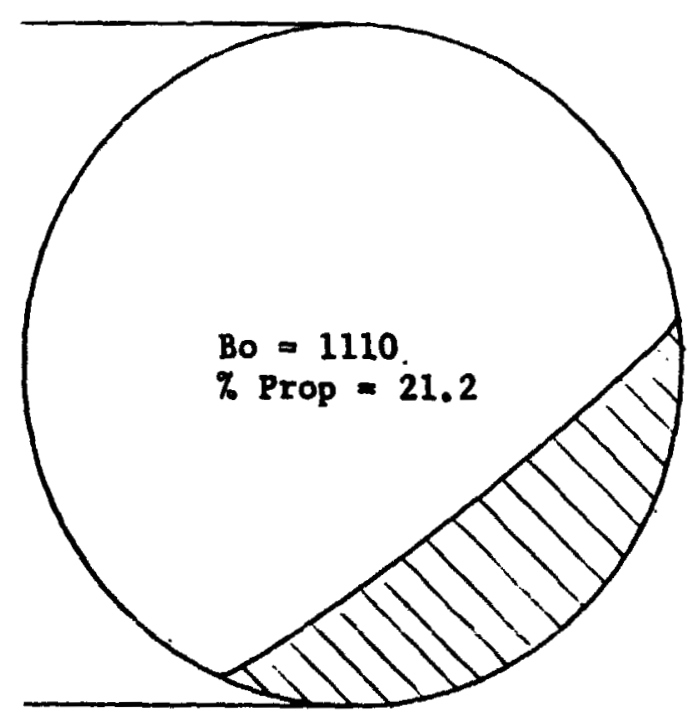

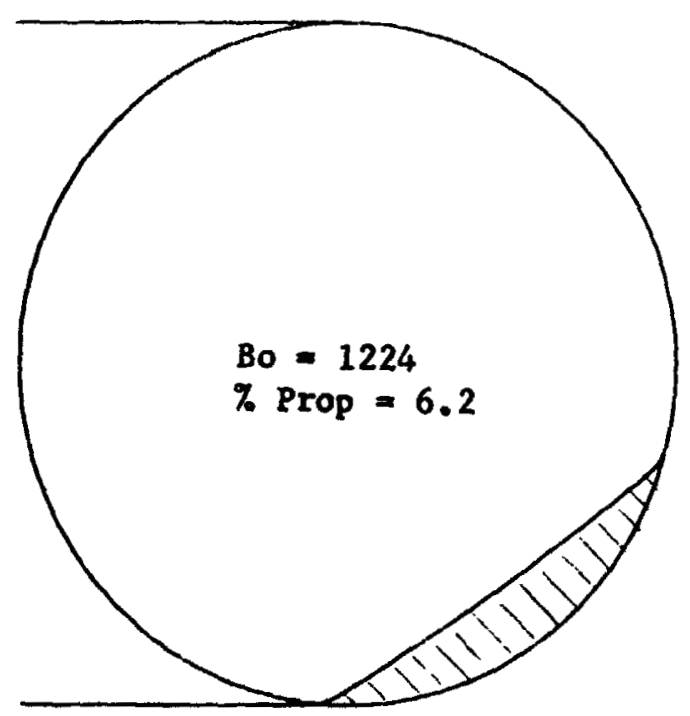

5 th - Apoapsis Reduction 
FOLDOUT FRAMF 3
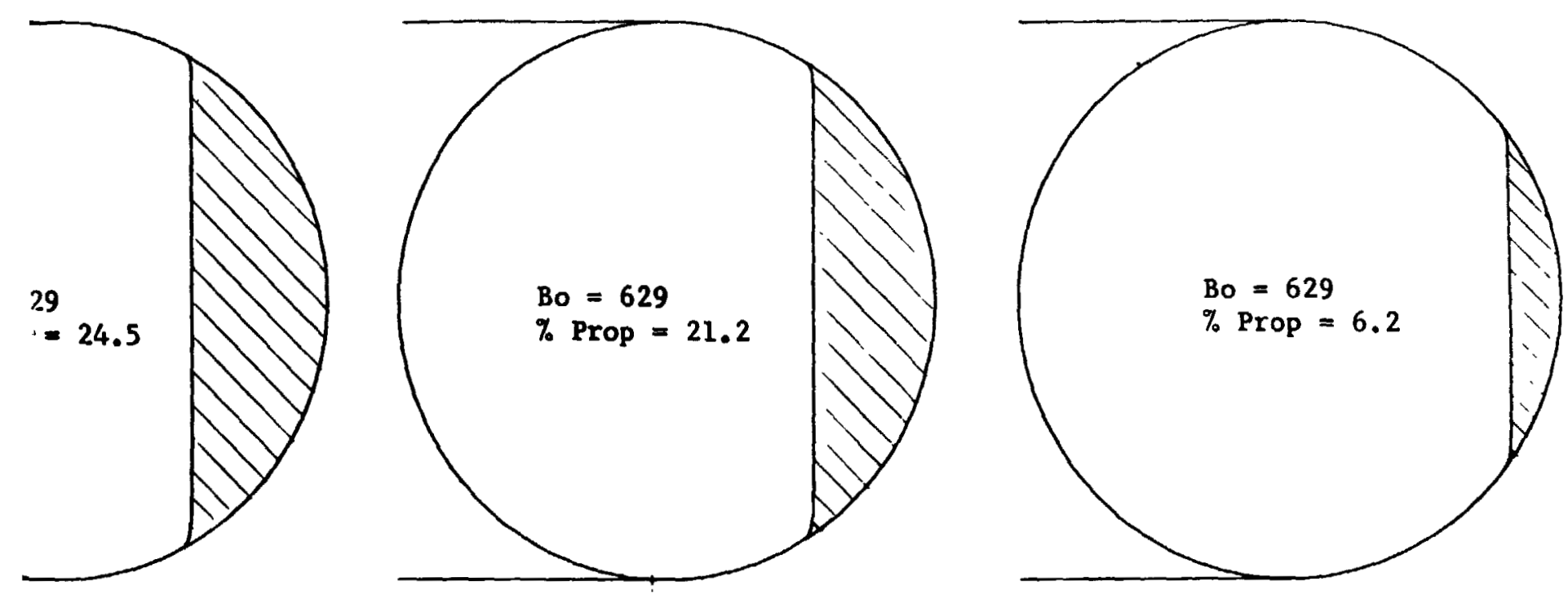

$\underset{\text { Irim }}{\text { Orbit }}$

5th - Apoapsis Reduction 6th - Orbit
Trim
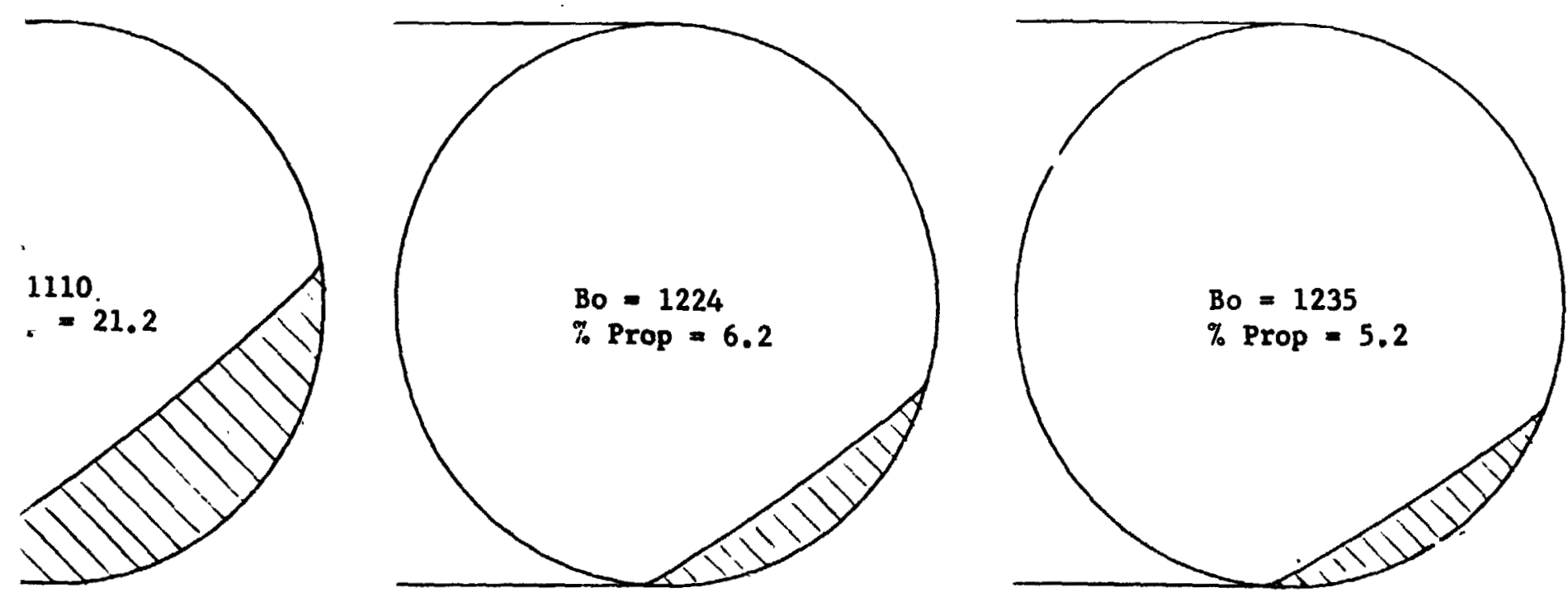

ag) 
The computer plots also verify the problem of tank outlet location discussed previously. At the beginning of the fifth and sixth burn periods, the orientation and displacement of the propellant is such that a gas-free start-up of the engine would be marginal for the fifth burn and imfossible for the sixth, unless some means of communication between the propellant bulk and the tank outlet is provided.

One problem that has receivad little previous attention is ullage bubble breakup during low accelerations. Two reports (Ref 24 and 25 ) pertaining to liquid-gas interface stability under zero-gravity conditions in toroidal tanks were found. Test results in these reports indicate that, at low liquid volumes (less than $50 \%$ 1iquid), the liquid moves to a position on the tank wall away from the toroidal axis while the gas occupies the wall nearest the axis. The gas volume was uniform around the inside of the torus. However, at larger liquid volumes, the toroidal gas cavity tended to be displaced from the symmetrical orientation, formir.g one or more bubbles shaped as toroidal segments with hemispherical ends. These results indicate a possible instability problem in orientation of the ullage bubble; however, the tests were conducted under zero-gravity conditions in a drop tower. In a spinning torus, the inherent centrifugal acceleration would tend to promote uniform distribution of all fluids and reduce the potential for bubble breakup. Further study is indicated. A siability analysis including bench testing, should be performed to determine the bubble breakup limits in the spinning torus.

\section{Tank Outlet Analysis}

It is desirable to minimize the number of tank outlets for several reasons. First, multiple outlets require increased tank shell weight due to the additional welding bosses required. The additional number of welds also tends to reduce the reliability of the tank system. Tank costs are also increased because additional operations are required during manufacturing. Finally, multiple outlets impose a flow-balance problem. If ..le pressure drop is not equal in each feedline, the resultant flow imbalance can induce premature dropout (gas ingestion) and increase trapped or residual propellants. 
The propellant ac isition system can reduce the number of outlets required. In Section $A$ of this chapter, the pressure retention capability, or bubble point, of screen material was defined and discussed. In the operation of any propellant acquisition device employing fine-mesh s:reen, it is necessary that the system operating pressure losses not exceed the bubble point of the screen or gas will be ingested. Thus, the bubble point must be greater than or equal to the total system pressure loss, which is composed of elevation, friction, screen, and momentum losses:

$\Delta P_{c} \geq \Delta P_{E}+\Delta P_{F}+\Delta{ }_{S}+\Delta P_{M}$

where $\Delta P_{E}=$ elevation pressure loss $=\rho g h$,

$\Delta P_{F}=$ friction pressure loss $=4 \mathrm{f}\left(\frac{\mathrm{L}}{\mathrm{D}_{\mathrm{h}}}\right)\left(\frac{\rho V^{2}}{2 \mathrm{~g}_{\mathrm{c}}}\right)$,

$\Delta P_{S}=\begin{aligned} & \text { screen pressure loss }=f\left(V_{S} \text {, screen }\right. \\ & \text { mesh })\end{aligned}$

$\Delta \mathrm{P}_{\mathrm{M}}=$ momentum pressure loss $=\frac{\rho}{2}\left(\mathrm{v}_{\mathrm{f}}^{2}-\mathrm{v}_{\mathrm{i}}^{2}\right)$,

and $\rho=$ propellant density,

$\mathrm{g}=$ vehicle acceleration,

$h=$ static height of propellant supported by the screen,

$f=$ friction factor in flow channels,

$\mathrm{L}=$ length of flow channel,

$D_{h}=$ hydraulic diameter of flow channel,

$\mathrm{V}=$ propellant velocity in channel,

$\mathrm{v}_{\mathrm{S}}=$ propellant approach velocity to screen,

$\mathrm{v}_{\mathrm{f}}=$ propellant velocity at outlet of channel,

$v_{1}=$ propellant velocity external to flow channel.

Considering the four component pressure losses making up the total pressure loss, it can be seen that the friction, screen, and momentum pressure losses are all dependent on propellant velocities. To reduce these 
three pressure losses, a reduction in propellant velocity would be required. Use cf multiple outlets would reduce propellant velocities in the commur ication channels and, therefore, reduce total system pressure loss.

To evaluate the need for multiple tank outlets, the system pressure loss in the propellant communication ring of configuration 2 was evaluated since this configuration would have the most severe pressure losses of the four candidate configurations. The following assumptions were also employed in the evaluation:

1) Single outlet employed in tank;

2) Ring cross-section is semi-circular;

3) Screen pressure loss is calculated from ArmourCannon relation ( $\operatorname{Ref} 26)$;

4) Screen surface area is $50 \%$ of circular surface of ring;

5) Friction pressure loss in ring is based on Moody pipe friction factor;

6) Fluid velocity in ring is corstant; and,

7) Outlet is located 0.524 radians $\left(30^{\circ}\right)$ from vertical.

The geometric arrangement and pertinent dimensions assumed in the analysis are shown in Figure 7 . The results are shown in Figures 8 and 9 for the oxidizer and fuel systems, respectively. Pressure drop across the screen at the tank outlet, $P_{G}-P_{L}$, where $P_{G}$ is the ullage gas pressure and $P_{L}$ is the liquid pressure inside the channel is shown as a function of the height of screen exposed to the ullage. Both $200 \times 1400$ and $325 \times 2300$ mesh Dutch-twill weave screen were considered. The screen bubble points in each propellant are also indicated.

Evaluation of the data presented in Figures 8 and 9 indicates that the system pressure loss is significantly less than the bubble point of the screen, except during the terminal draining phase of the mission. Because of these results obtalned with only one outlet, no need exists to use multiple outlets. A flow-channe1 

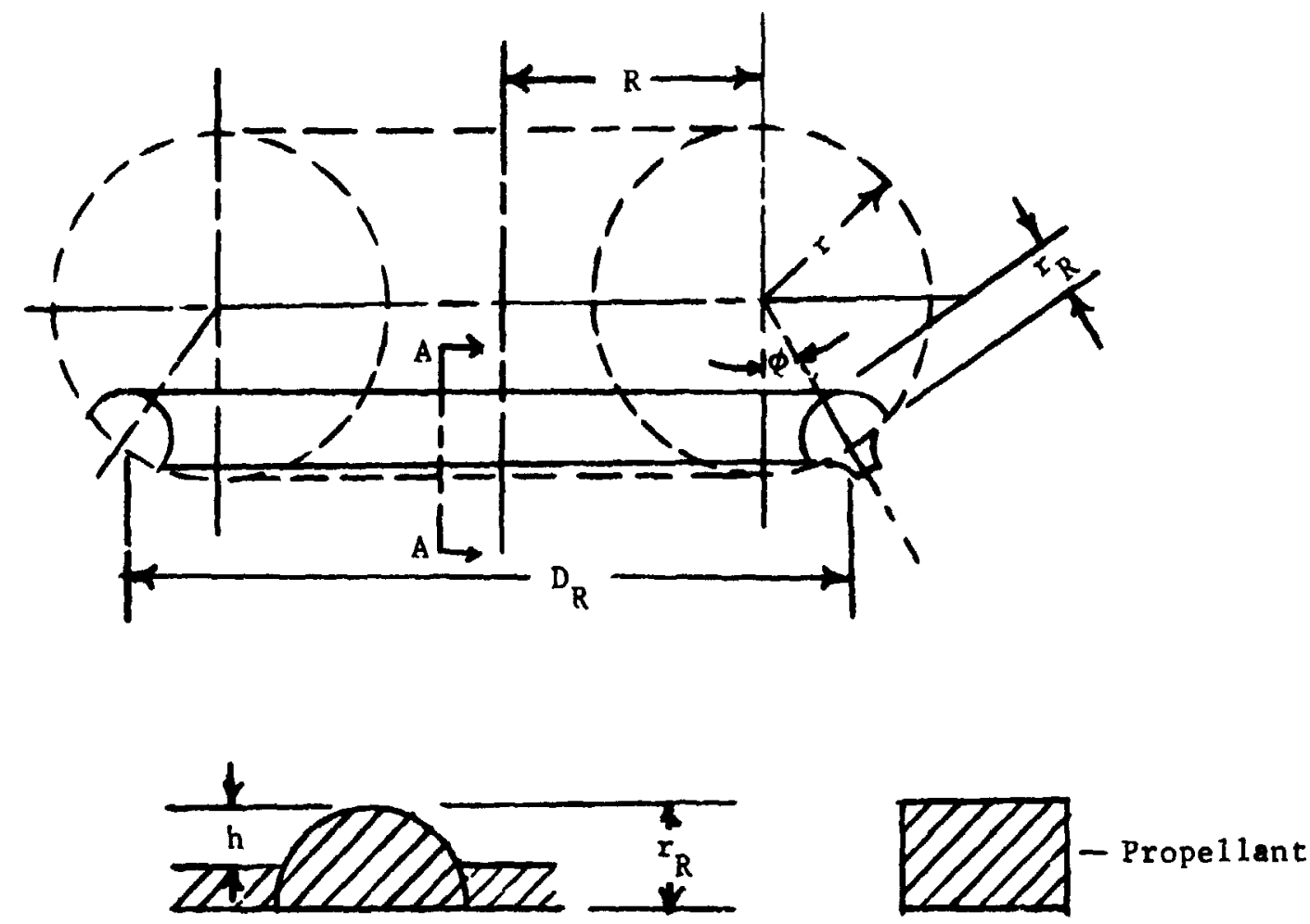

Section A-A

$$
\begin{aligned}
& R=0.459 \mathrm{~m}(1.505 \mathrm{ft}) \\
& r=0.154 \mathrm{~m}(0.505, \mathrm{ft}) \\
& \phi=0.524 \mathrm{rad} .\left(30^{\circ}\right) \\
& r_{R}=2.54 \mathrm{~cm}(1.0 \mathrm{in.}) \\
& D_{R}=1.078 \mathrm{~m}(3.53 \mathrm{ft})
\end{aligned}
$$

Figure 7 Geometric Arrangement of Propellant

Retainer Ring for Pressure Loss

Analys 18 


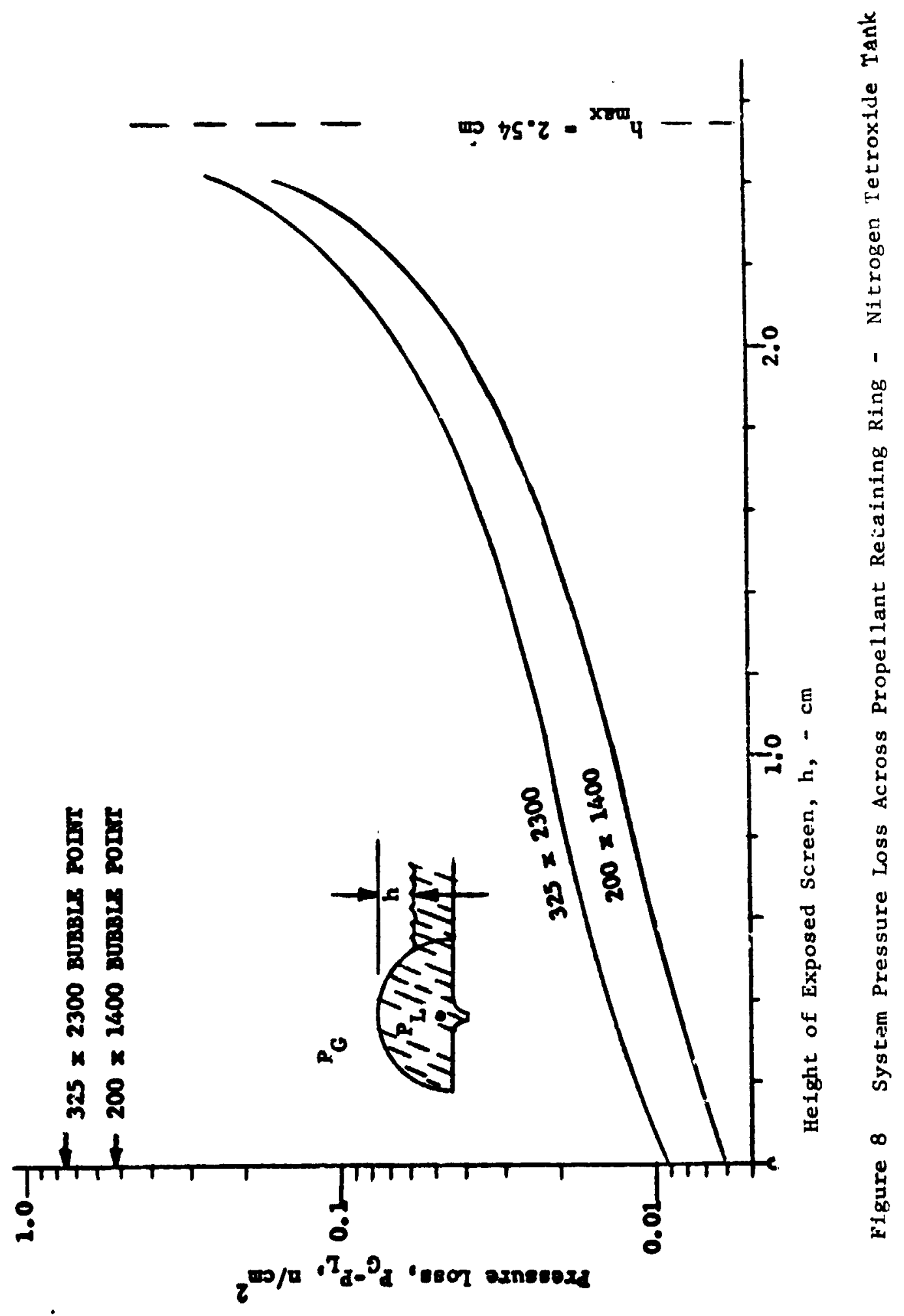

H. a 


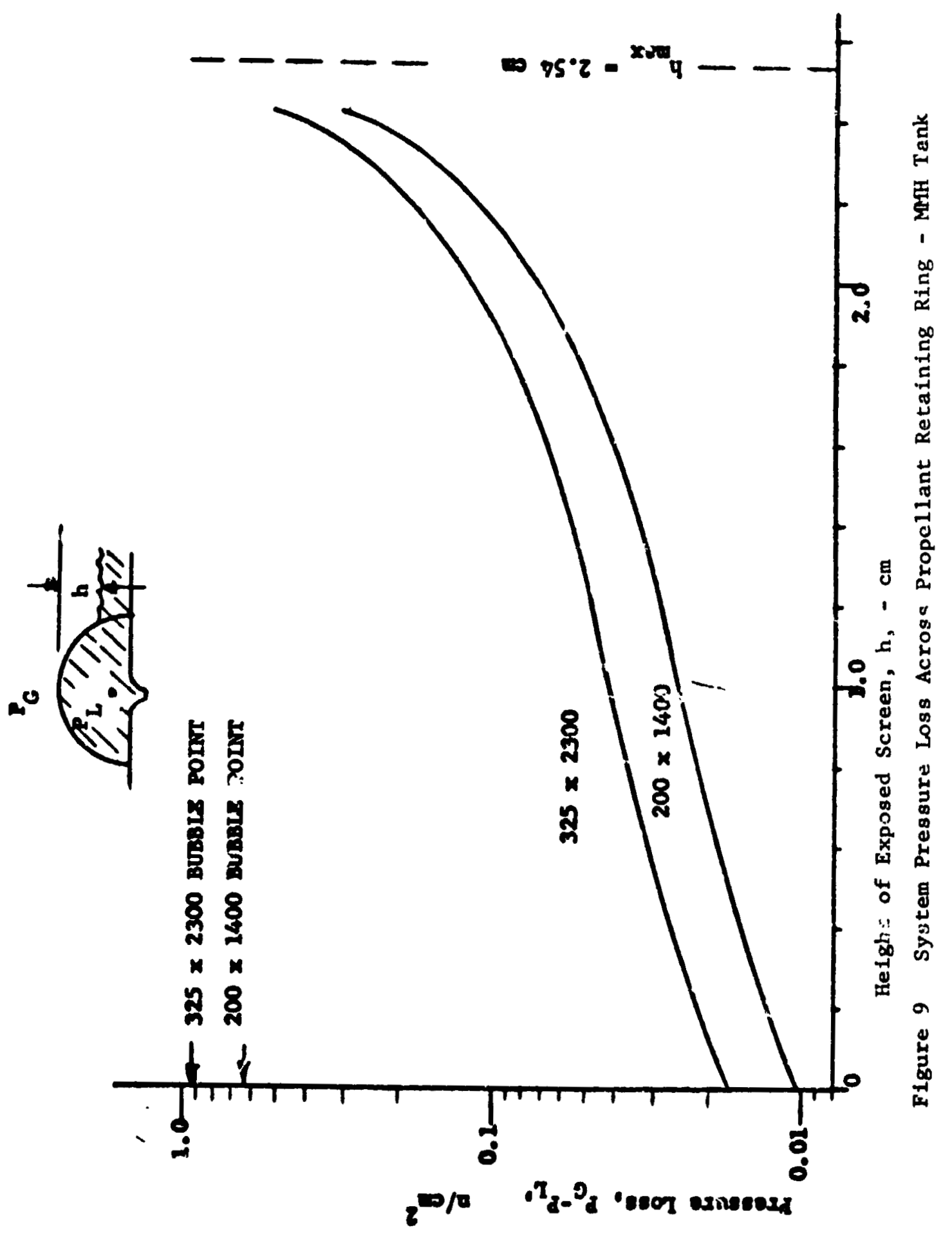


surface tension device can be employed to feed one outlet and will yield a high expulsion efficiency as discussed next.

3. Expulsion Efficiency

With any propellant acquisition system concept, $i$ is a design objective to minimize the quantity of trapped or unusable propellant. The degree of success is measured by the expulsion efficiency, defined as the propellant volume available for use divided by the total volume of propellant. The difference between these two quantities is the residual propellant. Expulsion efficiency, $q_{e}$, is expressed as:

$\eta_{e}=100\left(1-\frac{v_{T}}{v_{P}}\right)$

where $v_{P}=$ total propellant volume, and

$v_{T}=$ trapped or residual propellant volume.

Expulsion efficiencies were calculated for each of the four candidate systems assuming a total loaded propellant volume of $0.204 \mathrm{~m}^{3}\left(7.2 \mathrm{ft}^{3}\right)$. For the first three candidate systems, the propellant volume retained was assumed equal to the volume of the acquisition device. This volume and the associated expulsion efficiency were calculated for each system, using a pertinent dimension for each system as a variable. The dimensions used for the systems were:

$$
\begin{aligned}
& \text { Configuration } 1 \text { - the gap between the liner and } \\
& \text { the tank wall, } \\
& \text { Configuration } 2 \text { - diameter of semi-circular ring } \\
& \text { and comunication channels, } \\
& \text { Configuration } 3 \text { - width of square ring and commun- } \\
& \text { ication channels. }
\end{aligned}
$$

For Configuration 4, the expulsion efficiency was calculated as a function of propellant height above the outlet. For this particular configuration, the factor most controlling expulsion efficiency would be the propellant dropout or vapor pull-through height of 
the outlet. Previous terminal-draining work was reviewed in an altempt at estimating the dropout heights to be expected. Only one program was found that contained information concerning toroidal tank draining (Ref 27). Outflow testing during this program was conducted under static conditions, for the most part, tu evaluate outlet baffle and sump designs. Some lateral excitation was employed to induce slosh, but no spinning was considered. For this reason, the results of this test program were not used in calculating expulsion efficiency. Instead, the calculation was based on the height of liquid zmaining in the tank. Additional analytical and experimentel study is required to evaluate dropout in a spinning toroidal tank.

The calculated expulsion efficiencies for the candidate configuratiors are presented in Figures 10 through 13. For Configuration 1 (Figure 10), a gap of approximately $0.254 \mathrm{~cm}(0.1 \mathrm{in})$ is required to obtain a 99\% expulsion efficiency. Because of the large surface area of the liner, a small gap is req ired to minimize the trapped volume within the liner. While it is possible to manufacture a liner with this gap size, it would be difficult to maintain the gap uniform throughout the entire liner. Ine possible method of maintaining gap dimensions would be to use pleated or corrugated screen material in forming the liner. The pleats form flow passages and, at the same time, improve rigidity of the liner material. This procedure has been applied by Martin Marietta to spherical liners (Ref 4). The saine procedure could be applied to the toroidal liner although some development would be required for a toroidal shape.

The expulsion efficiency for Configuration 2 is shown in Figure 11. With this configuration, larger dimensions can be used while still maintaining high expulsion efficiency. For example, a $2.54-\mathrm{cm}(1.0-$ in) ring and communication channel dianeter produces an expulsion efficiency of approximately $99.5 \%$. Configuration 3 utilizes a propellant retainer ring and communication channels similar to Configuration 2, except that a square cross-section was assumed. The addition of the conical propellant sump penalizes the expulsion efficiency of this system (Figure 12). 


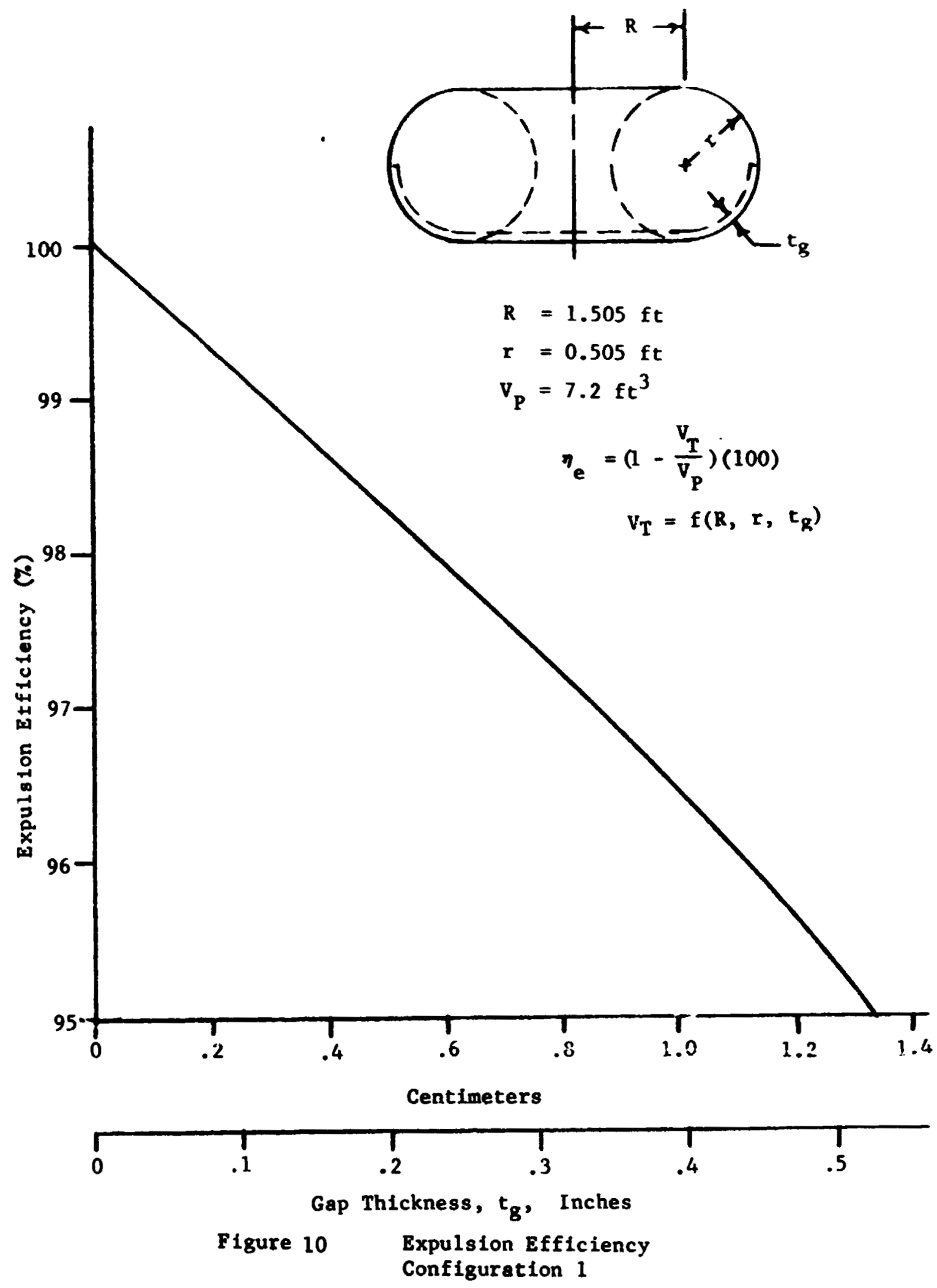




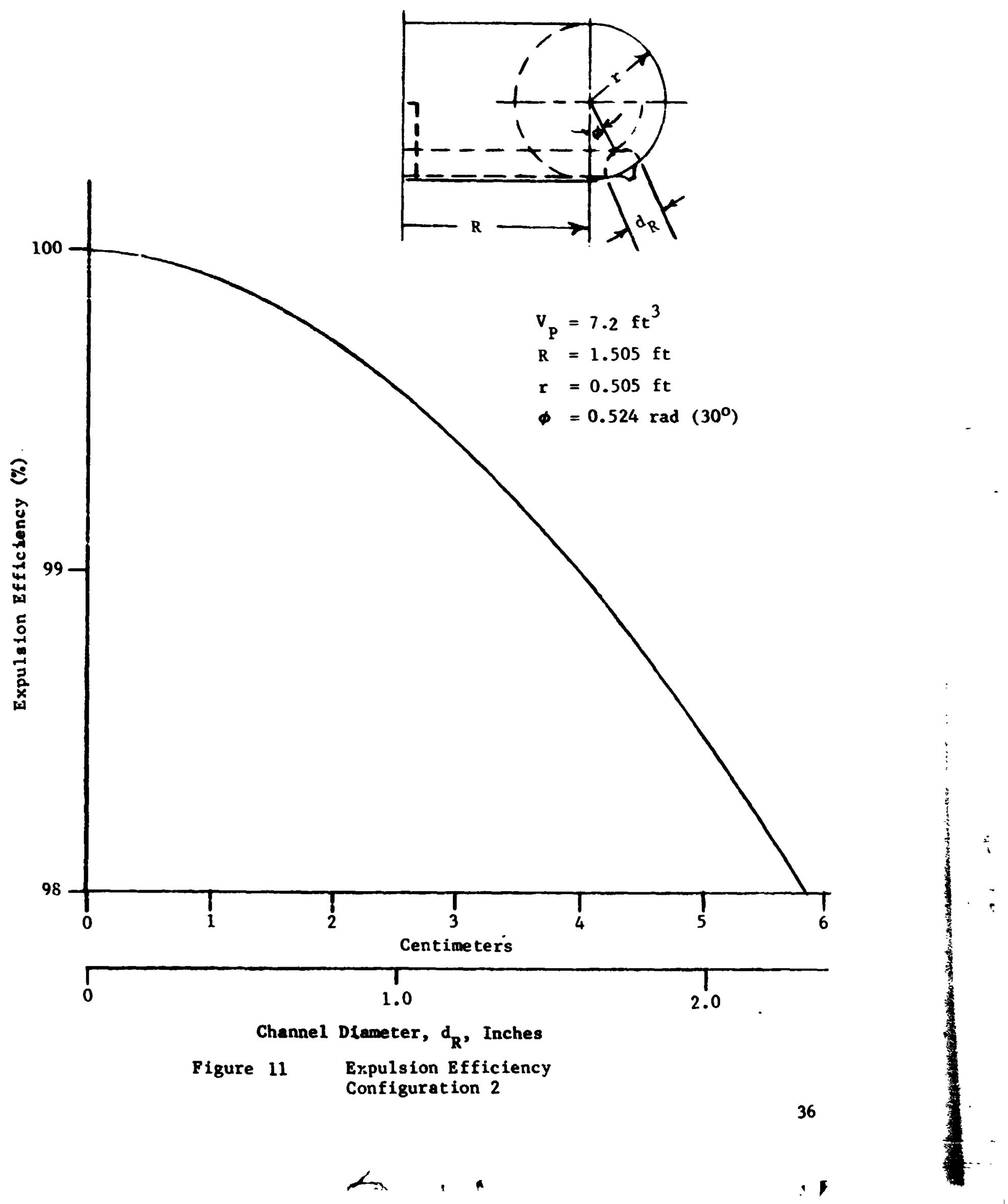



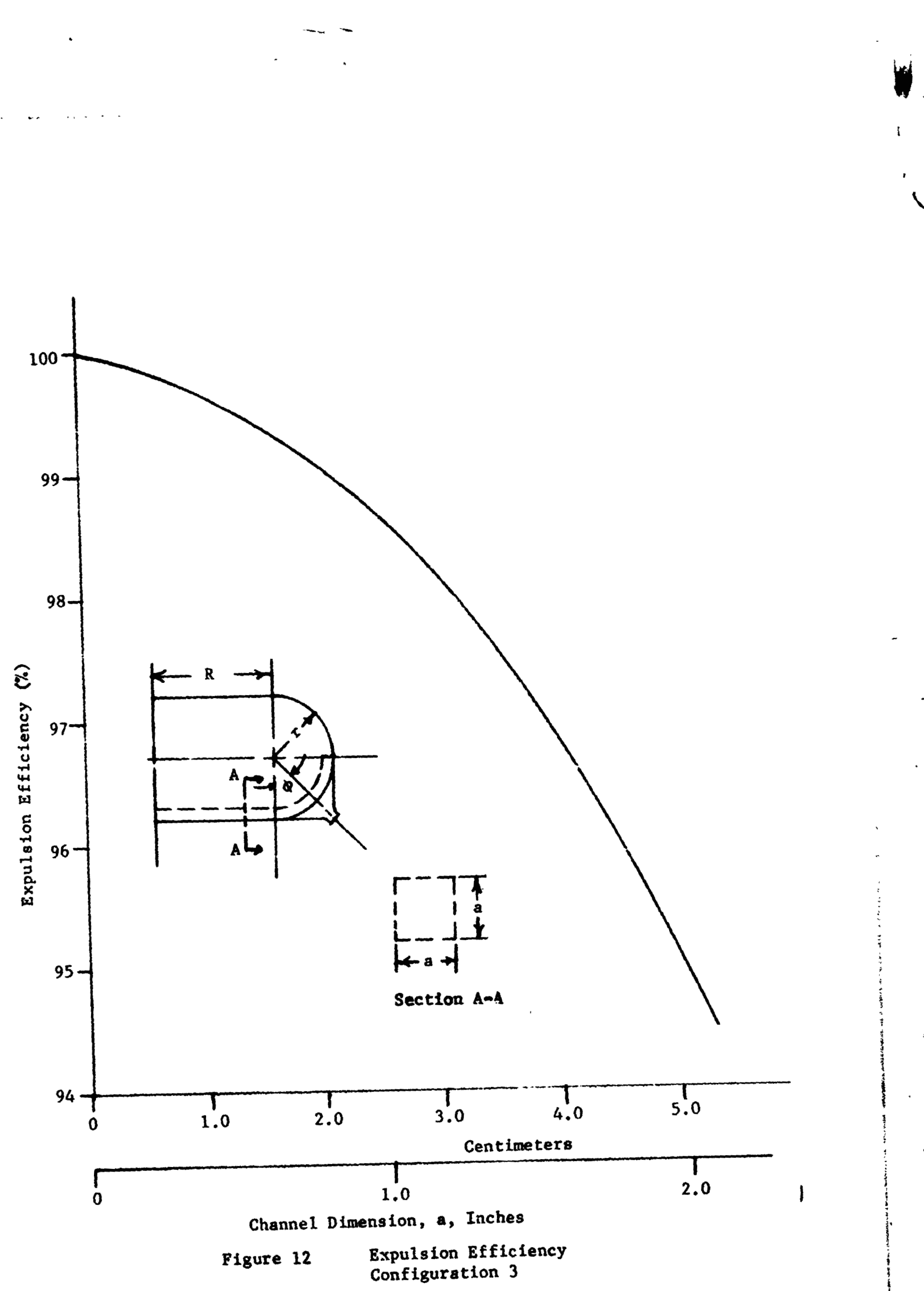


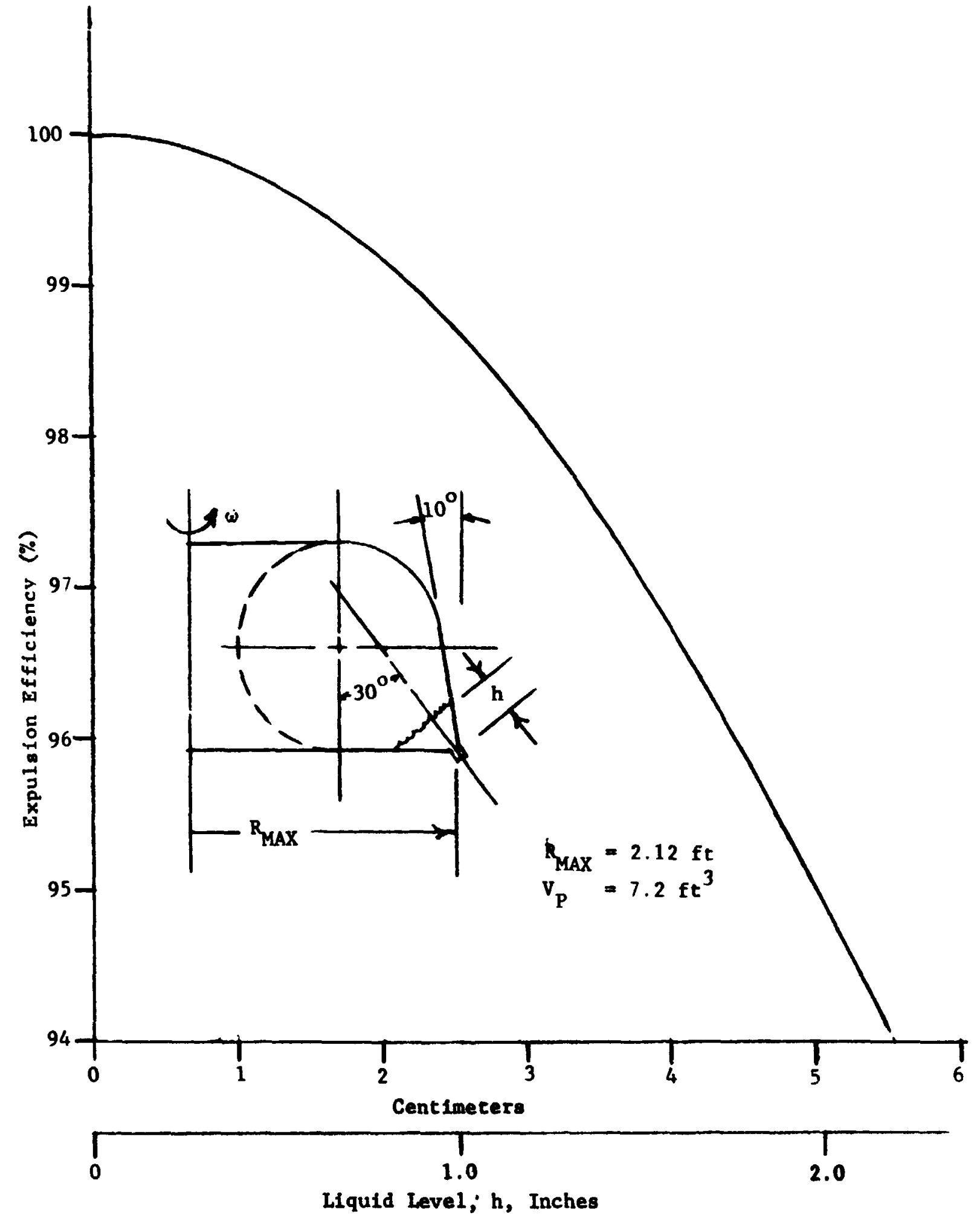

Figure 13 Expulsion Efficiency

Configuration 4 
The expulsion efficiency for Configuration 4 is shown in Figure 13. Assuming that the propellant can be drained to a level of $2.54 \mathrm{~cm}(1.0 \mathrm{in})$, an expulsion efficiency of $99 \%$ can be obtained.

\section{Slosh Analysis}

The smaller quantities of propellants in the tanks at the start of the $4 \mathrm{th}$ and subsequent burn periods, result in the possibility of propellant movement over a larger distance. Propellant slosh resulting from $\Delta V$ engine firing could present a potential problem. Just prior to engine ignition, the propellants are distributed on the outer wall of the torus due to spacecraft spin. After the engine is ignited, the axial acceleration of the spacecraft tends to move the propellant to the bottom of the tank and on up the inner wall. To evaluate the slosh problem, a simple two-dimensional pendulum model was developed, as shown in Figure 14. The propellant mass, $M$, was assumed to move as a solid mass along the torus wall in response to the centrifugal force due to spin and the axial force due to spacecraft acceleration $(\Delta V$ firing). These forces are designated as $F_{R}$ and $F_{A}$, respectively (Figure 14). In addition, a retarding or drag force due to skin friction, $F_{D}$, was assumed to act on the propellant mass. The centroid of the propellant mass was assumed to rotate about the cencer of the torus cross-section with radius, $\bar{r}$, which is the pendulum arm. It was also assumed that $r$ did not change with the position angle, $\phi$. Other symbols used in Figure 14 are:

$\omega=$ spacecraft spin rate,

$\mathbf{r}=$ torus minor radius,

$R=$ torus major radius,

$F_{e}=$ thrust produced by $\Delta V$ engine along spacecraft spin axis.

Applying Newton's second law, a force balance was developed to describe the motion of the mass, $M$ : 


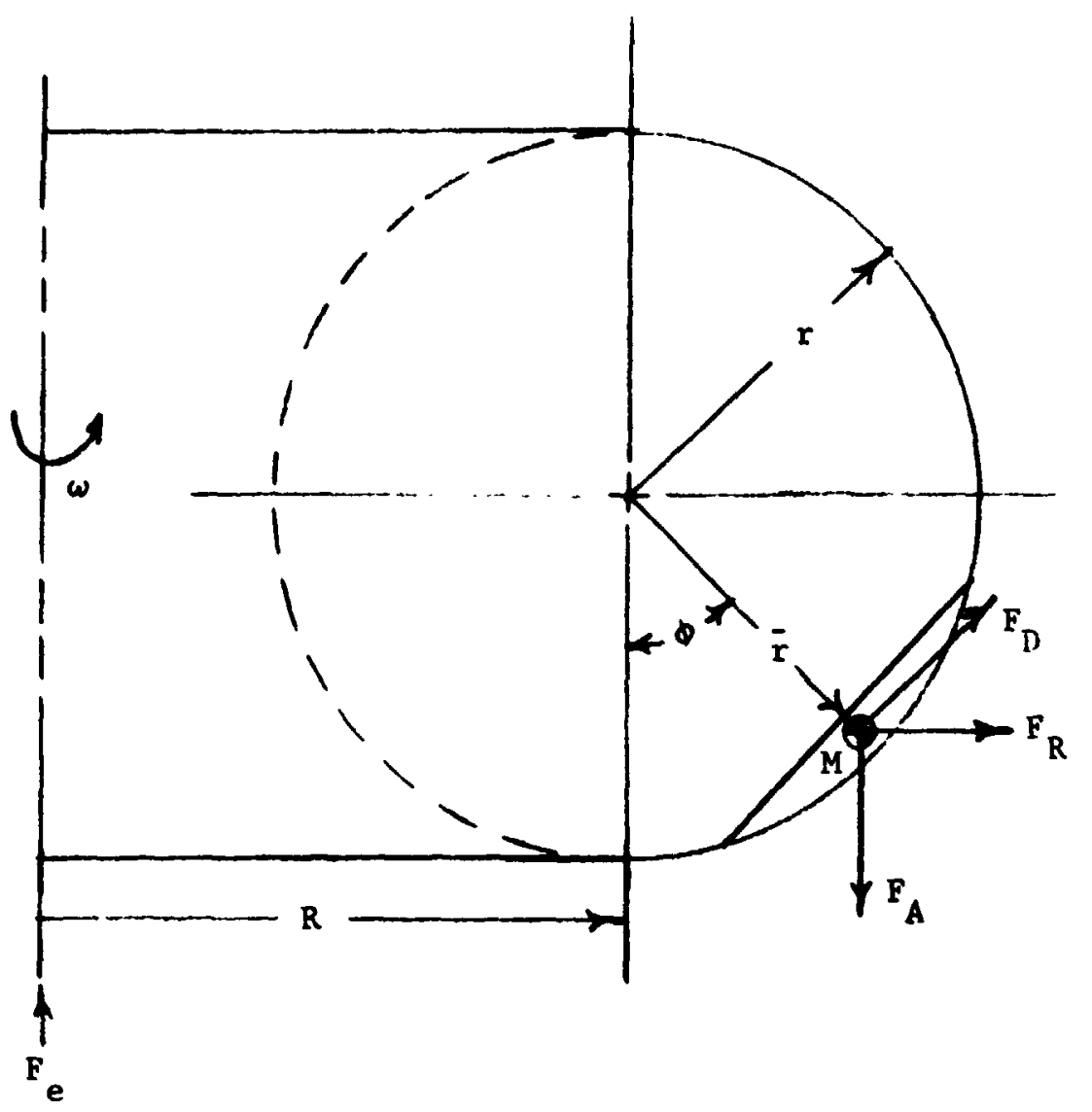

Figure $14 \quad$ Slosh Model 
$\overline{M r} \frac{d^{2} \phi}{d t^{2}}=F_{D}+F_{R} \cos \phi-F_{A} \sin \phi$

where $t=$ time.

This differential equation was solved numerically on the CDC 6600 digital computer for the oxidizer tank during the sixth burn period. Fxpressions for $F_{D}$ and $F_{R}$ were developed in terms of $\phi$ and $t . F_{A}$ was calculated from the engine thrust, $\mathrm{F}_{\mathrm{e}}$, and the spacecraft and propellant masses. The propellant mass, $M$, was assumed to be oriented initially at a position, $\phi$, of $\pi / 2$ radians $\left(90^{\circ}\right)$. Values of $\phi$ versus time, $t$, were plotted by the computer system and are presented in Figure 15. From this plot, it is obvious that the effect of skin friction alone is not sufficient to adequately damp fluid oscillations during the sixth burn since the length of the burn period is only 34 seconds. However, these results are conservative since the model assumes the propellant moves as a solid mass and, therefore, does not include internal propellant friction which would also tend to damp the motion.

To evaluate the slosh-damping effect of the propellant acquisition device, the analytical model was modified to include the drag effect of a propellant retaining ring in the bottom of the propellant tank. The ring was $2.54-\mathrm{cm}(1.0-i n)$ square in cross-section. The slosh-damping effect of the propellant acquisition device is shown by comparing the result obtained with the device (Figure 16) with that obtained without the device (Figure 15). It is seen that inclusion of the propellant retaining ring can significantly influence propellant motion, i.e., reduce slosh baffling requirements.

5. Center-of-Mass Control

Propellant distribution in a toroidal tank spinning at rates considered here is inherently uniform and predictable because of the centrifugal forces present and the symmetry of the tank. This uniform distribution was demonstrated by the previously discussed analysis of liquid-gas interface shape and orientation. Spacecraft control can be simplified and its stability 


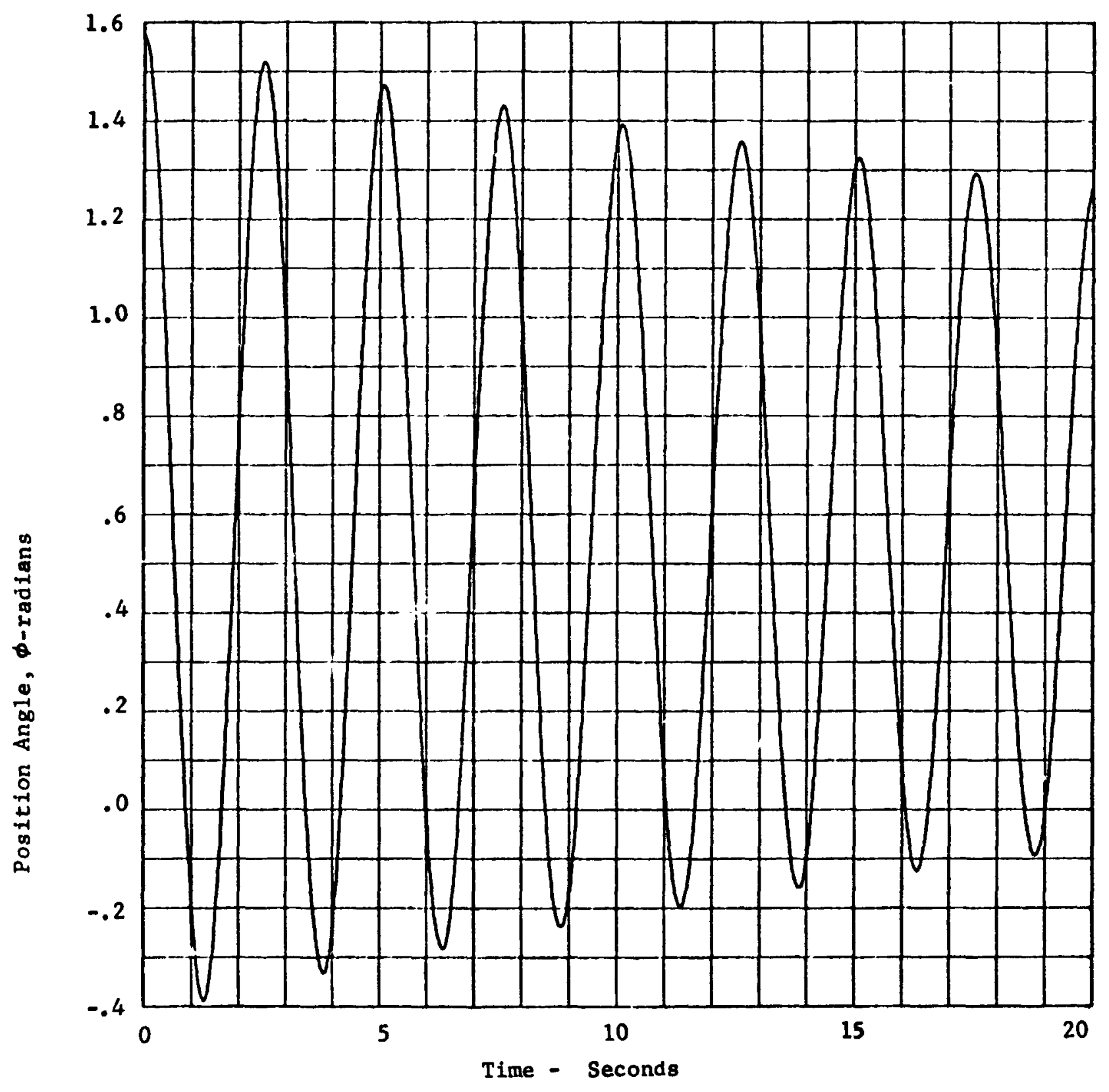

Figure 15 Propellant Displacement During Sixth Burn Period as Predicted by the Slosh Model No Baffling 


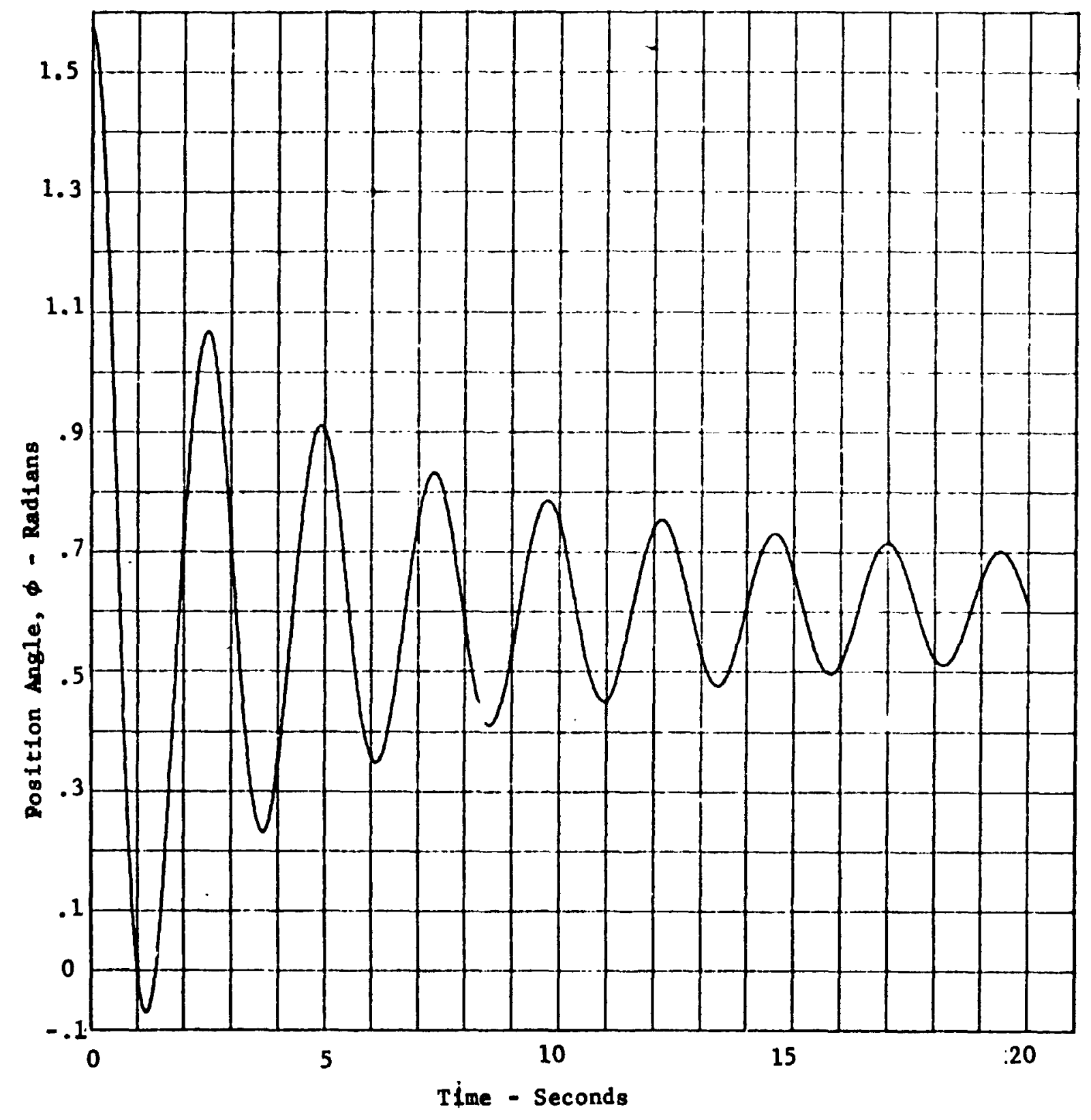

Figure 16 Effect of Propellant Retaining Ring on Propellant Displacement - Sixth Burn Period 
maintained if uniform propellant distribution can be provided. A propellant acquisition system, which retains some propellant mass, should be designed to distribute the retained propellant symmetrically about the tank spin axis. Configurations 1, 2, and 4 of the candidate concepts are symmetrical in design and, therefore, tend to promote uniform propellant distribution.

Another factor influencing propellant distribution is the effect of spin-rate changes. Propellant perturbations similar to the slosh behavior discussed in the previous section can occur during spin-rate changes. To minimize the effect of these perturbations, radial baffles could be installed across the torus section. These baffles would maintain uniform propellant distribution during increases or decreases in spin rate. Baffle requirements are reduced by the action of the feeder-arm channels included in the design of configurations 2 and 3 . The feeder arms transmit tank spin-rate changes to the propellant mass in the same manner as a baffle. Since the feeder arms are symmetrically placed in the toroidal tank, they would also tend to maintain uniform propellant distribution.

D. SYSTEM SELECTION AND DESIGN

Selection of the preferred propellant acquisition system for the toroldal tank was actually performed in two steps. First, the four candidate concepts were evalsated and compared on the basis of information obtained from the fluid behavior analysis. The candidate concept selected from this evaluation was then further analyzed and modifled to Improve toroldal tank system operation.

\section{System Selection Considerations}

The candidate concept selected was configuration 2 of Figure 5. This configuration provides a high expulsion efficiency without significantly influencing the toroidal tank configuration. Higher expulsion efficiency could possibly be provided by configiration 4. However, this configuration would require an extensively modified, non-circular cross-section tank which would be heavier and more difficult and expensive to fabricate. 
In regard to slosh control, the propellant retaining flow-channel rings included in both configurat ins 2 and 3 provide a significant damping effect on the propellant motion. This effect can be used to minimize the tank baffling required to reduce slosh. In a similar manner, the feeder-arms of these two configurations act as baffles to minimize the effect of spinrate changes on propellant distribution. However, configuration 2 is preferred because it is completely symmetrical. The propellant sump of configuration 3 inherently produces some unsymmetrical propellant distribution which would slightly afiect the spacecraft attitude control requirements. Propellant slosh or distribution would not. be a problem in configuration 4 , since the propellant would generally be located at the apex of the triangular part of the cross-section. At most, a few simple baffles would he required.

A relative weight estimate was made for the acquisition systems in configurations 1,2 and 3 . It was assumed that the devices were constructed of 300-series stainless steel screen and perforated plate. The resulting weights were:

$$
\begin{array}{ll}
\text { Configuration } 1 & 2.61 \mathrm{~b}_{\mathrm{m}} \\
\text { Configuration 2 } & 1.01 \mathrm{~b}_{\mathrm{m}} \\
\text { Configuration } 3 & 2.11 \mathrm{~b}_{\mathrm{m}}
\end{array}
$$

These weight differences are not great and are, in general, attributable to the amount of fine-mesh screen used in the concept. Configuration 1 , the liner concept, uses the largest quantity of screen. Configurations 2 and 3 both utilize propellant retainer rings and communication channels. The crosssection assumed in configuration 2 was semi-circular as opposed to square in configuration 3 . Therefore, the screen surface area in configuration 2 is less, making this the lightest system. The conical sump added to the weight of configuration 3 . Because of the extensive tank modifications for configuration 4, this system would be much heavier.

In summary, configuration 2 was selected as the preferred propellant acquisition sys'em because of the following factors: 
1) Good expulsion efficiency;

2) Unifurm propellant distribution during all mission phases;

3) Good slosh damping;

4) Low mass; and

5) No nted to modify tank geometry.

\section{Selected System Design}

Following its selection, the configuratinn 2 colcert was reviewed to determine whether any modifications to meet operational requirements or to ease fabrication protlems were desirable and feasible. As a result, the tank outlet was relocated to the bottom of the tank from the previou= 0.524 -radian (30-degree) displacement. This change simplified prcpellant draining on the launch pad in the event of an aborted launch. With the outlet displared 0.524 radians, a small quantity of oropellant. approximately 5.7 liters $\left(0.2 \mathrm{ft}^{3}\right)$, could not be drained fron the tank. Relocation of the oullet allcws complece tank draining on the launch pad. An increase in feederarm length of approximately $7.0^{\circ} \mathrm{cm}(3.0$ in.) was required. This increase in length did not increase the propellant static pr:- sure which must be supported sufficient to overconie the bubble point of the screen material in either propellant, i.e., causo premature gas ingestion into the propellant acquisition system in either tank.

A second design modification resulting from the ret iew was a change in cross-sectional shape of the relainer ring and communication channels. The uriginal con. figuration used a semi-circuiar cross-section. This would reauire forming screan surfaces of conpor at curvature which are more difficult to fabricate. For this reason, an alternate approach using ring and communication channels of square cross-section wis selected. With this configuration, only singlecurvature screen surfaces, which are easy to form, are required.

The final design of the selected propellant acquisition system consisted of four communicatiun chsanels, spaced $\pi / 2$ radians (90 degret?) apart, feeriing a propellant- 
retaining ring in the bottom of the tank which supplies propellant to a single outlet. Figure 17 iilustrates the concept as it would be installed in the toroidal tank. The cross-section for both the ring and tha communication channels is $2.54-\mathrm{cm}(1.0-\mathrm{in}$.) square, which provicies an expulsion efficiency of $99 \%$. The ring and channels are fabricated from $325 \times 2300$ mesh, Dutch-twill weave stainless steel screen supported by per orated stainless steel plate, having a 50 percent open area. The design is applicable to both the oxidizer and the fuel tank, since the tanks are identical and othe: considerations such as flow losses, slosh, and propellant properties do not indicate the need for different oxidizer and fuel designs.

A pressure-drop analysis was performed on the selected system to verify system stability. If the difference between the ullage gas pressure and the liquid fressure inside the retaining ring at the tank outlet, $P_{G}-P_{L}$, was less than the screen bubble point, $\Delta P_{c}$, the system would be stable. In order to be conservative in the calculation of the pressure difference, the following worst case assumptions were made:

1) Maximum propellant flow was established before $\Delta v$ engine thrust started;

2) All of the propellant flow was supplied through the communication channel farthest from the outlet;

3) Spacecraft spin rate was $10 \mathrm{rpm}$;

4) Propellant conditions were those at the start of the sixth burn.

The calculated pressure differencer for both the oxidizer and fuel systems are tabulate together with the screen bubble points. An operating margin, defined as the ratio of the bubble point, $\Delta P_{C}$, to the pressure difference, $P_{G}-P_{L}$, is included.

$\begin{array}{cll} & \text { Oxidizer } & \text { Fuel } \\ \begin{array}{c}\text { Pressure difference, } \\ P_{G}-P_{\bar{L}}, \mathrm{n} / \mathrm{cm}^{2}(\mathrm{psi})\end{array} & 0.317(0.46) & 0.626(0.91) \\ \begin{array}{c}\text { Bubble point, } \Delta \mathrm{P}_{\mathrm{C}}, \\ \mathrm{n} ; \mathrm{cm}^{2} \text { (psi) }\end{array} & 0.757(1.1) & 0.964(1.4)\end{array}$



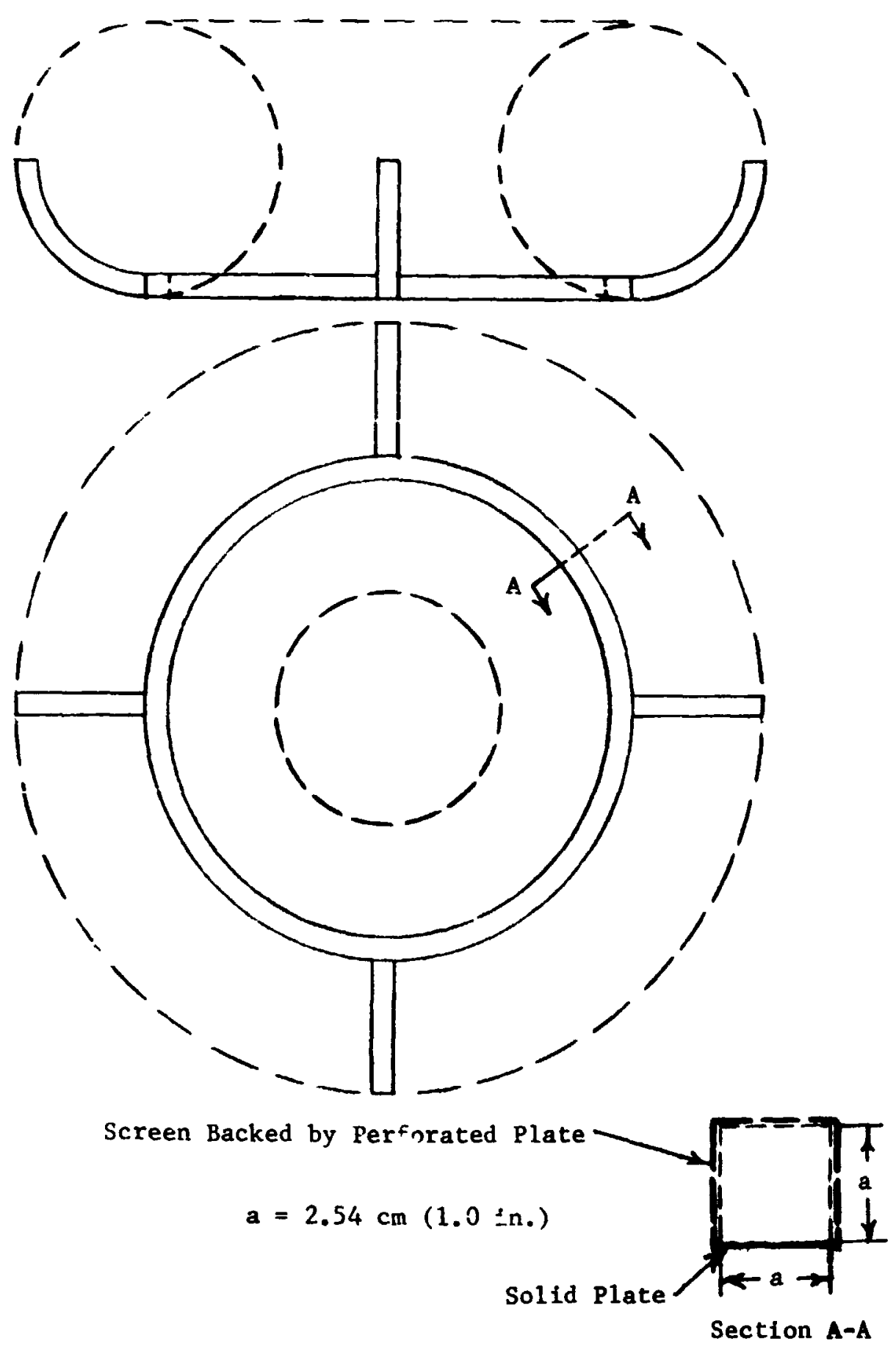

Figure 17 Selected Propellant Acquisition System for Use in a Spinning Toroldal Propellant Tank 
Uperating margin, $\frac{\Delta P_{c}}{\left(P_{G}-P_{L}\right)} \frac{\text { Oxidizer }}{2.39} \quad \frac{\text { Fuel }}{1.54}$

These results indicate a reasunabie opelating margin in each case and, therefore, the system will be stable and will provide gas-free propellant to the engine on demand.

One other aspect of system stability to consider is the maximum spin rate that the propellant-retaining ring and communication channels can tolerate and still retain propellant. If the spacecraft should overspeed during the spin-up phase prior to a $\Delta V$ engine ignition, static pressures within the ring and communication channels in excess of the bubble point could be developed from the resulting high centrifugal accelerations. If the bubble point should be exceeded, the ring and communication channels would lose propellant and, at the same time ingest pressurant gas to subsequently degrade oporation of the $\Delta V$ -ngine. An estimate was made of the spacecraft spin rate required to produce static pressures across the screen sufficient to exceed the bubble point of the screen and cause gas ingestion into the channel. The length of the channel determines the maximum height of propellant the screen must support during si.inning. This height in combination with the measured screen bubble point determines the spin rate required to produce gas ingestion. Calculations were made for both the oxidizer and fuel tanks for the selected system geometry in Figure 17. An oxidizer tank spin rate of $76 \mathrm{rpm}$ and a fuel tank spin rate of $110 \mathrm{rpm}$ would be required to produce liquid loss from the acquisition system during spacecraft operation. Since the noninal spin rate established as design criterla was $10 \mathrm{rpm}$, there is a significant safety factor in the selected system design to allow for accidental overspin. The system is non-operational d:ring boost and is immersed in propellant during that time. However, even if the device were to be exposed to ullage gas during the TE364-4 60-rpm spin rate, it would still retain propellant in a stable fashion with some margin of safety. The selected system is essentially insensitive to the effects of varying spacecraft spin rates and can supply gas-free propellant to the engine, as required throughout the mission. 
IV

Fabrication of a toroidal tank using the lected surface tension propellant acquisition system was evaluated in this part of the program. To support the evaluation, various tank manufacturers were contacted in regard to fabrication methods, problems, and costs. The results of these contacts together with tank weights and budgetary cost estimates for tank fabrication are presented in subsequent sections. A comparison is made between the two-toroidal-tank system and a four-sphericaltank system.

A. PREVIOUS EXPERIENCE

As nart of the task, a literature search was conducted to detemine previous industrial experience in the fabrication of toroidal tanks. A report prepared by the Illinois Institute of Technology Research Institute under Contract NAS7-388 (Ref 28) summarizes tank development programs in the aerospace industry over a period of years. This report identifies four toroidaltank programs, two of which contain information applicable to this study. One of these two programs concerned the fabrication of a titanium toroidal tank by Fansteel, Incorporated, for the Hibex system. Although information regarding the Hibex tank was not published in the report, Fansteel was contacted and pertinent information regarding fabrication of the tank was obtained. The other program was conducted by the Baltimore Division of Martin Marietta Corporation for the Langley Research Center under Contract NASw-913 (Ref 29). During this program, a toroidal tank was fabricated from 2219 aluminum by explosive forming. In addition, the Titan III solid rocket motor thrust vector control system utilizes a toroidal-shaped manifold for injection of nitrogen tetroxide into the solid motor nozzle. The torus is fabricated by welding two 6061-T6 aluminum forgings (Ref 30). The major radius of this torus is approximately $108 \mathrm{~cm}(42.5$ in.) and its minor radius is $10.2 \mathrm{~cm}(4.0 \mathrm{in.})$. System operating pressure is $757 \mathrm{n} / \mathrm{cm}^{2}$ (1100 psia) resulting in wall thicknesses on the order of $1.27 \mathrm{~cm}(0.5 \mathrm{in}$.).

B. CANDIDATE MATERIAL SELECTION

Prior to contacting tank manufacturers regarding fabrication methods and costs, three candidate tank structural materials were selected on the basis of thei availability, propellant compatibility, and fabr: cability. These materials were 2219 aluminum, 6i, aluminum, and $6 \mathrm{Al}-4 \mathrm{~V}$ titanium, which are generaliy non-magnetic and are, therefore, satisfactory for the 
proposed Jupiter-orbiter mission. In addition, these materials have sufficiently high annealing temperatures to allow sterilization, if required. The maximum sterilization temperature presently used on Viking is $125^{\circ} \mathrm{C}\left(257^{\circ} \mathrm{F}\right)$. The annealing temperature for the alumirum alloys is the lowest of the candidate materials being between 370 and $425^{\circ} \mathrm{C}$ ( 700 and $800^{\circ} \mathrm{F}$ ). For comparison purposes, $304 \mathrm{~L}$ stainless steel was also included in the tank fabrication analysis.

Discussions were held with Martin Marietta personnel in both the Advanced Structures Department and the Mechanical Design Department in order to define minirim handling gages for the candidate materials. The following thicknesses were suggested as minimum handling gages for the candidate materials:

$\begin{array}{ll}304 \mathrm{~L} \text { stainless steel } & 0.051 \mathrm{~cm}(0.020 \mathrm{in} .) \\ 2219 \text { and } 6061 \text { aluminum } & 0.064 \mathrm{~cm}(0.025 \mathrm{in} .) \\ 6 \mathrm{~A} 1-4 \mathrm{~V} \text { titanium } & 0.038 \mathrm{~cm}(0.015 \mathrm{in} .)\end{array}$

C. TANK WEIGHT COMPARISON

A tank weight comparison was made between toroidal and spherical tanks for each of the four materials. Tank weights were obtained, assuming that membrane stress theory was applicable for calculating the required wall thickness. For a toroidal tank, the meridional stress rather than hoop stress determines required wall thicknesses ( $\operatorname{Ref} 31$ ). The meridional stress is given by the following equation:

$S=\frac{P b}{2 t}\left(\frac{r+a}{r}\right)$

where $S$ is the meridional stress, $P$ is the internal pressure, and $t$ is the wall thickness. The dimensions $a, b$, and $r$ are defined in Figure 18. A toroidal shell possesses a unique characteristic in that, for a constant wall thickness, the working stress in the shell varies from a maximum at the innermost points to a minimum at the outermost points. The nnint of maximum stress is designated " 0 " in Figure 18. It is this point that determines the minimum wall thickness allowable in a torus of constant wall thickness. An alternate approach to designing the torus wall is to assume a constant working stress in the wall. Then the required wall thickness can vary from a maximum at the innermost points to a 


\section{$\cdot$}

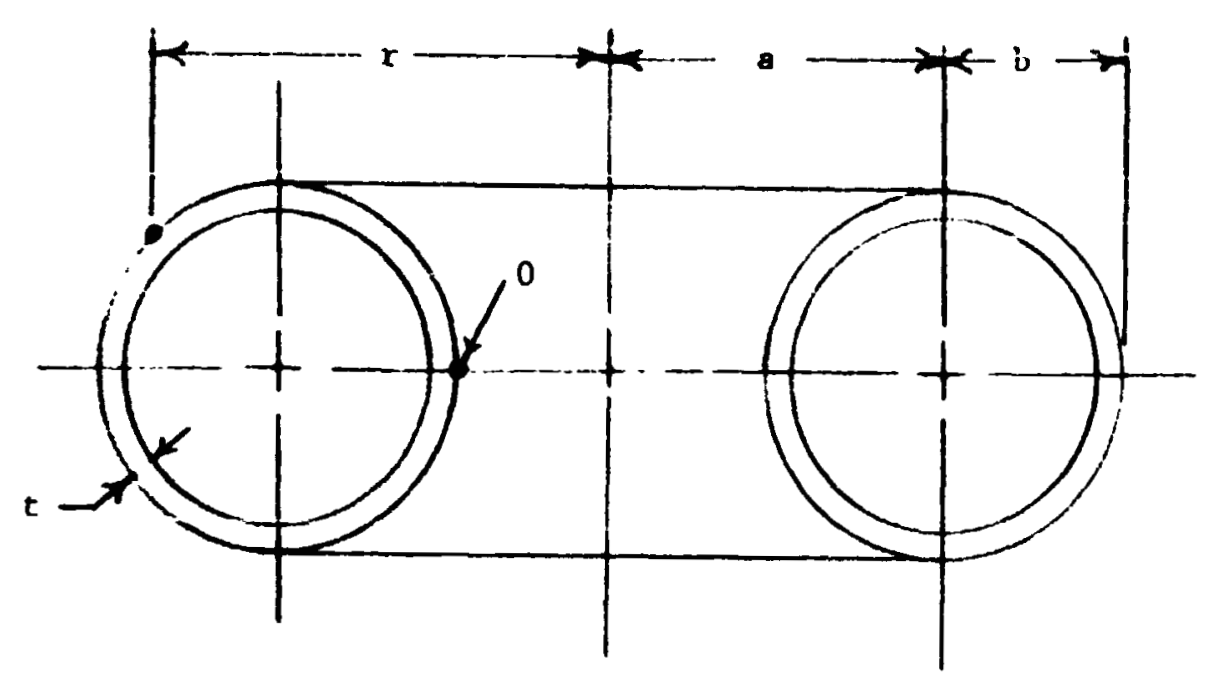

Figure 18 Toroidal Dimensions for Stress Calculations 
minimum at the outermost points of the torus. The variation in wall thickness results in a lighter tank for the same pressure and volume requirements.

In the weight comparison, calculations were made for toroidal shell weights for both cases of consta: : wall and varying wall thicknesses. For each material, the minimum wall thickness calculated from equation (13) was found to be larger than the minimum gage requirements discussed previously. Calculations of spherical shell weights were based on the hoop stress formula. The required wall thicknesses for the spherical shells were also greater than the minimum gage for each material.

Working stress for each material was obtained from the smaller of the ultimate strength or the yield strength of the material at room temperature divided by an applicable safety factor. The safety factors used were 2.0 on ultimate strength and 1.5 on yield strength in accordance with derospace tank design practices (Ref 32 and 33). Th $=$ working stress for the stainless steel was obtained :- om the yield stress while those for the aluminum and ticiulium alloys were based on the ultimate strength. The resulting working stresses used in the analysis are tabulated below:

Material

304L stainless steel

2219 aluminum

6061 aluminum

$6 \mathrm{Al}-4 \mathrm{~V}$ titanium

Heat Treat Condi
$\begin{aligned} & \text { Cold worked } \\ & \mathrm{T}-87 \\ & \mathrm{~T}-6 \\ & \text { Anneal ed }\end{aligned}$

Working Stress $\mathrm{n} / \mathrm{cm}^{2}$ (psi)

$34,400(50,000)$

$23,700(34,500)$

$15,500(22,500)$

$47,500(69,000)$

In addition to shell weights, caiculations for tank closure welds and $0.64-\mathrm{cm}(0.25-\mathrm{in}$. $)$ diameter inlet and outlet bosses were made. For the spherical tanks, the weight of a $15.24-\mathrm{cm}\left(6.0-\right.$ in. $\left._{\text {. }}\right)$ diameter outlet flange, similar to that used on the Mariner Mars 71 tank (Ref 34 ), was included in the weight tabulation. Material strength in the vicinity of the welds and bosses was assumed to be the annealed value.

The calculated weights are summarized in Table 8 , which shows the effect of material on tank system weight and also compares the weight of two toroidal tanks with the weight of four spherical tanks of equivalent volume. The comparison clearly indicates the advantage of 


\begin{tabular}{|c|c|c|c|c|c|}
\hline \multirow{3}{*}{ 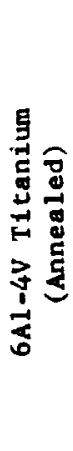 } & 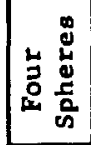 & 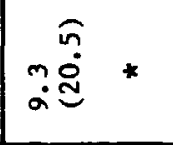 & & 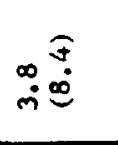 & 会 \\
\hline & 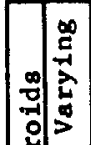 & 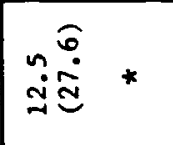 & & + & 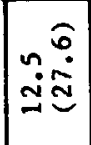 \\
\hline & \begin{tabular}{|c|c|c|c|}
0 \\
0 \\
0 \\
0
\end{tabular} & 吾 & & + & 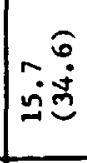 \\
\hline \multirow{3}{*}{ 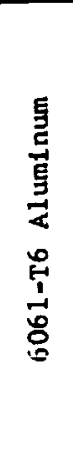 } & 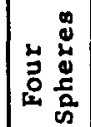 & 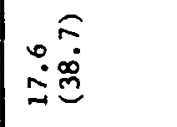 & $\stackrel{m}{-\infty} \stackrel{\infty}{i}$ & î̃ & 每 \\
\hline & 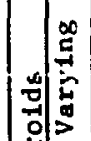 & 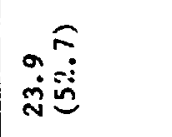 & †ै & $\stackrel{\infty}{0} \stackrel{0}{0}$ & 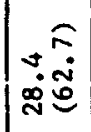 \\
\hline & (ํ) & 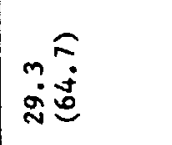 & نे & $\stackrel{\infty}{\circ} \stackrel{0}{0}$ & 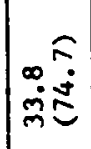 \\
\hline \multirow{3}{*}{ 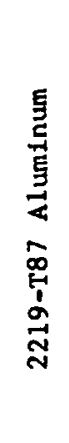 } & 蒫 & 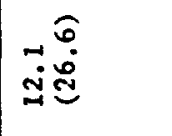 & $\stackrel{\circ}{i \stackrel{+}{i}}$ & רُ & 齐 \\
\hline & 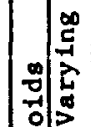 & 莤 & 可话 & : & 包 \\
\hline & | & 全 & 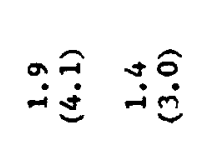 & ำ & 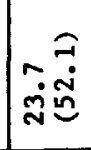 \\
\hline \multirow{3}{*}{ 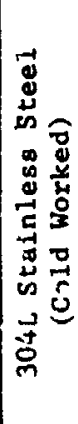 } & 焉 & 离昰 & $\stackrel{n}{\text { กิ }}$ & : & |ch \\
\hline & 揭 & 它 & 워 & 웡 & 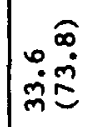 \\
\hline & |r & 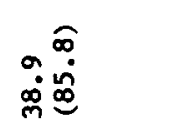 & 突 & 舟: & 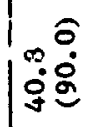 \\
\hline 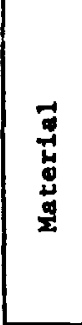 & 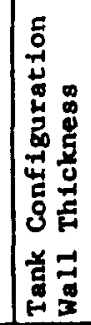 & 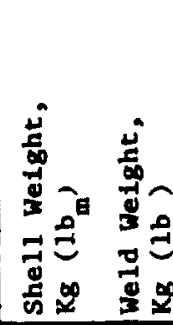 & 岌 & 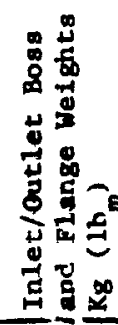 & 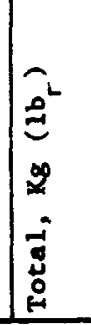 \\
\hline
\end{tabular}

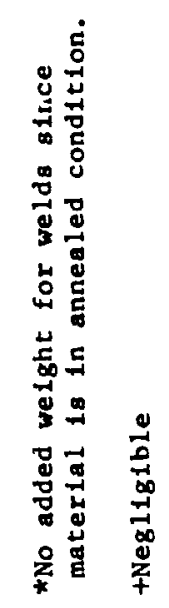

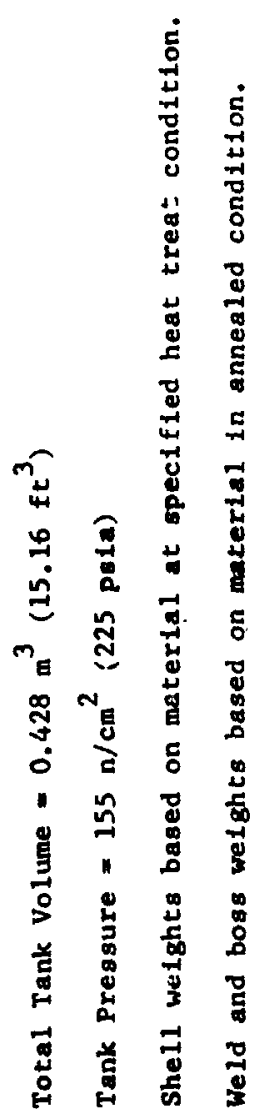

苜 
fabricating tanks from titanium. As expected, stainless steel results in the heaviest system with the stainless steel toroidal tank being 2.6 times heavier than the titanium torus; the stainless steel spherical tanks are 2.3 times heavier than equivalent titanium tanks. The lighter aluminum toroidal tank is 1.5 times heavier than that made of titanium.

Comparison of the weight of the two toroidal tanks with that of four spheres indicates that the spherical system is lightest for steel and aluminum materials. However, for the titanium material, the constant-wall toroidal tanks are slightly heavier while the varying wall toroidal tanks are slightly lower weight than the fourspherical-tank system. Comparison of the aluminum toroidal tank weights for constant-versus varying-wallthickness designs indicates a 16 -percent reduction if a varying wall thickness is used. Therefore, the weight differential between the toroidal and spherical tanks can be reduced approximately 50 percent if the torus can be fabricated with a varying wall thickness.

\section{TANK FABRICATION}

Toroidal tank fabrication considerations included torus assembly methods, manufacturing processes required, material selection, and fabrication costs. These factors were evaluated during Task 3 of the program and are Jiscussed in the following paragraphs.

\section{Torus Assemb1y Methods}

Three methods were proposed by which a toroidal tank could be assembled (Ref 35 ). These methods use symmetrical halves, unsymmetrical halves, or bent tubing, as shown in Figure 19. In assembling the torus from symmetrical halves, two identical parts are weldnd together at the mid-plane normal to the toroidal axis (Figure 19a). An inner and outer weld joint arte required. The method using unsymmetrical halves (Figure 19b) has a center spool-section encompassed by a ring of semi-circular cross-section. Circular closure welds are required at the top and bottom of the torus. The third assembly technique would use bent tube sections, as indicated in Figure 19c. Although four sections are shown, more sections could be used if desired. These sections would be joined by girth welds around the torus. From the standpoint of installing the propellant acquisition device into the tank, the method using 


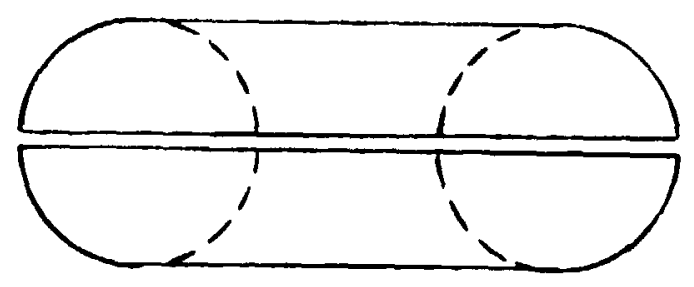

(a) Symmetrical Halves

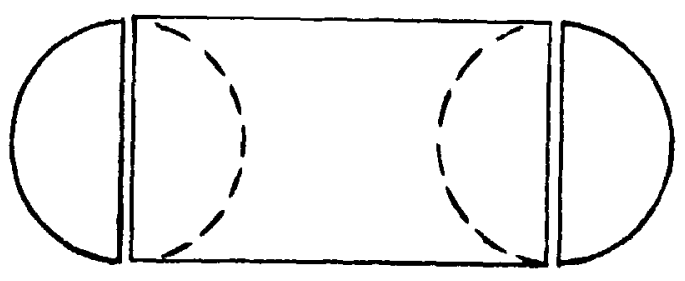

(b) Unsymmetrical Halves

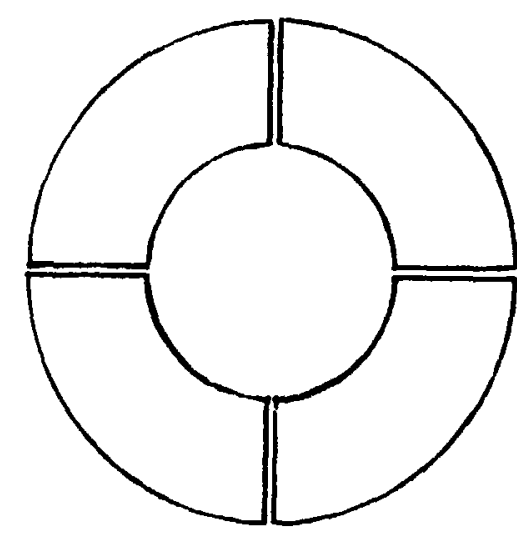

(c) Bent Tubing

Figure 19 Torus Assembly Methods 
symmetrical halves would be preferable. The acquisition device could be installed in the lower half of the torus just prior to the final closure tank weld. Furthermore, symmetrical halves could be produced on similar if not identical tooling which would also tend to reduce manufacturing costs. However, this method involves welding at the points of maximum stress (Figure 18). With the other two methods, installation of the acquisition device would not be possible as a fixed or single unit. Joints and connections would be required in the acquisition device which would greatly compound the difficulty of fabrication. For these reasons, the assembly method employing symmetrical halves was selected.

\section{Manufacturing Processes}

In order to define the problems associated with manufacturing a toroidal tank, contact was made with the following companies:

Pressure Systems, Incorporated

Los Angeles, California

Fansteel Precision Sheet Metal

Los Angeles, California

Beech Aircraft Corporation

Boulder, Colorado

Explosive Fabricator Industries

Louisville, Colorado

Discussions were conducted regarding fabrication techniques, candidate materials, tank mass, and budgetary cost information.

Three possible methods of forming the torus halves, identified through these contacts, were spinning, forging, and explosive forming. Recommendations for forming of aluminum alloy tanks were generally a combination of hydroforming and spinning ( $\operatorname{Ref} 36$ and 37 ). Spinning was definitely not recommended for titanium; the low ductility of this material makes it extremely difficult to work. Fabrication of titanium tanks can best be accomplished by forging. However, after forging, machining and aging processes are also required which increases the manufacturing costs (Ref 38 ). 
The possibility of explosive forming of the toroidal tank was also investigated ( $\operatorname{Ref} 39$ ). Forming of titanium by explosive forming is not recommended. The aluminum alloys and the stainless steel could be formed by this process with the stainless steel being the preferred material. In explosive forming, the material is initially in the annealed condition. After forming, some work hardening is accomplished. The resulting increase in strength is apparently not well known. This uncertainty would require additional safety factors in determining wall thickness which, in turn, would tend to increase the tank weight. For $t$ 's reason, explosive forming was not given further consideration.

Another aspect considered was the possibility of tapering the torus wall. The effect of this tapering process on tank weight was discussed previously. Methods of tapering the wall include chemical milling, machining with profile-controlled tooling, or using speciallyshaped dies in the original forging process. Chemical milling was not considered practical for this application; profile-controlled machining is feasible aithough it would increase the cost of the tank ( $\operatorname{Ref} 38$ ). Forging with special dies would be expensive for a small number of tanks.

3. Budgetary Cost Estimates

Estimates of the costs invulved in fabricating toroidal tanks from 6061 aluminum, 2219 aluminum, and $6 \mathrm{~A} 1-4 \mathrm{~V}$ titanium were made for comparison purposes. Stainless steel was not considered in this comparison since it would not be used in a flight system because of the higher mass. The estimates were made based on information obtalned from References 36 and 38 , assuming production of two toroidal tanks of constant wall thickness. The cost comparison is presented in Table 9, which clearly indicates a significant cost iifference between aluminum and titanium tanks. This difference is mainly due to the incieased difficulty in working with titanium. The difference between the cost of the two aluminum alloys, although not very large, is due to the easier workability of the 6061 alloy. However, the increased cost may be justified by the difference in tank weight since the 2219 alloy tank system is approximately 30 percent 11ghter than the 6061 alloy tank system.

A comparison of the cost of fabricating spherical tanks versus that for toroidal tanks was also made. Cost of a 


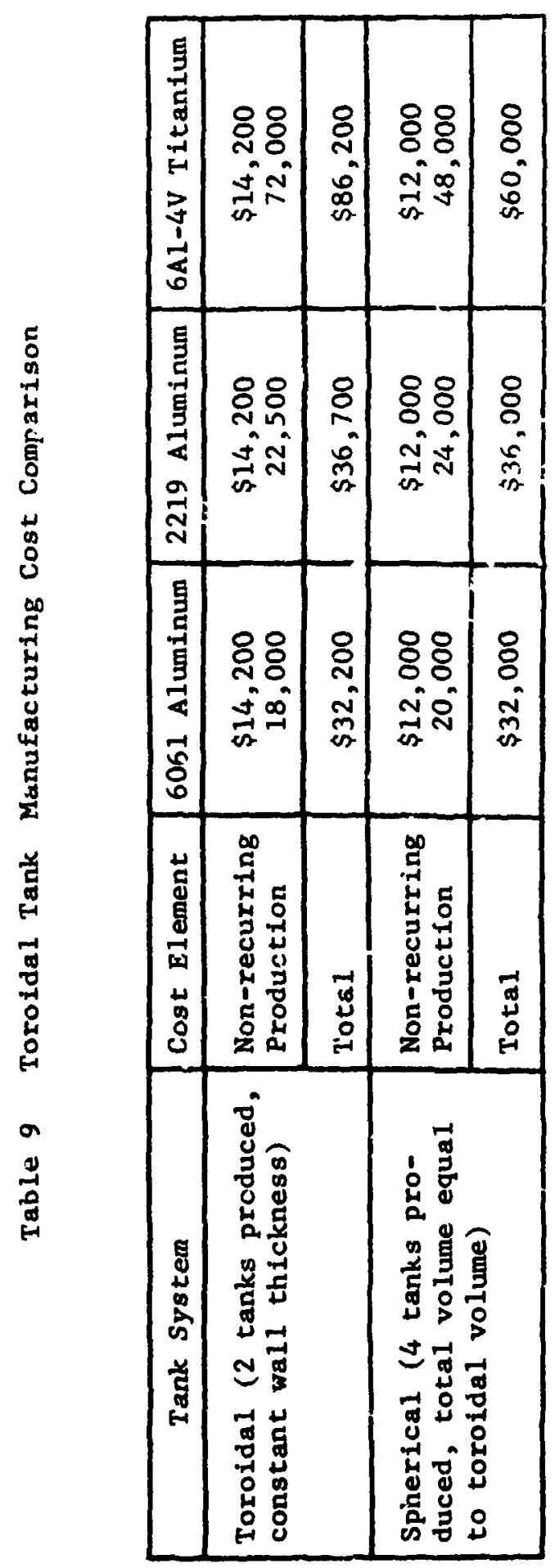


four-spherical-tank system was compared with that of a two-toroidal system having the same total volume. Fabrication costs for the aluminuin materials are about the same for the two systems. Huwever, fabrication cost of titanium for the spherical-tank system is approximately $30 \%$ less than that for the toroidal-tank system, as indicated in Table 9.

Another cost factor considered, but not included in Table 9, was the production of a variable wall thickness torus. An additional production cost of $\$ 2,000$ per aluminum tank and $\$ 4,000$ per tit'nium tank would be required +o machine the tank wali tr the desired contour and additional tooling costs ould also be incurred (Ref 38 ;.

E. TANK SYSTEM DESI TN

Installation of the selected propellant acquisition device in the toroidel tank is shown in Figure 20. The $t$ In: can be fabricated from either aluminum or titanium. be:-use of the iifference in weight, 2219 aluminum is preferred over the 6061 alloy. The propellant acquisition civice would be fabricated from $325 \times 2300$ Lutch-twill screen supported by perforated plate. Both the screnn and the perforated plate would be $3 n$ sti ies stainless steel. The screen-to-plate construction concept proposed for the propellant acquisition device has been developed and verified by Martin Marsetta during both contractual and in-house research and deveiopment programs ( $\operatorname{Ref} 2,4,9,12,14,20,21,43$ ). Joining of scr.en to plate has been azcomplished and tested. Complete acquisition devices háve been fabricated from screen and plate construction under research and development tasks (Ref $20,21,40$; and contractual programs (Kef $2,9,12,14$ ).

Resistance sean welding is preferred for screen joining. This process produces a relatively narrow weld of high integrity that is easily cleaned. A detailed discussion of joining and cleaning procedures is resented ir Reference 9. No problems are evident with regard to cleaning screen devices. More than adequate experience has been acquired with the propellants Procedures have been developed and demonstrate: for cleaning fine-mesh Dutch-twill screen devices for use with liquid fluorine (Ref 41). Fluorine presei.ts the most stringent, cleaning requirements of any fluid. Results of tne Martin Marietta-sponsored program showed that welded screen systems could be cleaned for fluorine use; specimens exposed to liquid fluorine for up to 35 days were not 
FOLDOUT FRAME

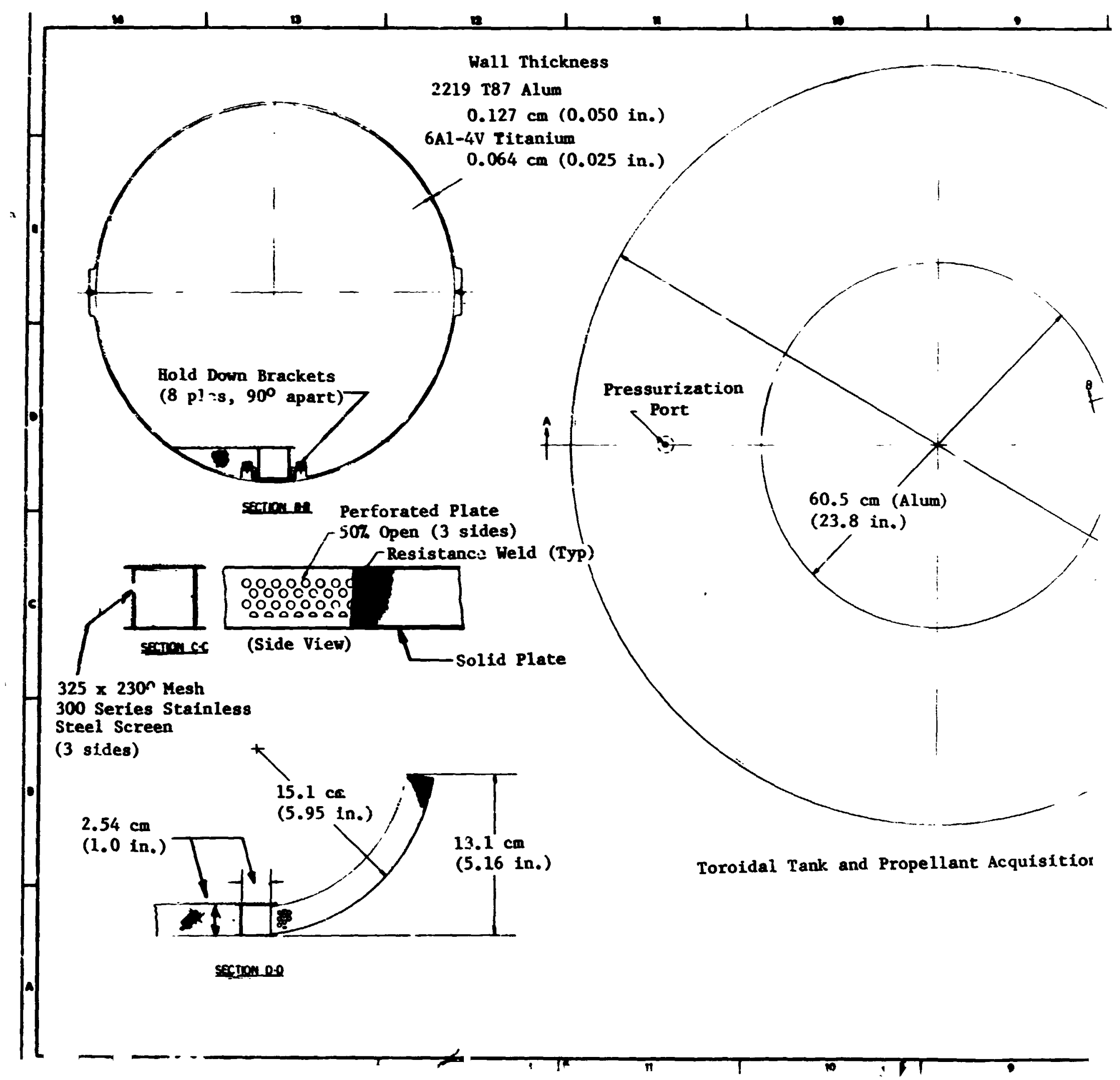




\section{-OLDOUT FRAME}

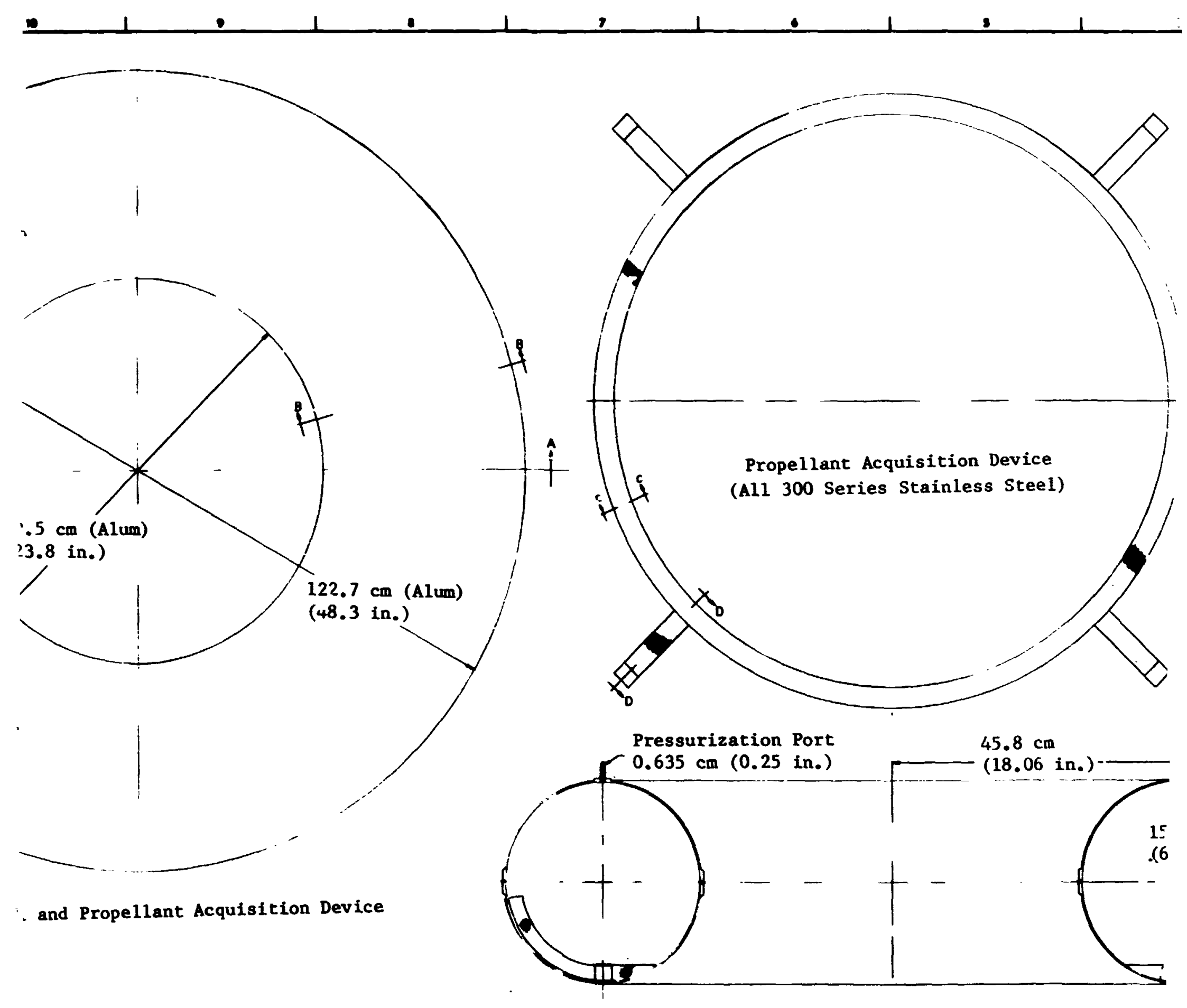

setron A.A 
FOLDOUT FRAME 3

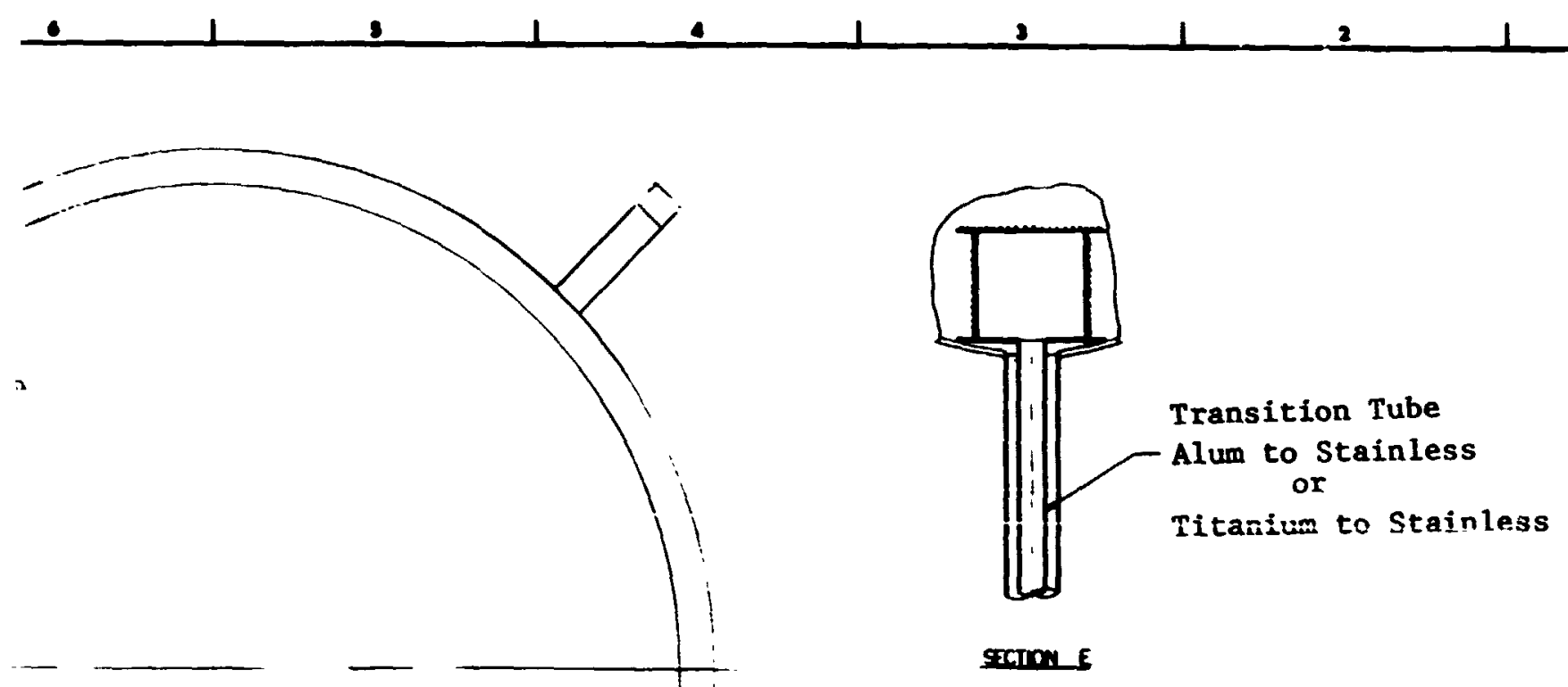

spellant Acquisition Device

300 Series Stainless Steel)

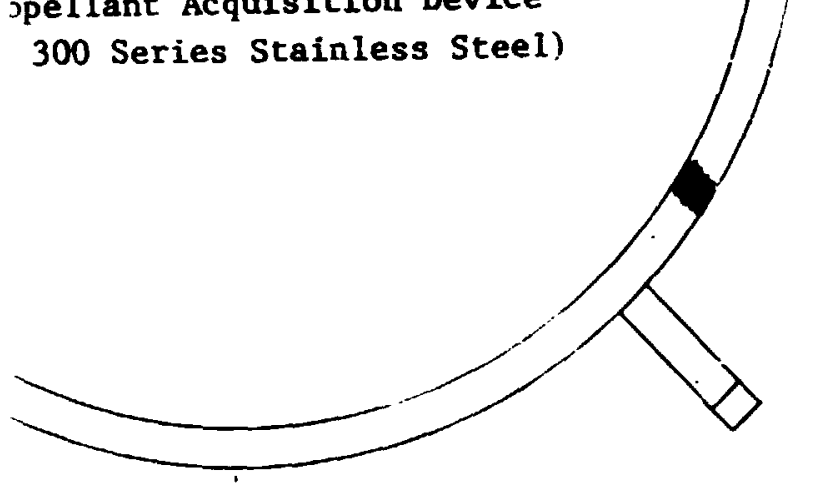

Port

.5 in.)

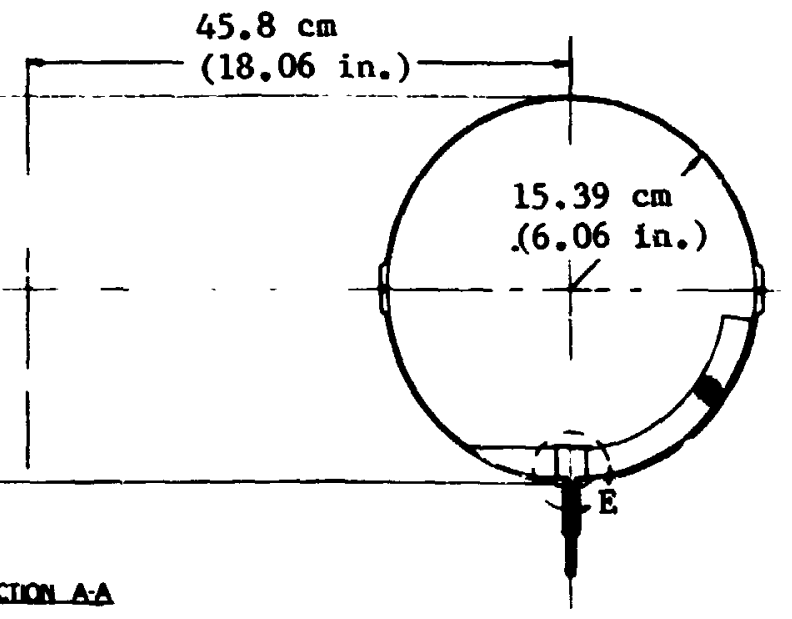

Figure 20

Propellant Acquisition System Design, Toroidal Tank System 
damaged and their capillary-retention capability was not reduced.

In the system design, attachment of the propeliant acquisition device to the tank wall is accomplished by mechanical means. This technique was chcsen in place of welding to eliminate the problems associated vith dissimilar metal welding. The communication channels extend along the tank wall from the retaining ring to a position $2.54-\mathrm{cm}(1.0-$ in.) below the split-line of the tank. This shortening of the communication channel precludes any heat damage to the acquisition device during final closure welding with no decrease in propellant acquisition capability.

A tank system weight tabulazion was prepared to compare a to-toroidal-tank system empluying surface tension propellant acquisition with a four-spherical-tank system using bladders. The comparison was made with the spherical tank system since it was the comparable system selected in Reference 16. Propellant tank weights are those presented in Section $C$ of this chapter. Mass of the surface tension propellant acquisition system was calculated assi.uing $0.051-\mathrm{cm}$ (0.020-in.) thick stainless steel perforated plate, having a 50-percent open area, and a fine-mesh screen weight (325 $\times 2300$ Dutch-twill) of $8.4 \times 10^{-5} \mathrm{Kg} / \mathrm{cm}^{2}$ $\left(1.2 \times 10^{-3} 1 \mathrm{~b}_{\mathrm{m}} / \mathrm{in}^{2}\right)$. The resul $\because$, mass per device was $1.23 \mathrm{Kg}\left(2.71 \mathrm{~b}_{\mathrm{m}}\right)$. An estim: $\mathrm{f}$ the polymeric bladder weight used in the spherı. tank was obtained from Reference 3 as $2.95 \mathrm{Kg}(6.51 \mathrm{~b}$; per unit. The system mass is tabulated in Table 10. Included in the table are torus system masses for both aluminum and titanium tank materials. Comparison of the titanium toroidal system with the four-sphere titanium system shows a significant $6.7-\mathrm{Kg}\left(15-1 \mathrm{~b}_{\mathrm{m}}\right)$ advantage for the toroidal system. This mass difference is primarily due to the lighter surface tension acquisition system. Even the aluminum. toroidal system compares favorably with the four-sphere titanium system; $26 \mathrm{Kg}\left(581 \mathrm{~b}_{\mathrm{m}}\right.$ ) compared with $25 \mathrm{Kg}\left(551 \mathrm{~b}_{\mathrm{m}}\right)$, respectively. The heavier aluminum toroidal-tank weight is offset by the low-mass surface tension propellant acquisition system. The spherical tank system mass presented in the table compares favorably with data given in Reference 16, whin lists a total tank system mass of $29.09 \mathrm{Kg}\left(64.01 \mathrm{~b}_{\mathrm{m}}\right)$. Tata from the Mariner Mars ' 71 
Table 10 Mass Comparison Between a Two-Toroida1-Tank System and a Four-Spherical-Tank System

\begin{tabular}{|c|c|c|c|c|}
\hline Tank System & \multicolumn{2}{|c|}{ Toroidal } & \multicolumn{2}{|c|}{ Spherical } \\
\hline $\begin{array}{c}\text { Type Acquisition } \\
\text { Device }\end{array}$ & $\begin{array}{l}\text { Surface } \\
\text { Tension }\end{array}$ & $\begin{array}{l}\text { Surface } \\
\text { Tension }\end{array}$ & Bladder & $\begin{array}{l}\text { Surface } \\
\text { Tension }\end{array}$ \\
\hline Number of Tanks & 2 & 2 & 4 & 4 \\
\hline Tank Material & $\begin{array}{l}\text { 2219-T6 } \\
\text { Aluminum }\end{array}$ & $\begin{array}{l}6 \mathrm{Al}-4 \mathrm{~V} \\
\text { Titanium }\end{array}$ & $\begin{array}{l}6 \mathrm{Al}-4 \mathrm{~V} \\
\text { Titanium }\end{array}$ & $\begin{array}{l}6 \mathrm{Al}-4 \mathrm{~V} \\
\text { Titanium }\end{array}$ \\
\hline $\begin{array}{l}\text { Mass, } \mathrm{Kg}\left(1 \mathrm{~b}_{\mathrm{m}}\right) \\
\text { Tank } \\
\text { Acquisition } \\
\text { Device }\end{array}$ & $\begin{array}{l}23.7(52.1) \\
2.45(5.4)\end{array}$ & $\begin{array}{l}15.7(34.6) \\
2.45(5.4)\end{array}$ & $\begin{array}{l}13.1(28.9) \\
11.82(26.0)\end{array}$ & $\begin{array}{l}13.1(28.9) \\
1.36(3.0)\end{array}$ \\
\hline $\begin{array}{l}\text { Total Mass } \\
\mathrm{Kg}\left(1 b_{m}\right)\end{array}$ & $26.15(57.5)$ & $18.15(40.0)$ & $24.92(54.9)$ & $14.46(31.9)$ \\
\hline
\end{tabular}


program (Ref 34) also support the system mass estimates presented here.

In evaluating tank system weights, the primary comparison was between $z$ two-toroidal-tank system using surface tension propellant acquisition devices and an equivalentvolume four-spherical-tank system using bladders for propellant expulsion. This comparison was extended to include a four-spherical-tank system using surface tension propellant acquisition devices. These weights are also presented in Table 10 . In preparing this estimate, the same spherical tank weights were assumed. The surface tension acruisition device consisted of a single feederarm channel in each spherical tank, similar tc those used in the toroidal tanks. The channel would be located on the tank wall farthest from the spacecraft spin axis and woild extend from the outlet in the tank bottom to just bciow the tank equator. The weight of the su=face tension devices would be only one-ninth of that for bladders. This results in a $10-\mathrm{Kg}\left(23-1 b_{m}\right)$ weight savings if surface tension devices are employed in place of bladders for the four-spherical-tank system. Comparing the toroidal-tank system $w_{-}$th the spherical-tank system on a completely equal basis (titanium tanks and surface tension acquisition devices with both systems), the spherical tank system provides a weight advantage of $3.7 \mathrm{Kg}\left(8.11 \mathrm{~b}_{\mathrm{m}}\right)$.

Quantitative mass and cost comparisons have been presented for torojdal and spherical tanks. It has been snown that the toroidal tanks can be fabricated by conventional manufacturing techniques and compare favorably with an equivalent spherical tank system. Additional quantitative and qualitative results supporting the attractiveness of toroidal tanks using surface tension devices for the spinning spacecraft application were also noted during the study:

1) Only two toroidal tanks, stacked vertically on the spin axis, are required, one for fuel and one for oxidizer. Four spherical tanks, spaced $\pi / 2$-radians (90-degrees) apart around, but offset from, the spin ax's are required for balancing. The two fuel tanks would be $\pi$-radians (180-degrees) apart, as would the two oxidizer tanks (Figure 2); 
2) Because of the axisymmetric packaging of the toroidal tanks, spacecraft balancing should be simplified and more reliable. Fewer demands should be placed on the spacecraft control system. Packaging, itself, appears easier and tank support should be simpler;

3) Coupled with a surface tension system, only one outlet is required to provide a high expulsion efficiency. With toroidal tanks, therefore, propellant outflow balancing, with attendant probability of increased residuals (premature dropout), is not required;

4) With toroidal tanks being symmetrical with the spin axis, propellant motion (slosh) resulting from $\Delta V$ engine firing is symmetrical, producing a uniform mass distribution. The surface tension system acts as a baffle to attenuate this slosh;

5) The toroidal tank system with the surface tension propellant acquisition device will be compatible with the long duration required by deep space missions. The reliability of the system is high because of both the passive operation of the surface tension device and the compatibility of the structural materials with the propellants over long periods of time. 
V.. . . _CONCLUSIONSS_AND_RECGMMENDATIIONS _. . . . . . . .

A. CONCLUSIONS

1) A propellant acquisition device is required to assure gas-free propellant expulsion from a spinning toroidal tank of circular cross-section.

2) A passive surface tension acquisition system is particularly attractive for this ling-1ife application.

3) The continuous acceleration environnent resulting from spacecraft spin precludes the use of low-g propellant acquisition devices of the type presently used in the Viking Orbiter propulsion system. A device employing fine-mesh-screen communication channels between the tank outlet and the propellant bulk is required. This fine-mesh screen system can be developed with present technology.

4) Multiple tank outlets are not required with the selected propellant acquisition concept. The low propellant flow rates for the $\Delta V$ engine result in system pressure losses much below the bubble-point Iimit for the acquisition system. This system provides high expulsion efficiency (low propellant residuals) while circumventing suction dip problems.

5) The propellant acquisition system design is the same for both $\mathrm{MMH}$ fuel and $\mathrm{N}_{2} \mathrm{O}_{4}$ oxidizer.

6) Fabrication of a toroidal tank from either titanium or aluminum alloys is faasible with present manufacturing technology. Tanks fabricated from 6A1-4V titanium result in the lowest tank-system mass. For the same titanium alloy, the two-toroidal-tank system including the surface tension device was $6.7 \mathrm{Kg}$ (15 $1 b_{m}$ ) lighter than an equal-volume four-sphericaltank system using bladders. If surface tension devices are used in these titanium tanks, the spherical tank system would be $3.7-\mathrm{Kg}\left(8.1-1 b_{m}\right)$ lighter than the toroidal tank system.

B. RECOMENDATIONS

A combined toroidal tank/surface tension propellant acquisition system is fcasible for use in spinstabilized spacecraft. Additional studies should be conducted to further evaluate operational requirements and manufacturing procedures. Specific areas to be investigated are: 
1) An evaluation of the stability and shape of the ullage bubble, particularly at small ullages, should be made for the spinning torus. Previous work has been limited to a zero gravity environment. This evaluation would include the effect of spin perturbations on bubble stability, propeilant distribution, and 1iquid-gas interface shape.

2) A more detailed study of propellant sloshing in a spinning toroidal tank should be conducted to define tank baffling requi-ements and geometry.

3) Means of supporting the toroidal tanks within the spacecraft structure should be identified. This evaluation should include an assessment of the impact on spacecraft mass and structural complexity, as well as the influence of the tank supports on tank manufacturing.

4) Propellant tank and acquisition device fabrication and integration procedures should be demonstrated by conducting a full-size tank system program. This demonstration would provide: tank/acquisition system design including tank support, pressurization inlet and propellant outlet details; fabrication, quality control, and acceptance test procedures; acquisition system inspection techniques; and a ground handling evaluation of propellant fill and drain, tank pressurization, and propellant outflow.

5) An experimental program comprised of drop tower and nne-g bench tests should be conducted to verify analytical results. Tests would be conducted to evaluate the effects of tnrust on slosh and propellant settling, ullage bubble orientation versus ullage volume, and the effects of spin and wobble on liquid-gas orientation. Plus and minus one-g outflow tests world also be performed. 
VII $-\ldots$ REFERENGES $\ldots \ldots-\ldots-\ldots-\ldots$

1. D. L. Balzer, et a1.: Advanced Propellant Management System for Spacecraft Propulsion Systems, Phase I Survey Study and Evaluation. MCR-69-87. Martin Marietta Corporation, Denver, Colorado, February 1969. (Contract NAS9-8939)

2. D. L. Balzer, et al.: Advanced Propellant Management System for Spacecraft Propulsion Systems, Phase II Detail Design. MCR-69-436. Martin Marietta Corporation, Denver, Colorado, September 1969. (Contract NAS9-8939)

3. H. L. Paynter, et a1.: Investigation of Space Storable Propellant Acquisition Devices, Final Report, Volume IEvaluation. MCR-70-171 (Vol I). Martin Marietta Corporation, Denver, Colorado, October 1970. (Contract NAS7-754)

4. H. L. Paynter, et a1.: Investigation of Space Storable Propellant Acquisition Devices, Fina1 Report, Volume II - Design and Analysis. MCR-70-171 (Vo1 II). Martin Marietta Corporation, Denver, Colorado, December 1970. (Contract NAS7-754)

5. D. A. Fester, et al.: Space Storable Propellant Acquisition System. NASA CR 114493. Martin Marietta Corporation, Denver, Colorado, October 1.972. (Contract NAS2-6548)

6. C. D. Brown: Viking Orbiter 1975 Propellant Management Device Final Report. SE-010-47-01. Martin Marietta Corporation, Denver, Colorado, May 1973. (JPL Contract 953261)

7. D. A. Fester, et a1.: Main Tank Injection for Jackaged Liquid Missiles, Final Technical Report. AFRPL-TR 67-154. Martin Marietta Corporation, Denver, Colorado, July 1967. (Contract AF04-611-11398)

8. D. A. Fester, et al.: Acquisition/Expulsicn System for Earth Orbital Propulsion System Study, Farth Storable System Comparison, Interim Repc =t. 1662-73-n1. Martin Marietta Corporat to , T nver, blorado, April 1973. (Contract NAS9-12:82) 
9. D. A. Fester, et al.: Acquisition/Expulsicn System for Earth Orbital Propulsion System s+udy, Final Report, Volume V - Earth Storable Design. MCR-73-97 (Vol V). Martin Marietta Corporation, Denver, Colorado, Aüguist 1973. (Contract NAS9-12182)

10. D. A. Fester and R. N. Eberhardt: Acquisition/Expulsion System for Earth Orbital Propulsion, Earth Storable Reaction Control System Comparison. K-73-48782001. Martin Marietta Corporation, Denver, Colorado, Apri1 1973.

11. Space Tug Systems Study (Stcrable), First Review Presentation - Propulsion Addendum. MCR-73-151. Martin Marietta Corporation, Denver, Colorado, May 30, 1973. (Contract NAS8-29675)

12. H. L. Paynter, et al.: Passive Retention/Expulsion Methods for Subcritical Storage of Cryogens, Final Report. MCR-71-58. Martin Marietta Corporation, Denver, Colorado, July 1971. (Contract NAS9-10480)

13. G. R. Page, et al.: Acquisition/Expulsion System for Earth Orbital Propulsion System Study, Final Report, Volume II - Cryogenic Design. MCR-73-97 (Vo1 II). Martin Marietta Corporation, Denver, Colorado, August 1973. (Contract NAS9-12182)

14. G. R. Page, et al.: Acquisition/Expulsion System for Earth Orbital Propulsion System Study, Final Report, Volume III - Cryogenic Test. MCR-73-97 (Vo1 III). Martin Marietta Corporation, Denver, Colorado. August 1973. (Contract NAS9-12182)

15. J. E. Anderson: A Feasibility Study of Developing Toroidal Tanks for a Spinning Spacecraft, Design Criteria and Study Guideline Document. YCR-73-102. Martin Marietta Corporation, Denver, Cosorado, April 1973. (Contract NAS2-7489)

16. Study of Follow-On Pioneer Missions to Jupiter, Volume 2 Technical, Pioneer Jupiter Orbiter Mission. 204066004-RO-00. TRW Systems Group, Redondo Beach, California, August 13, 1971. (Contract NAS2-6454)

17. G. A. Lyerly and H. Peper: Studies of Interfacial Surface Energies. NASA CR-54175. Harris Research 
Labcratory, Washington, D. C., December 1964. (Contract NAS3-5744)

18. C. D. Brown. Propel lant Management Device Cleaning Study. SE-004-47-05. M.ertin Marietta Corporation, Denver, Colorado, July 1972. JPL Coniract 953261)

19. C. D. Brown: Impact of Contact Angle on PMD Performance. SE-004-47-03. Martin Marietta Corporation, Denver, Colorado, March 1973. (JPL Contract 953261)

20. R. N. Eberhardt: Propellant Mass Gaging, Venting, and Handling Technology. S-72-48828-003. Martin Marietta Corporation, Denver, Colorado, December 1972.

21. P. E. Bingham: Capillary Screen Device Fabrication Technology. D-72-48735-001. Martin Marietta Corporation, Denver, Colorado, December 1972.

22. H. L. Paynter, et al.: Experimental Investigation of Capillary Propellant Control Devices for Low Gravity Environments. MCR-69-585. Martin Marietta Corp'ration, Denver, Colorado, June i970. (Contract NAS8-21 459)

23. I. J. Hastings and $\because$ Rutherford: Low Gravity LiquidVapor Interface Suapes in Axisymmetric Containers and a Computer Solution. N SSA TMX-53790. George C. Marshall Space Flight Center, Huntsville, Alabama, October 7, 1968.

24. E. P. Symons and K. L. Abdulla: Liquid-Vapor Interface Configurations in Toroidal Tanks During Weightlessness. NASA TND-4819. Lewis Research Center, Cleveland, Oh 10 , October 1968.

25. E. P. Symons: Zero Gravity Equilibrium Configuration of Liquid-Vapor Interface in Toroidal Tanks. NASA TND6076. Lewis Research Center, Cleveland, Ohio, November, 1970.

26. J. C. Armour and J. N. Cannon: "Fluid Flow Through Woven Screens." AICHE journal. Volume 14, No. 3, May 1968.

27. J. J. Traxler and A. P. Lane: Study of Terminal DrainIng for Liguid Oxygen and lilquid Hydrogen Propellants, Final Summary Report. CR-64-47. Martin Marietta 
Corporation, Denver, Colorado, August 1964. (Contcact NAS8-5417)

28. Apros :ce Tanks, Volume I. Illinois Inscitute of Technology ?osearch Institute, Chicago, Illinois, January 1969. ('sntract NAST-388)

29. P. F. Jordan: Analytical and Exper Jental Investigation of Pressurized Toloidal Shells. Res aarch Report RR-64. Martin Marietta Corporation, Baltimore, Maryland, April 1965. (Contract NASw-91j)

30. Personal communication between S. Clendenin, United Technology Corporation, Sunnyvale, California, and J. E. Anderson, Martin Marietta Corporation, Denver, Colorado, September 5, 1973.

31. R. J. Roark: Forraulas for Stress and Strain, Third Edition. McGraw-Hill. Book Company, Inc., New York, New York, 1954.

32. Structural Design Criteria Applicable to a Space Shuttle. NASA SP-8057. National Aeronautics and Space Administration, March 1972.

33. Persoual communication between J. Marcus and D. Fester, Martin Marietta Corporation, Denver, Colorado, August 29, 1973.

34. C. D. Brown: Mariner Mars ' 71 Spacecraft Propulsion Subsystem Fina! Report. CPR-39-69-4. Martin Marietta Corporation, Denver, Colorado, August 1970. (JPL Contract 952460)

35. Personal communication between D. Kohurst, Pressure Systems Incorporated, Ios Angeles, "dlifornia, and J. E. Anderson, Martin Marletta Corporation, Denver, Colorado, June 1973.

36. Lerter from K. J. Kearns, Fansteel Precision Sheet Metal, Los Angeles, California, to P. G. Tyler, Martin Marietta Corporation, Denver, Colorado, dated May 21, 1973.

37. Personal communication between Perry Hardy, Beech Aircratt, Boulder, Colorado, and J. E. Anderson, Martin Marietta Corporation, Denver, Colorado, July i8, 1973. 
38. Personal communication between A. DeHaeseleer. Fansteel Precision Sheet Metal, Los Angeles, California and J. E. Anderson, Martin Marietta Corporation, Denver, Colorado; July thru September 1973.

39. Personal cummunicatiun between D. Krantz, Explosive Fabricator Industries, Lorisville, Colorado, and J. E. Anderson, Martin Mailetta Corporation, Denver, Colorado, July 24, 1973.

40. P. E. Bingham: Gapillary Screen Device Tecinology. M-70-18. Martin Marietta Corporation, Denver, Colorado, July 1970.

41. D. A. Fester and P. E. Bingham: Evaluation of Fine Mesh Screen Levice in Liquid Flourine. R-70-1.8631010. Martin Marietta Corporation, Denver, Colorado, July 1970. 